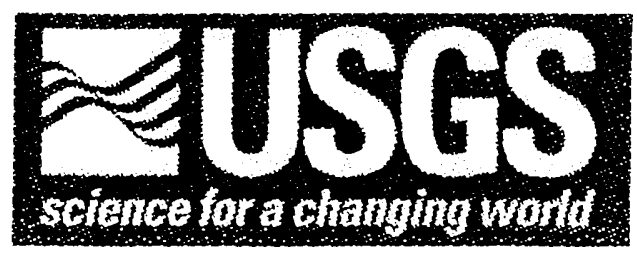

\title{
3-D Spherical Models of Mantle Convection with Floating Continents
}

By Valery P. Trubitsyn ${ }^{1,2}$ and Vitali V. Rykov ${ }^{1,2}$

Open-File Report 00-218

2000

This report is preliminary and has not been reviewed for conformity with U.S. Geological Survey editiorial standards or with the North American Stratigraphic Code. Any use of trade, firm, or product names is for descriptive purposes only and does not imply endorsement by the U.S. Government.

\section{U.S. DEPARTMENT OF THE INTERIOR}

U.S. GEOLOGICAL SURVEY

${ }^{1}$ Russian Academy of Science, Institute of Physics of the Earth, 10 Bolshaya Gruziuskaya, Moscow, Russia 123810

${ }^{2}$ Visising Scientists, United States Geological Survey, 345 Middlefield Road, MS 977 CA 94025 


\section{ABSTRACT SUMMARY \\ 3-D SPHERICAL MODELS OF MANTLE CONVECTION WITH FLOATING CONTINENTS}

One of the major questions within the Earth Sciences is to understand the mechanism behind plate tectonics, which results in the quasi-periodic assembly of the continents into a super continent similar to Pangaea. In addition to understanding the tectonics of the oceanic plates, we are attempting to carry out quantitative analysis to describe the forces behind continental plate motion. The first fully selfcontained 3-D spherical numerical model of mantle convection with eight freely floating continents is presented. The mantle is modeled by a spherical liquid layer, which is heated from below. The viscosity of the liquid depends on temperature and pressure. The continents are modeled by thick, rigid, buoyant plates.

Mantle flow velocities, temperature and pressure are determined from the space and time coordinates from the well-known equations of thermal convection (equations of mass, heat and momentum transfer). To find the velocities of the continents, we first use Euler's equations of motion for a solid 3-D body. These two systems of equations assume strong coupling by the boundary conditions on the surfaces of the continental plates (due to heat and momentum exchange). We use an original numerical method for solving these equations.

The eight modeled continents are similar in shape and size to the real continents (North and South America, Africa, Eurasia, Australia, Antarctica and two large islands: Madagascar and Kalimantan). As an initial state, we assume a motionless mantle with a 3-D temperature distribution $\mathrm{T}=\mathrm{T}(\mathrm{r}, \theta, \varphi, \mathrm{t}=0)$, recalculated from seismic tomography data. The initial positions of the continents are similar to their present state. A numerical solution to the coupled models of mantle convection and floating continents results in a distribution over 3-D space and time of temperature, viscosity, and mantle flow velocities, as well as continental movement.

The main results of our numerical model are as follows:

1. We obtained a repeatable model for the assembly and dispersion of the continents into a super continent similar to Pangaea.

2. The distribution of the aforementioned parameters describes the evolution of the asthenosphere and lithosphere because, by definition, the asthenosphere and 
lithosphere are areas of anomalous low and high viscosity. The appearance of deep continental roots was obtained and is of particular interest.

3. The solution shows the evolution and break-up of subducted slabs, and the splitting and pulsation of giant plumes under the Pacific and Africa.

Comparisons of calculated continental velocities with observed data (e.g. GPS data) will give new constraints for the interior structure of the Earth and its dynamics. 


\section{TABLE OF CONTENTS}

Section

Cover Sheet
A. Abstract
B. Table of Contents
C. Project Description
D. References Cited
J. List of Figures
E. Biographical Sketches

Total No. of

Pages in Section
Page No.

2

\begin{tabular}{ll}
\hline 1 & \multicolumn{1}{c}{4} \\
29 & 5 \\
\hline 4 & 34 \\
& -38 \\
\hline 5 & 40 \\
\hline
\end{tabular}




\section{3-D SPHERICAL MODELS OF MANTLE CONVECTION WITH}

\section{FLOATING CONTINENTS}

\section{Valery P. Trubitsyn}

Russian Academy of Science, Institute of Physics of the Earth,

10 Bolshaya Gruziuskaya, Moscow, Russia 123810

Visiting Scientist, United States Geological Survey, 345 Middlefield Road, MS 977, California 94025, U.S.A

\section{Vitali V. Rykov}

Russian Academy of Science, Institute of Physics of the Earth,

10 Bolshaya Gruziuskaya, Moscow, Russia 123810

Visiting Scientist, United States Geological Survey, 345 Middlefield Road, MS 977, California 94025, U.S.A

\section{INTRODUCTION}

In the 1960 s and 1970 s there were radical changes in the theories of the Earth's internal constitution and those processes that shape the Earth's surface. Having an opportunity to study these processes at the bottom of the oceans, American and European scientists created the theory of plate tectonics. They found that the oceanic lithosphere takes part in the global circulation of the mantle by convection. The oceanic lithosphere is born at oceanic ridges by magma differentiation and solidification, becoming thicker and heavier as it moves away from the ridge, passing through the horizontal portion of the convection cell. It then dips into the mantle at the subduction zones.

The theory of plate tectonics consists of two branches: kinematics and 
dynamics. Kinematic plate tectonics studies the history and future of oceanic plate movements, while dynamic plate tectonics investigates the driving forces of the plates and studies mantle convection. The equations of mantle convection with temperature dependent viscosity describe the oceanic lithosphere as resting on an area of mantle with anomalously high viscosity and where the temperature is less than the solidus temperature $\left(1100-1300^{\circ} \mathrm{C}\right)$. The mean length of the oceanic lithospheric plates is about $5,000 \mathrm{~km}$ and their mean velocity is about $5 \mathrm{~cm} / \mathrm{yr}$; therefore, the average age of the oceanic lithosphere is about $100 \mathrm{My}$. The presentday map of plate configuration shows that there are no purely continental plates. Each continent is partly frozen within a lithospheric plate. The theory of plate tectonics thus considers the continents as buoyant bodies moving passively along with oceanic plates.

According to the modern theory of plate tectonics, global geodynamics is managed by a non-steady state, semi-chaotic mantle convection with variable viscosity, including a highly viscous oceanic lithosphere. From this point of view, the assembling of all continents into one super-continent and then dispersing them is a simple result of chaos and disorder.

This view of Earth's dynamics conflicts with some newly observed data. We would like to emphasize three unsolved problems concerning the continental lithosphere. Present-day geodynamics presents these questions as some of the most important among the unsolved problems in the Earth Sciences.

1. Continents prevent heat from escaping the mantle. Therefore the subcontinental mantle must be warmer than the sub-oceanic mantle. However, observational data shows that the temperature under the continents at a depth of $200-300 \mathrm{~km}$ (in the continental lithosphere) is about $200{ }^{\circ} \mathrm{C}$ less 
than that under the oceans. Why is the continental lithosphere colder and two to three times thicker than the oceanic lithosphere?

2. The continental crust is soft compared to the rigid oceanic plates. Why do the oceanic plates not squash the continents? Why is the age of the continental crust forty times greater than the oceanic crust?

3. Tomographic data reveal two giant hot anomalies in the mantle beneath Africa and the Pacific. What is their origin?

Present-day tectonics has not yet answered these questions. The theory presented in this paper explains the formation and evolution of the oceanic lithosphere, but it does not consider the origin and evolution of the continental lithosphere, nor can it explain the laws of continental drift or some features of mantle dynamics. The aim of the presented report is to advance our present understanding of the above-mentioned problems to create a new quantitative concept - the tectonics of floating continents should be considered in addition to the tectonics of the oceanic lithosphere.

\section{HISTORY OF THE PROBLEM}

A lot of numerical modeling of mantle convection has been done to date. Two-dimensional, 3-D Cartesian and 3-D spherical models have been used to explain the effects of variable viscosity, phase transitions, and internal heating as functions of temperature and stress [e.g. Jarvis and McKenzie, 1980; Christensen, 1983, 1984; Christensen and Yuen, 1984; Glatzmaier, 1988; Machetel and Weber, 1991; Schubert, 1992; Balachandar et al., 1992; Lenardic and Kaula, 1994; Solheim and Peltier, 1994; Tackley et al., 1994; Parmentier et al., 1994; Bunge et al., 1997; Brunet and Machetel, 1998]. These models show how the oceanic lithosphere was 
created at the oceanic ridges and how it evolved as a viscous area of convecting mantle [Jacoby and Schmeling, 1982].

Despite the great success of numerical modeling, the current theory of plate tectonics is not complete. There is no model that consistently describes the origin, movement and break-up of the viscous oceanic lithosphere into separated plates. Nor does plate tectonics explain why the continental lithosphere is colder, thicker and older than oceanic lithosphere.

The statement that there are no continental plates concerns only a small time interval. Oceanic lithospheric plates are recycled many times during the four billionyear-age of the continents. Therefore we cannot consider a continent to be a passive insertion in an oceanic plate. To study the properties and movement of oceanic plates, observational data from the ocean bottom were used. Continental lithosphere dynamics, however, can only be studied by the numerical modeling of mantle convection coupled with drifting continents using all available data.

Trubitsyn and Fradkov [1985] showed how mantle convection under large continents can be suppressed, and how mantle heat flow through the continents can be three times less than through the oceans. They noticed that the oceanic plates do not prevent mantle heat from escaping. Instead, oceanic plates take part in the convective circulation of the mantle, and in doing so, increase conductive heat loss. Trubitsyn et al. [1993,1994], Trubitsyn and Bobrov [1993,1996,1997], Lowman and Jarvis [1993, 1995,1996], Bobrov and Trubitsyn [1996], Nakakuki et al. [1997] and others numerically showed that a fixed continent at first suppresses convection, but increases the size of the convection cell and changes the structure of the mantle. A new hot upwelling could then appear after some hundreds of millions of years.

If the continents were allowed to move the new effects in mantle convection could still take place. At first, the models took into account the mechanical effects 
of moving continents as a boundary condition. Lux et al., [1979], Trubitsyn and Fradkov [1986], and Doin M. -P. et al. [1997] assigned a horizontal velocity to the continent instead of assuming a stationary but thick continent. Further, the investigations of continental effects were modeled in two different ways.

In the first case, the continent is modeled simply as a highly viscous area of the mantle [e.g. Hager, 1984; Tackley, 1998; Bercovici, 1998, and others] giving the same equations of mantle convection with variable viscosity. 2-D models with two free-floating, highly viscous plates were created showing that continents could assemble and later move apart, similar to the history of Pangaea. This description of continents as a highly viscous, buoyant area of the mantle is natural and understandable, but there are mathematical difficulties in calculating the rotation of the continents.

Trubitsyn and Rykov [1995, 1997,1998a, 1998b, 1999], and Rykov and Trubitsyn [1996a, 1996b] proposed another way to incorporate the continents into mantle convection. They considered the continent to be a rigid, thick, buoyant plate, floating freely in the mantle. To describe the floating continental movement they used Euler's general equation for solid 3-D bodies. The free-floating continent moves due to the viscous forces on all sides of the submersed continent.

The numerical solution of the coupled system of equations for the viscous mantle and solid continents is provided. The first fully self-contained 3-D model of mantle convection with two floating continents [Trubitsyn and Rykov, 1995] revealed many new interesting effects in addition to reproducing the main periods of the assembly and dispersal of the continents. Structures similar to the Atlantic and Pacific Oceans appeared after the super continent dispersed. The calculated downwelling on the western boundary of the Pacific shows a near vertical dip, while on the east, the dip is almost horizontal. These are similar to the Eurasian and S. 
American subduction zones. For another trial, Rykov and Trubitsyn, [1996b] used two continents that coupled similarly to what is believed to have occurred with North and South America.

A simplified method to incorporate the thick, rigid, free-floating continent with mantle convection was also proposed by Bobrov and Trubitsyn [1996], and Trubitsyn and Bobrov [1994, 1997]. They used a two-region method. For any time interval, they calculate mantle convection within a box, with the area placed on the moving continent. All boundaries of the box, including the continent-mantle interface, are taken to be slip-free. They then solved the equation for mantle convection and found the mean mantle velocity of the mantle flow (V) beneath the continent. Next, they prescribe this velocity to the rigid continent and shift it a distance $\Delta \mathrm{l}=\mathrm{V} . \Delta \mathrm{t}$, until a new velocity is found. The temperature for the continent is calculated by a conductive heat transfer equation, and for the mantle, by the equation of convection. This approach is very simple and can be used to test these models.

Trubitsyn and Rykov [1997, 1999] showed that one additional reason for the inclination of the subduction zones could be the influence of the overriding continent. They used a very low Rayleigh number $\left(\mathrm{Ra}=210^{4}\right)$ to exclude the chaotic effects of mantle convection. In a first approximation a cold, highly viscous area of mantle was used to describe the dynamics of the oceanic lithosphere. Vertical downwelling declined when a free-floating, rigid, thick continent approached it. Additional numerical experiments for continents moving with a prescribed horizontal velocity showed that the dip angle of downwelling increases with an increase in continental velocity.

Trubitsyn and Rykov [1998b] checked the effect of the diminishing upwellings under the continent on a 2-D model of mantle convection. The 
assumptions included: a constant viscosity incorporating one free-floating continent with Rayleigh number $\mathrm{Ra}=10^{6}$ in an elongated box (10:1 ratio) with a grid of $200 \times 80$; the thickness of the continent $(d)=90 \mathrm{~km}$; and the length $(\mathrm{l})=6,000 \mathrm{~km}$. This was found to be similar to convection under the Pacific with a moving Eurasia. The model shows how even a thin continent can change the structure of mantle flow, despite the chaotic style of mantle convection.

An Internet review of 2-D and 3-D geodynamic models with attached long films was made by Trubitsyn and Rykov [1998b]. They illustrate four main features of global geodynamics: a) plume style of mantle convection, b) effects of a highly viscous oceanic lithosphere, $c$ ) the rate of mass exchange between the upper and lower mantle due to phase transitions, and d) the effects of floating continents on mantle convection.

In 1998 Trubitsyn and Rykov [1998a] proposed incorporating the tectonics of the floating continents with the tectonics of oceanic lithospheric plates. Plate tectonics explains only the dynamics of oceanic lithosphere coupled with mantle flow by mass and heat exchange. The tectonics of the floating continents additionally explains the dynamics of the continental movement coupled with mantle flow by mechanical and thermal exchange.

In an Internet paper of Trubitsyn and Rykov [1998b] a long film was attached, demonstrating the drift of five continents (resembling North and South America, Africa, Eurasia and Australia) on a 3-D Earth with mantle convection. The film demonstrated the history of Pangaea: the assembled continents in Laurasia and Gondwana; the assembly of six continents into one super continent like Pangaea; and their dispersal. The initial position of the continents was taken to be similar to their present state, but the initial state of the mantle with non-steady state convection was taken as arbitrary. This model, therefore, showed only the principal history of 


\section{Pangaea.}

This report presents the first 3-D spherical, geodynamic model for the real Earth. The shapes and sizes of the eight continents were taken to be similar to the real continents and as an initial value for the calculation we took the temperature distribution calculated from the seismic tomography data for the present-day Earth.

\section{THE MODEL}

The Earth is modeled by a viscous sphere. We do not consider the effects of core-mantle coupling and assume a fixed temperature $\mathrm{T}=\mathrm{T}_{0}$ as a boundary condition on the core-mantle boundary (c-m.b.). This boundary condition implies that the mantle is heated from below, but the temperature at the c-m.b. is always fixed. We believe that any lateral inhomogeneities in relief or heat flow at the c-m.b. are generated not by core processes, but by those of the mantle.

The mantle is modeled as a liquid of high viscosity. The continents are modeled as thick, rigid plates, partially submerged into the mantle. They move atop the mantle as a result of viscous drag forces. Continents can move on a spherical Earth and rotate around an instant vertical axis (from Euler's theory of solid body motion we describe the motion of each continent on the Earth's surface with two spherical components of vector velocity $\mathrm{u}=\mathrm{U}_{\theta}$ and $\mathrm{v}=\mathrm{U}_{\varphi}$, of the center of gravity and the angular velocity of continent rotation around an instant vertical axis $\left.\omega_{3}=d \varphi / d t\right)$. Each continent floats freely until there is a collision and we do not consider the deformation of the continents. Instead, we describe collisions only as forces introduced at the points where the continents begin to overlap. Therefore the continents have no contact with each other except at points which overlap.

The continents can assemble and form super continents similar to Pangaea, but we do not consider any mass transfer between the continents at their contact 
points. We assume the super continent is a system of continents that are only very closely spaced with respect to each other. In this way, we model the break-up of the super continent as a dispersal of continents when the viscous force becomes greater than the critical stress value.

Constant temperature, heat flow and velocity values are assumed at all the continent-mantle interfaces. The continents do not drift passively, but can change mantle convection due to mechanical and thermal interactions that occur.

The viscosity of the mantle is taken as a function of temperature and pressure due to a simplified version of Weertman's law. The viscosity can also be a function of phase and chemical factors. The coefficients of the Weertman formula are chosen to obtain the calculated viscosity as a function of the depth in accordance with the available observational data.

\section{The input data are as follows:}

1. The known Earth parameters (radius of the Earth $\mathrm{R}$ and its core $\mathrm{R}_{\mathrm{c}}$, acceleration due to gravity $\mathrm{g}$, mean thermal expansion $\alpha$, mean thermal conductivity $\mathrm{k}$ and mean density $\rho$ )

2. The viscosity $\eta(T, p)$ as a function of temperature and pressure (as a property of the material only)

3. The initial temperature distribution $T_{0}(r, \theta, \phi)$, taken from seismic tomography data.

Seismic velocities depend on density and elasticity. As a result, they depend greatly on the temperature $(\mathrm{T})$ and less on the chemical composition (C). To a first approximation, we can find the variation of temperature by the simple formula $\delta V_{s}=\left(d_{\mathrm{s}} / \mathrm{dT}_{\mathrm{c}}\right) \delta \mathrm{T}$, taking the value for the coefficient $\left(\mathrm{dV}_{\mathrm{s}} / \mathrm{dT}_{\mathrm{c}}\right)$ from theoretical 
and experimental data.

\section{The output data are as follows:}

1. The Mantle flow velocities $\mathrm{V}(\mathrm{r}, \theta, \phi, t)$

2. The velocities of continental drift (as functions of $\theta, \phi$, and $t$ )

3. The temperature distribution $\mathrm{T}(\mathrm{r}, \theta, \phi, \mathrm{t})$

4. The viscosity distribution $\eta(\mathrm{r}, \theta, \phi, \mathrm{t})$

5. The heat flow distribution $\mathrm{q}(\mathrm{r}, \theta, \phi, \mathrm{t})$

6. The history of continental drift (location of continents, assembly and dispersal of continents

7. The relief of the ocean bottom $\mathrm{h}(\theta, \phi, \mathrm{t})$

We input the minimum data and attempt to create a preliminary global geodynamic Earth model.

\section{EQUATIONS FOR MANTLE CONVECTION}

The thermal convection of a viscous mantle is described by the distribution of convective flow vectors $V_{i}(x, y, z)$, temperature $T(x, y, z)$ and pressure $p(x, y, z)$. In the Boussinesq approximation these unknown functions are found by solving a system of three equations: mass, energy and momentum transfer:

$$
\begin{aligned}
& \rho d V_{i} / d t=-\partial p / \partial x_{i}+\partial S_{i j} / \partial x_{j}+\rho g \delta_{i 3} \\
& d T / d t=\partial\left(k \partial T / \partial x_{i}\right) \partial x_{i}+Q \\
& \partial \rho / \partial t+\partial\left(V_{i} \rho\right) / \partial x_{i}=0 \\
& i=1,2,3
\end{aligned}
$$

where $\rho$ is the density of the mantle, $\mathrm{g}_{\mathrm{i}}$ is the gravity, $\mathrm{T}$ (potential temperature) is the 
temperature variation relative to an adiabatic thermal state $\left(T_{a d}\right), k$ is the thermal conductivity, $\mathrm{Q}$ is the rate of internal heat flow per unit volume, $\delta_{\mathrm{ij}}$ is Kronecker delta function which is equal to 1 if $\mathrm{i}=\mathrm{j}$ and equals 0 if $\mathrm{i} \neq \mathrm{j} . \mathrm{S}_{\mathrm{ij}}$ is a deviatoric stress tensor [Landau and Livshitz, 1959] where

$$
\mathrm{S}_{\mathrm{ij}}=\eta\left(\partial \mathrm{V}_{\mathrm{i}} / \partial \mathrm{x}_{\mathrm{j}}+\partial \mathrm{V}_{\mathrm{j}} / \partial \mathrm{x}_{\mathrm{i}}\right)
$$

and $\eta$ is the viscosity.

The value of the inertial terms on the left-hand side of the momentum (impulse) transfer equation is approximately $\mathrm{k} \rho / \eta \approx 10^{-23}$, relative to the viscous force on the right side. Therefore we can neglect the inertial terms. For the Boussinesq approximation the density depends on the temperature but not on the pressure, $P=P_{0}(1-\alpha T)$ and this dependence is taken into account in the buoyancy term of equation (1) only. Here $\alpha$ is the thermal expansion. The pressure variation will be calculated relative to the hydrostatic $\left[\mathrm{p}_{0}(\mathrm{z})\right]$ distribution $\left[\nabla \mathrm{p}_{0}=-\rho_{0} \mathrm{~g}\right]$. We use the following dimensionless variables: length, $\mathrm{D}$; velocity, $\mathrm{D} / \mathrm{k}$; time, $\mathrm{D}^{2} / \mathrm{k}$; temperature, $\mathrm{T}^{*}$; viscosity, $\eta_{0}$; pressure, $\eta_{0} \mathrm{k} / \mathrm{D}^{2}$; rate of internal heating, $\mathrm{kT}_{0} / \mathrm{D}^{2}$, where $\mathrm{k}$ is thermal conductivity.

The dimensionless equations (1)-(3) are derived as follows:

$$
\begin{aligned}
& 0=-\partial \mathrm{p} / \partial \mathrm{x}_{\mathrm{i}}+\partial \mathrm{S}_{\mathrm{ij}} / \partial \mathrm{x}_{\mathrm{j}}+\operatorname{RaT} \delta_{\mathrm{i} 3} \\
& \partial \mathrm{T} / \partial \mathrm{t}+\mathbf{V} \nabla \mathrm{T}=\partial\left(\partial \mathrm{T} / \partial \mathrm{x}_{\mathrm{i}}\right) \partial \mathrm{x}_{\mathrm{i}}+\mathrm{Q} \\
& \partial \mathrm{V}_{\mathrm{i}} / \partial \mathrm{x}_{\mathrm{i}}=0
\end{aligned}
$$

where $\mathrm{Ra}$ is the Rayleigh number, thus,

$$
\mathrm{Ra}=\alpha \rho_{0} \mathrm{gT} \mathrm{T}^{3} / \mathrm{k} \eta_{0}
$$

Our aim is to study the effects of the continents on mantle convection. For 
simplicity we neglected internal heating (i.e. $Q=0$ ), the depth dependence for the thermal expansion $(\alpha)$ and the thermal conductivity $(\mathrm{k})$. Their variations have an influence on the mantle convection, which is insignificant relative to the viscosity variations.

\section{EQUATIONS FOR A FREE-FLOATING RIGID CONTINENT}

We will consider each continent as a rigid body, floating on the mantle. We assume they are partially submerged into the mantle (below a free mantle surface). The forces acting on the continent are as follows: 1) The gravity of the Earth acting on the entire continent, and 2) the viscous forces of the mantle (pressure and shear forces) acting on any point of the continent surface that is submerged into the mantle.

The motion of the continent can be found by Euler's general equations for any solid body. According to Euler, the velocity components for any point of the solid continent $\mathbf{u}(\mathrm{u}, \mathrm{v}, \mathrm{w})$ can be written as follows [Landau and Livshitz, 1958]

$$
\mathbf{u}_{\mathrm{k}}(\mathrm{x}, \mathrm{y}, \mathrm{z})=\mathbf{U}_{0 \mathrm{k}}-\varepsilon_{\mathrm{ijk}} \omega_{\mathrm{i}}\left(\mathrm{x}_{\mathrm{j}}-\mathrm{x}_{\mathrm{j} 0}\right)
$$

where $\mathbf{U}_{0 \mathrm{k}}$ is the vector of the instant velocity of the center of gravity $\mathbf{U}_{0 \mathrm{k}}=\left(\mathrm{u}_{0}, \mathrm{v}_{0}\right.$, $\left.\mathrm{w}_{0}\right) ; \omega_{\mathrm{i}}$ is the vector of the instant angular velocity of rotation relative to a center of gravity; $\omega=\left(\omega_{\mathrm{x}}, \omega_{\mathrm{y}}, \omega_{\mathrm{z}}\right) ; \mathrm{x}_{\mathrm{j}}$ is the co-ordinate of any point on the continent; $\mathrm{x}_{\mathrm{j} 0}$ is the co-ordinate of the instantaneous center of gravity; and $\varepsilon_{\mathrm{ijk}}$ is Levi-Cheviot's symbol (which is equal to 0 for the equality of any two indices, equal to 1 for the even transposition of the index relative to 123 , and equal to -1 for the odd transposition).

The vector of the instantaneous velocity of the center gravity is calculated as

$$
\mathbf{U}_{0 \mathrm{k}}=(1 / \mathrm{M}) \int \rho_{\mathrm{c}} \mathrm{u}_{\mathrm{k}} \mathrm{d} \tau, \quad M=\int \rho_{\mathrm{c}} \mathrm{d} \tau
$$

where $\rho_{c}$ is the density distribution in the continent, $\mathrm{d} \tau$ is the volume element, and $M$ is the mass of continent. 
The general Euler's equations for a solid body are as follows [Landau and Livshitz, 1958]

$$
\begin{aligned}
& M \partial \mathbf{U}_{0 i} / \partial \mathrm{t}=\mathbf{F}_{\mathrm{I}} \\
& \mathbf{d M}_{\mathrm{i}} / \mathbf{d t}=\mathbf{K}_{\mathrm{I}}
\end{aligned}
$$

where $\mathbf{F}_{\mathrm{i}}$ represents external forces, and $\mathbf{M}_{\mathrm{i}}$ is the impulse moment

$$
\mathbf{M}_{\mathrm{i}}=\mathbf{I}_{\mathrm{il}} \omega_{\mathrm{l}}
$$

$\mathbf{I}_{\mathbf{i k}}$ is the moment tensor

$$
\mathbf{I}_{\mathrm{ik}}=\int_{\rho_{\mathrm{c}}}\left[\left(\mathrm{x}_{\mathrm{l}}-\mathrm{x}_{\mathrm{lo}}\right)^{2} \delta_{\mathrm{lj}}-\left(\mathrm{x}_{\mathrm{i}}-\mathrm{x}_{\mathrm{io}}\right)\left(\mathrm{x}_{\mathrm{k}}-\mathrm{x}_{\mathrm{ko}}\right)\right] \mathrm{dv}
$$

The whole moment of force $\mathbf{K}_{\mathbf{i}}$ is the sum of force moments $\mathbf{k}_{\mathbf{i}}$ for each body element $\mathbf{k}_{\mathbf{i}}$

$$
\mathbf{K}_{\mathbf{i}}=\varepsilon_{\mathrm{ijl}}\left(\mathrm{x}_{\mathrm{i}}-\mathrm{x}_{\mathrm{io}}\right) \mathbf{f}_{\mathrm{j}}
$$

The forces acting on the continent are as follows: the gravity force (acting on the center of gravity); and the viscous coupling forces which act on the portion of the continental surface, which is submerged into the mantle. Under these forces the continent floats in the mantle, moving along its surface and rotating around its vertical axis.

The pressure and velocity of the mantle flow changes in space and time. In the general case the vertical center of gravity velocity $\left(\mathrm{w}_{0}\right)$, and the angular velocities $\omega_{\mathrm{x}}$ and $\omega_{\mathrm{y}}$ around the $\mathrm{x}$ and $\mathrm{y}$ axes are not equal to zero. We assume the continents can sink and rise with the mantle and also that these changes can be different on various sides of the continent. For simplicity we will consider the horizontal motions (for Cartesian models) and the motion along a spherical surface (for spherical models) of the continents and their rotations along vertical axes only, neglecting all other effects. We therefore set $\mathrm{w}_{0}=0$ and $\omega_{\mathrm{x}}=\omega_{\mathrm{y}}=0$.

The gravity force acts on the center of gravity and balances the hydrostatic buoyancy force, leaving the viscous coupling force as the only external force acting 
on the continent. In this way, $\mathrm{p}$ is the pressure variation relative to the hydrostatic pressure $\mathrm{p}_{0}(\mathrm{z})$. Also,

$$
F_{\mathrm{i}}=\iint\left(-\mathrm{p} \delta_{\mathrm{jk}}+\mathrm{S}_{\mathrm{jk}}\right) \mathrm{n}_{\mathrm{k}} \mathrm{df}
$$

where $\mathrm{df}$ is the absolute value of the surface element of the rigid continent and $\mathrm{n}_{\mathrm{j}}$ is a normal unit vector directed to the external continent surface. The integral is taken over the entire surface that is submerged in the mantle.

As a result, in a case of horizontal motion and rotation around a vertical axis $\mathrm{z}$ of the continent, Euler's equations reduce to a system of three equations

$$
\begin{aligned}
& M \mathrm{Mu}_{0} / \mathrm{dt}=\iint\left(-\mathrm{p} \delta_{1 \mathrm{j}}+\mathrm{S}_{1 \mathrm{j}}\right) \mathrm{n}_{\mathrm{j}} \mathrm{df} \\
& \mathrm{Mdv}_{0} / \mathrm{dt}=\iint\left(-\mathrm{p} \delta_{2 \mathrm{j}}+\mathrm{S}_{2 \mathrm{j}}\right) \mathrm{n}_{\mathrm{j}} \mathrm{df} \\
& \mathrm{I}_{33} \mathrm{~d} \omega_{3} / \mathrm{dt}=\iint \varepsilon_{\mathrm{ij} 3}\left(\mathrm{x}_{\mathrm{i}}-\mathrm{x}_{0 \mathrm{i}}\right)\left(-\mathrm{p} \delta_{\mathrm{jk}}+\mathrm{S}_{\mathrm{jk}}\right) \mathrm{n}_{\mathrm{k}} \mathrm{df} \\
& \text { where } \mathrm{dx} \mathrm{x}_{\mathrm{c}} / \mathrm{dt}=\mathrm{u}_{0}, \quad \mathrm{dy} \mathrm{d} / \mathrm{dt}=\mathrm{v}_{0}, \mathrm{~d} \varphi / \mathrm{dt}=\omega_{3}
\end{aligned}
$$

and where $x_{c}(t)$ and $y_{c}(t)$ are the co-ordinates of the center of gravity of the continent, and $\varphi$ is the angle of continental rotation.

In the special case of infinitely thin continents and assuming a Cartesian model, there is a single viscous force on the bottom of the continent and the normal vectors reduce to $n_{k}=(0,0,-1)$. In this case, Euler's equations reduce to:

$$
\begin{aligned}
& M \partial \mathrm{u}_{0} / \partial \mathrm{t}=-\iint \mathrm{S}_{\mathrm{xz}} \mathrm{dxdy} \\
& \mathrm{M} \partial \mathrm{v}_{0} / \partial \mathrm{t}=-\iint \mathrm{S}_{\mathrm{yz}} \mathrm{dx} d \mathrm{y} \\
& \mathrm{I} \partial \omega / \partial \mathrm{t}=\iint\left[\left(\mathrm{y}^{\prime}-\mathrm{y}^{\prime}{ }_{0}\right) \mathrm{S}_{\mathrm{xz}}-\left(\mathrm{x}^{\prime}-\mathrm{x}^{\prime}{ }_{0}\right) \mathrm{S}_{\mathrm{yz}}\right] \mathrm{dx} \mathrm{x}^{\prime} d \mathrm{y}^{\prime}
\end{aligned}
$$

where $\mathrm{I}$ is the inertial moment of the continent relative to the $\mathrm{z}$ axis, with the center co-ordinate at the center of gravity in the moving frame [Trubitsyn and Rykov, 1997, 1998b, 1999]. The x' and y' axes must be directed along the main inertia axes of the continent.

$$
I=\int \rho_{c}\left[\left(x-x_{0}\right)^{2}+\left(y-y_{0}\right)^{2}\right] d \tau
$$


Similar to the equations for mantle convection the inertial terms in the lefthand side of Euler's equations (11-12) or (17-19) are in the order of $k \rho / \eta \approx 10^{-23}$ and can be neglected.

As a result, we have six equations with six unknown variables [Trubitsyn and Rykov, 1997, 1998b, 1999]: three continent velocities $\mathrm{u}_{0}(\mathrm{t}), \mathrm{v}_{0}(\mathrm{t})$ and $\omega_{3}(\mathrm{t})$; two coordinates of the center of gravity of the continent $x_{c}(t), y_{c}(t)$; and the angle of its rotation,

$$
\begin{aligned}
& \iint\left(-p \delta_{1 j}+S_{1 j}\right) n_{j} d f=0 \\
& \iint\left(-p \delta_{2 j}+S_{2 j}\right) n_{j} d f=0 \\
& \iint \varepsilon_{i j 3}\left(x_{i}-x_{0 i}\right)\left(-p \delta_{j k}+S_{j k}\right) n_{k} d f=0 \\
& d x_{c} / d t=u_{0}, \quad d y_{c} d t=v_{0}, d_{-} / d t=\omega_{3}
\end{aligned}
$$

The temperature inside of the solid continent $\left(T_{c}\right)$ can be found from the equation for conductive heat transfer, taking into account advective heat transfer (9).

$$
\partial \mathrm{T}_{\mathrm{c}} / \partial \mathrm{t}+\mathbf{u} \nabla \mathrm{T}_{\mathrm{c}}=\partial\left(\partial \mathrm{T}_{\mathrm{c}} / \partial \mathrm{x}_{\mathrm{i}}\right) \partial \mathrm{x}_{\mathrm{i}}+\mathrm{Q}_{\mathrm{c}}
$$

where $\mathbf{u}$ is the continent velocity by (9) and Qc is the rate of internal heating due to radioactive elements in the crust.

\section{BOUNDARY CONDITIONS}

The equations for mantle convection (1-3) and equations for continental movement (17-19) and heat transfer (29) necessitate boundary conditions. On the bottom (and sides of the box for Cartesian models) we assume slip-free and zero mass flux conditions. This means that the normal velocity and tangential components of viscous forces on these boundaries are zero.

$$
\mathrm{V}_{\mathrm{k}} \mathrm{n}_{\mathrm{k}}=0, \quad \mathrm{~S}_{\mathrm{ki}} \tau_{\mathrm{i}}=0, \quad \mathrm{i}=1,2 .
$$

where $-n_{k}$ is the normal unit vector and $\tau_{1}$ is the tangent unit vector for the boundary 
surfaces. On the surface boundary of the solid continent we assume a non-slip and zero mass flux. That is, the mantle flow velocities are equal to the continent velocity

$$
\mathrm{V}_{\mathrm{i}}=\mathrm{u}_{\mathrm{I}}
$$

on the surface of the continent, which is submerged into the mantle below the free mantle surface.

The temperature on the c-m.b. is fixed. (in dimensionless form $\mathrm{T}=1$.)

For Cartesian models we must define the boundary conditions on all sides of the box. For these models (besides the slip-free boundaries) we assume a zero heat flux on all sides of the box

$$
\partial \mathrm{T} / \partial \mathrm{n}_{\mathrm{k}}=0
$$

where $n_{k}$ is the normal unit vector to the box side.

The temperature equals zero on the upper surface only for the oceanic part of the mantle. On the submerged surface of the continent we assume constant temperature and heat flow between the mantle and the continent.

$$
\mathrm{T}=\mathrm{T}_{\mathrm{c}}, \partial \mathrm{T} / \partial \mathrm{n}=\partial \mathrm{T}_{\mathrm{c}} / \partial \mathrm{n}
$$

The temperature also equals zero on the upper surface of the continent.

$$
\mathrm{T}_{\mathrm{c}}=0
$$

We are left with the following mathematical problem. We have three unknown functions (of co-ordinates and time) for mantle convection: the vector velocity of mantle flow $V_{i}(x, y, z, t)$; the temperature $T(x, y, z, t)$; and the pressure $p(x, y, z, t)$. We also have four unknown functions for the continent. There are three functions of time describing the movement of the continents as a unit, each function having two components for instant velocity of the center of gravity $u_{0}(t)$ and $v_{0}(t)$, as well as one component of the instant angular velocity around the center of gravity and $\omega(t)$. The fourth unknown function is an unknown temperature distribution inside of the continent $T_{c}(x, y, z, t)$. To find these seven functions we have seven 
equations: three differential equations of mantle convection (1-3), three integral equations (25-27) (reduced Euler's equations), and the equation of heat transfer inside of a moving continent (29). If we know the continent's position in time and its velocities $\left[\mathrm{u}_{0}(t), \mathrm{v}_{0}(\mathrm{t})\right.$ and $\left.\omega(\mathrm{t})\right]$, we can find its position at another time by equation (28). Arbitrary constants of integration of the differential equations can be found from the boundary conditions (30-34).

We consider a free-floating continent to be a more complicated case than a fixed, motionless continent. We must include the boundary conditions for mantle flow velocities and temperature with the position of the continent at a given time, but this position as well as its velocity are unknown and must be found from the coupled system of differential equations. If we have many continents, we must solve the velocity equations (25-27) and temperature equation (29) for each continent separately. At times of continent collision, however, we must change these equations to accommodate the collision forces [Trubitsyn and Rykov, 1995, 1998a, 1998b; Rykov and Trubitsyn, 1996a, 1996b]. Here we present the results for the evolution of continental drift until continent assembly.

\section{NUMERICAL CODE}

\subsection{ONE AND TWO-REGION METHODS}

For Cartesian models we tested the numerical code for mantle convection by well-known published standards. For mantle convection with floating continents we compared the results of using both a one and two-region method. In the one-region method we input the set of parameters and consider the continent to be a highly viscous liquid. In the two-region method for each time step we solve the equations for mantle convection and temperature inside of the solid continent separately. The solutions are then re-examined to fit the boundary conditions. Both methods produce 
solutions that are in a good agreement with each other.

\subsection{NUMERICAL METHOD FOR DIFFERENTIAL EQUATIONS OF MANTLE CONVECTION}

The solution of the equations of mantle convection with floating continents was provided by a finite difference method [Rykov and Trubitsyn, 1997]. The method of flux-corrected transport algorithms and alternating triangle matrix decomposition with iterative parameters was obtained by the conjugate method of Zalesak [1979] and was used for the numerical solution of the temperature equations $(6,29)$. The equations for velocity and pressure $(5,7,25-28)$ are reduced to elliptic equations with variable coefficients (generalized Poisson's equations). They are solved by the triangular method with a three-layer modification. The iterative parameters are chosen by the method of conjugating gradients [Samarskii and Nikolaev, 1978]. Further details of this numerical technique are published in [Rykov and Trubitsyn, 1996a].

\section{RESULTS}

Most of the presented results were found for 3-D spherical models. Therefore, the above equations were rewritten in spherical co-ordinates for the spherical components of the mantle flow velocities $\mathrm{V}_{\mathrm{r}}(\mathrm{r}, \theta, \phi, t), \mathrm{V}_{\theta}(\mathrm{r}, \theta, \phi, t), \mathrm{V}_{\phi}(\mathrm{r}, \theta, \phi$, $\mathrm{t})$, the pressure $\mathrm{p}(\mathrm{r}, \theta, \phi, \mathrm{t})$ and temperature $\mathrm{T}(\mathrm{r}, \theta, \phi, t)$. We also used spherical coordinates for the angular solid body velocity $\omega_{3}(\theta, \phi, t)$ around a local vertical axis for a specific time frame and for the continental velocities at the center of gravity $\mathrm{u}_{\theta}(\theta, \phi, \mathrm{t}), \mathrm{u}_{\phi}(\theta, \phi, \mathrm{t})$

To show the role that the continents play in global geodynamics we present four models: 
A very simple 2-D model of mantle convection with one small continent having a low Rayleigh number. This model shows the mechanism of flow reversal due to a moving continent.

A 3-D spherical model with five floating solid continents, floated in a mantle with a constant viscosity for $\mathrm{Ra}=10^{6}$ at arbitrary time $(\mathrm{t})$ of the evolution of a nonsteady convection. This model demonstrates the assembly and dispersal of super continents similar to Pangaea.

A 3-D spherical model of mantle convection with eight continents having variable viscosity for $\mathrm{Ra}=5 \times 10^{6}$. The initial state is taken from tomographic data. To save computer time we assume a very rough grid to show continental evolution until the time of Pangaea formation.

A 3-D spherical model similar to the previous model but with a finer grid. This model shows only the beginnings of the Earth's future evolution (during the future Atlantic expansion), but reveals many new present-day features of the current Earth's interior.

\subsection{2-D MODEL OF MANTLE CONVECTION WITH ONE FREE-FLOATING CONTINENT}

The mantle was modeled as a very viscous liquid in a box with an $\mathrm{X}: \mathrm{Z}$ ratio $=$ 10:1 and a grid 200x80. The viscosity is temperature and pressure dependent, with very small convective variations in pressure. Hydrostatic pressure is proportional to depth or $(1-z)$ where $z$ is the vertical axis. Similar to Christensen $[1984,1985]$ we used a simplified formula for viscosity

$$
\eta=\eta_{0} \exp [-4.6052 \mathrm{~T}+0.921(1-\mathrm{z})]
$$

where $\eta_{0}$ is surface viscosity. We chose the values for the coefficients of viscosity to increase two orders of magnitude due to temperature, and decrease a 0.5 order due 
to pressure. To exclude any chaotic effects of mantle convection we assume a low surface Rayleigh number, $\mathrm{Ra}_{0}=10^{5}$. The mean viscosity was less than that on the surface, therefore an effective Rayleigh number is equal to about $\mathrm{Ra}=210^{5}$.

Initially, we assumed a steady state mantle convection. Without continents the convective cells are regular and downwellings (modeling subducted slabs) are all near vertical. We then modeled continents by putting a small, rigid plate into the mantle with thickness $(d)=0.1 \mathrm{D}$ and length $(\mathrm{l})=0.7 \mathrm{D}$. The whole calculated history of this continental drift and evolution of mantle flow are shown in Figs. 1.11.17 for dimensionless variables. The $\mathrm{Z}$-axis is directed vertically, and the $\mathrm{X}$-axis to the right. The upper curve shows the heat flow distribution (Nusselt number) on the surface. Figs. 1.1 and 1.4 show vigorous convection occurring at time $\left(t=2.556 \times 10^{-}\right.$ ${ }^{2}$ ) when a continent is put on the mantle. Figs. 1.2 and 1.3 show temperature and viscosity distributions for $t=2.55610^{-2}$. Calculated by equation (35), the viscosity depicts variations in the oceanic lithosphere, asthenosphere, lower mantle and cm.b. layer. Figs. 1.4-1.17 show the calculated evolution of the mantle/continent system. The continent drifts to the nearby downwelling and attempts to override the downwelling. At the same time the continent shifts the upper part of the subducted zone and reduces the pressure in the subduction wedge. As a result, the downwelling shifts from vertical to a steep angle. As revealed by additional calculations this effect is proportional to the continent velocity, explaining why the slabs subducted under slow-moving Eurasia dip close to vertical, while the slabs subducted under the faster-moving South America dip very steeply. The structure of mantle convection for time $t=2.6310^{-2}$ (Fig. 1.6) is similar to present day South America. After some length of time (Figs. 1.8-1.10) upwelling is pulled under the drifted continents. This structure is similar to the state of North America, beginning at a time $40 \mathrm{Ma}$ after the break-up of the subducted slab. Figs. 1.10-1.17 show the 
evolution of the nearby downwelling. As the continent prevents the heat from escaping from the mantle, the sub-continental mantle becomes warmer and the downwelling disperses. Figs. 1.14-1.17 show how the continent then approaches, covers, and terminates the next downwelling.

\subsection{3-D SPHERICAL MODEL WITH FIVE FLOATING CONTINENTS}

The mantle is modeled as a spherical shell filled by a liquid with constant viscosity that is heated from below with $\mathrm{Ra}=10^{6}$. As an initial state we assume that vigorous convection took place within the mantle, which is in a non-steady state. We assumed an arbitrary moment of mantle evolution and put into the mantle five rigid plates whose shapes roughly resemble the continents of North and South America, Africa, Eurasia and Australia. The initial positions of these plates were taken to be similar to their present-day locations (Fig. 2.1). The thickness of the continents was taken to be $100 \mathrm{~km}$. The calculated history of continental drift is shown in Figs. 2.1-2.12. We can see how three continents drift to the north to assemble into a super continent similar to Laurasia (Fig. 2.3) and two others drift to the south to assemble into Gondwana (Fig. 2.4-2.6). These results reveal the mechanism of global mantle processes due to thermal and mechanical coupling of the mantle and continents. Figs. 2.7-2.11 show how all five continents try to assemble into a super continent, and Fig. 2.12 shows the dispersal of continents.

\subsection{3-D SPHERICAL MODEL OF MANTLE CONVECTION WITH EIGHT CONTINENTS AND TOMOGRAPHIC DATA ON A ROUGH GRID}

To model the mantle we assume a 3-D spherical shell filled with a cold, motionless, viscous liquid. Then we set eight thick, buoyant, solid plates into a viscous mantle. The thickness of all the continents was set to $d=0.02$ and $R \approx 130$ 
$\mathrm{km}$. The shape of these plates was taken to be similar to the shapes and sizes of the actual continents (North and South America, Africa, Eurasia, Australia, Antarctica and two islands: Madagascar and Kalimantan).

The initial temperature distribution $\mathrm{T}(\mathrm{r}, \theta, \phi, \mathrm{t}=0)=\mathrm{T}_{0}(\mathrm{r}, \theta, \phi)$ for the real Earth was obtained from seismic tomography data. Lateral variations of temperature can be found directly from the formula $\delta V_{s}=\left(d_{v} / d_{c}\right) \delta T$ [Anderson et al., 1968] with an effective coefficient $\left(\mathrm{dV}_{\mathrm{s}} / \mathrm{dT}_{\mathrm{c}}\right)$ as a function of pressure and temperature [Cadek et al., 1994]. We assume these lateral variations of temperature were similar to those calculated by S. Sobolev (personal communication) from tomographic data. To find the variation of temperature with depth we need to use additional constraints from another data set. In the Boussinesq approximation, the depth-temperature distribution for various values of the Rayleigh numbers is known from the theory of thermal convection. The full temperature in the mantle is the sum of the Boussinesq over-adiabatic (potential) temperature $T(r, \theta, \phi, t)$ and the adiabatic temperature $\mathrm{T}_{\mathrm{ad}}(\mathrm{r})$ calculated using the accepted parameters of the Earth. [e.g. Zharkov and Trubitsyn, 1979]. Figs. 3.1-3.14 show the lateral variations of the temperature distributions at various depths, taken as initial $\mathrm{T}_{0}\left(\mathrm{r}_{\mathrm{i}}, \theta, \phi\right)$ in our calculations of mantle convection for model 3 and 4. They are from the Sobolev (personal communication) data and are shown graphically in Figs. 3.1-3.14. The scale for temperature variation is on the left side.

The mantle viscosity was modeled as a property of the material (as a function of pressure (p) and temperature (T)) and we assumed the simplified Weertman's formula

$$
\eta(p, T)=A \exp \left\{\left(\mathrm{E}_{0}+\mathrm{p} \mathrm{V}_{0}\right) /\left(\mathrm{T}+\mathrm{T}_{\mathrm{ad}}+\mathrm{T}_{0}\right)\right\}
$$

Here $T_{0}$ is the cut-off temperature (to prevent an infinitely great viscosity for $T=0$ ). 
We neglect the stress dependence of viscosity, so A is constant. The values of the activation energy $E_{0}$ and activation volume $V_{0}$ are unknown for the lower crust and poorly constrained for the upper mantle, since they can also depend on the chemical and mineralogical composition, as well as on the rheology of the mantle. Therefore, we considered this formula to be effective and chose the parameter values that gave a calculated depth distribution for viscosity that is consistent with the available data. In dimensionless form, we assume the $\mathrm{p}-\mathrm{T}$ dependence for viscosity as follow:

$$
\eta(\mathrm{p}, \mathrm{T}) \approx 0.01 \exp \{(21-20 \mathrm{r}) /(\mathrm{T}+2.4-2.2 \mathrm{r})\},
$$

We assume a slip-free velocity and fixed temperature $\mathrm{T}+\mathrm{T}_{\mathrm{ad}}=3500{ }^{\circ} \mathrm{C}$ as a condition on the core-mantle boundary. On the upper surface we assume $\mathrm{T}=0$ and the same slip-free condition to be valid on the oceanic part of the surface as well as continuity for temperature, heat flow and velocities on the continent-mantle boundaries.

We then set $\mathrm{Ra}=5 \times 10^{6}$ in the equations of thermal convection with floating continents $(1-3,25-29)$ and carried out the numerical calculations. To save computer time we calculated a history of continental drift on a rough grid of $32 \times 32 \times 32$. Fig. 3.15 shows the initial positions of continents over the entire Earth. The calculated evolution of the coupled mantle/continent system is shown in Figs. 3.15- 3.30.

The positions of the continents, the calculated heat flow distribution (shown by the color scale on the left side of each figure), the calculated velocity of mantle flow and velocities of the points for all eight continents (scale for velocity is in the upper-left corner) are shown. We calculated up to the time at which all the continents begin to assemble to form Pangaea. This calculation took about one week ( 200 hours) on a PC-IT Pentium-II 400Mhz. 


\subsection{3-D SPHERICAL MODEL OF MANTLE CONVECTION WITH EIGHT CONTINENTS ON A FINER GRID}

In our next calculations we assumed the same model, but used a finer grid $\left(r_{x} \theta_{x} \phi=32 \times 72 \times 144\right)$. Our numerical program used a variable grid with finer spacing in the areas of greatest variation of the unknown function and rougher spacing in areas of small variation. The previously mentioned value of the grid is a mean value taken over the entire grid range. We calculated the present-day state of the mantle under the oceans and continents and modeled the future Earth's mantle/continent system up to $200 \mathrm{My}$ from now. The initial positions of the continents were taken to be the same as used in the previous model. They are shown in Fig. 3.15.

Fig. 4.1 shows the depth variations of the adiabatic, $T_{a d}(r)$, over-adiabatic Boussinesq potential temperature, $T_{0}(r)$ and full initial temperature in the mantle, $\mathrm{T}_{0}(\mathrm{r})+\mathrm{T}_{\mathrm{ad}}(\mathrm{r})$.

If we put an initial temperature, $\mathrm{T}_{0}(\mathrm{r}, \theta, \phi)$ into this formula (37) for viscosity $(\eta(p, T))$, we will find the 3-D space distribution of the viscosity in the mantle. Fig. 4.2 shows the calculated mean viscosity as a function of depth (averaged by $\theta$ and $\phi)$. To a first approximation this distribution fits the available data: highly viscous oceanic lithosphere, low viscosity asthenosphere, and an increase of viscosity with depth in the lower mantle [e.g. Mitrovica and Forte, 1997].

The main input data were as follows: initial positions of continents (Fig. 3.15), $\mathrm{T}_{\mathrm{o}}(\mathrm{r}, \theta, \phi)$, and formula (37) for viscosity $\eta(p, T)$. We again assumed $\mathrm{Ra}=510^{6}$. To show the results in dimensional form we assumed the following values for the relevant Earth's parameters: $\alpha=210^{-5} \mathrm{~K}^{-1}, \rho=4,000 \mathrm{~kg} \mathrm{~m}^{-3}, \mathrm{cp}=1.210^{3} \mathrm{~J} \mathrm{~kg}^{-1} \mathrm{~K}^{-1}$, $\mathrm{T}^{*}=2,500 \mathrm{~K}, \mathrm{~g}=10 \mathrm{~m} \mathrm{~s}^{-2}, \kappa=4.8 \mathrm{Wm}^{-1} \mathrm{~K}^{-1}, \mathrm{~K}=10^{-6} \mathrm{~m}^{2} \mathrm{~s}^{-1}, \eta_{0}=10^{22}$ Pas. 
Fig. 4.3 shows the initial temperature distribution, taken from tomography data in a cross-section at $\phi=15^{\circ}$. The color scale on the left side gives the temperature. The continents are shown as a brown color. In this cross-section we see Antarctica (bottom), a piece of N. America (upper-left), Africa (on the right) and two pieces of Eurasia (upper-right). Figs. 4.4-4.28 show the calculated evolution of the mantle convection with floating continents. Arrows show the calculated velocity of mantle flow and all points of the continents, with the scale shown in the upperleft corner of each figure. The red line outside the Earth shows the heat flow distribution in this cross-section $\left(\phi=15^{\circ}\right)$. The maximum and minimum of the calculated heat flow are shown on the left side of the figures. The black line shows the $670 \mathrm{~km}$ phase boundary between the upper and lower mantle.

From these figures we can see the coldest areas of mantle and those with highest viscosity (pictured by the blue color). We see the thin oceanic lithosphere and two giant hot anomalies under Africa and the Pacific. Fig. 4.4 shows the mantle flow and continental velocities calculated after one time step. Recall that we assumed a non-slip boundary condition under the moving continents. The evolution of mantle flow is therefore shown to differ greatly in comparison to the models with slip-free conditions currently being used in published papers. Near the beginning of the 50 My time period our model already begins to show properties of the continental lithosphere. This must occur due to the equations of mass, heat and low momentum transfer. Figs. 4.5-4.17 show the evolution of giant plumes under Africa and the Pacific.

The model we present is a preliminary one. Our scenario is only one possible evolution of the future Earth. We can distinctly see the break-up of the subducted slabs (Fig. 4.14) and the decrease in the uplift of the hot plumes (Fig. 4.16). Beginning at $t>100 \mathrm{My}$, the asthenosphere spreads under the oceans and there is 
almost always no asthenosphere left beneath the continents. Our schematic model predicts a very hot mantle in the north after 150 My have passed.

Let us compare the static tomography picture (Fig. 4.3) with the results of our numerical calculations (Figs. 4.8-4.12). For example, we do not see any continental lithosphere on Fig. 4.3 (Possibly new tomographic data will show it). After some time $\mathrm{t}>100$ My the numerical results distinctly show a continental lithosphere. Numerical modeling can improve some of the mistakes in the initial tomographic data by using the general equations of mass, heat and momentum transfer. The distributions of all calculated geophysical fields must be fully repeatable with each other and must even correct the initial tomographic data.

These results may indicate one of the possible paths for Earth's future evolution, predicting a hot North Pole in the next $100 \mathrm{My}$. This model also indicates that a very long time should pass before the formation of the next Pangaea $(t \sim 1.0-1.5 \mathrm{By})$. This corresponds to the time necessary for the continents to move a distance of about $10,000 \mathrm{~km}$ with a velocity of about 0.5 $\mathrm{cm} / \mathrm{y}$. The time of the previous Pangaea formations took 2-4 times less because the Earth was $50-100^{\circ} \mathrm{K}$ hotter. The mantle viscosity, therefore, was 5-10 times lower and the velocity of the mantle flow was 2-4 times greater.

\section{CONCLUSION}

Three main coupling processes manage global geodynamics: a non-steady state semi-chaotic mantle convection, a highly viscous oceanic lithosphere, and the motion of floating continents. We studied the third and found that floating continents play a very important role in global tectonics.

1. First, to exclude the chaotic effects of thermal convection we assumed 
a very low Rayleigh number and used a simple 2-D model of mantle convection with one small continent to reveal:

a) For low Rayleigh numbers without continents all upwellings and downwellings are vertical. The continent moves due to viscous coupling with mantle flow, is drawn towards a nearby downwelling and tries to cover the downwelling. Simultaneously, the continent shifts the upper portion of the subduction zone and reduces the pressure in the subduction wedge. As a result the downwelling reorients from vertical to a steep angle. This effect is proportional to continental velocity. It was found that the slabs subducting under a slow-moving Eurasia dip close to vertical, while the slabs subducting under faster-moving South America are very steep.

b) During most of its "life" the continent exists over the coldest (downwelling) part of the mantle. This explains why the lithosphere under most of the continents is cooler than the average suboceanic lithosphere.

c) The insulating effect of the continent prevents heat from escaping the mantle. The material beneath a continent consequently becomes warmer and lighter. The downwelling beneath the continent eventually disappears and is replaced by upwelling. About 200-400 My are required to reverse the mantle flow under a large fixed continent. This effect may explain the origin of the giant hot anomaly beneath Africa.

d) Beneath Africa an upwelling has split into two branches (similar to the upwellings of the Atlantic and Indian ridges). This has resulted in Africa being stationary for a long time but this state of mantle convection with a floating continent is not stable. Mantle flow will eventually begin to push the continent towards the next nearby downwelling that will result in the downwelling being reversed. 
e) The substitution of upwelling for downwelling occurs as follows. In some cases new upwelling comes from the core-mantle boundary, but often existing nearby upwellings are pulled beneath continents. At the same time active downwellings can be terminated.

2. 3-D spherical models of mantle convection with five floating continents showed that the equations of mass, heat and momentum transfer lead both to the assembly of continents into a super continent and to their dispersal. This process is possible due to a strong mechanical and thermal interaction between the mantle flow and the continents. The huge downwelling pulls the continents toward downwelling trenches and assembles them, but the super continent diminishes this downwelling and creates an upwelling that disperses the continents once again.

3. 3-D spherical models with floating continents use an initial state taken from the tomographic data and can be incorporated into a full, preliminary geodynamic model. The model includes all three main processes mentioned above to describe the global Earth's tectonics. This model shows the evolution of asthenosphere, continental lithosphere, splitting of the huge African upwelling, division of upwellings, the break-up and separation of downwellings (similar to those of subducted slabs) and the settling of downwellings to the core-mantle boundary.

This model must be improved in future projects. A finer grid is needed as well as more precise tomographic data and better values of the Earth's parameters for input purposes. At present, this model gives new output data and three velocities for each continent. Comparisons of calculated continental velocities with observed data (e.g. GPS data) will give new constraints which 
are very sensitive to the Earth's interior structure. Numerical modeling of mantle convection with the oceanic lithosphere and continents using tomography will give a 3-D view through time of the interior's structure and dynamics. We can therefore predict the future geodynamic evolution of the Earth, and in principal, reconstruct its history.

\section{ACKNOWLEDGMENTS}

Preliminary results on the effects of the continents on global

geodynamics were obtained in Moscow, where discussions with D. Rundkwist were very helpful. Presented results, especially concerning calculations of the 3-D spherical models with the parameters of the real Earth, were obtained mainly owing to the assistance and many helpful discussions with Walter D. Mooney. For the initial state of mantle convection, we used the lateral temperature distribution, calculated from tomographic data by Stephan Sobolev. This manuscript greatly benefited from discussions we had with R. Meissner, R. Girdler and T. Romanyuk on the tectonic interpretation of the results. Editing by Geoff Clitheroe, David Cornwell, Shane Detweiler, Clodagh Heverin. This work was supported by the USGS. 


\section{REFERENCES CITED}

Anderson O.L., E. Schreiber, R.C. Liberman and N. Soga, 1968. Some elastic constant data on minerals relevant to geophysics, Rev. Geophys., 6: 491-524.

Balachandar S., D.A. Yuen and D. Reuter, 1992. Time-dependent 3-dimension compressible convection with depth-dependent properties, Geophys. Res. Lett., 19: 2247-2250.

Bercovici, D, 1998. Generation of plate tectonics from lithosphere-mantle flow and void-volatile self lubrication, Earth Planet. Sci. Lett., 154, 139-151.

Bobrov A. M., and V. P. Trubitsyn, 1996. Times of rebuilding of mantle flows beneath continent. Izvestiya, Physics of the solid Earth, 31: 551-559. (English translation of Fizika Zemli. Published by American Geophysical Union and Geological Society of America).

Brunet D. and P. Machetel, 1998. Large-scale feature induced by mantle avalanches with phase, temperature, and pressure lateral variations of viscosity, J. Geophys. Res., 103: 4929-4945.

Bunge H.P., M.A. Richards and J.R. Baumgardner, 1997. A sensitivity study of threedimensional spherical mantle convection at $10^{8}$ Rayleigh number: Effects of depth-dependent viscosity, heating mode, and an endothermic phase change. J. Geophys. Res. 102: 11,991-12,007.

Cadek O., D.A. Yuen, V. Steinbach, A. Chopelas and C. Matyska, 1994. Lower mantle thermal structure deduced from seismic tomography, mineral physics and numerical modeling, Earth Planet. Sci. Lett., 121: 385-402.

Christensen U. R., 1983. Numerical model of coupled subcontinental and oceanic convection, Tectonophysics. 95: $1-23$.

Christensen U.R., 1984. Convection with pressure- and temperature- dependent nonNewtonian rheology, Geophys. J. Astr. Soc., 77: 343-384.

Christensen U.R., 1985. Heat transfer by variable viscosity convection. II. Pressure influence, non-Newtonian rheology and decaying heat sources, Phys. Earth Planet. Inter., 37: 183-205.

Christensen U.R. and D.A. Yuen, 1984. The interaction of a subducting lithospheric slab with a chemical or phase boundary, J. Geophys. Res., 89: 4389-4402.

Doin M.-P., L. Fleitout and U. Christensen, 1997. Mantle convection and stability of depleted and undepleted continental lithosphere, J. Geophys. Res., 102: 2771 2787.

Glatzmaier G. A., 1988. Numerical simulation of mantle convection: Time-dependent, three-dimensional, compressible, spherical shell, Geophys. Astrophys. Fluid 
Dyn, 43: 223-264.

Hager B.H., 1984. Subducted slabs and the geoid: Constraints on mantle rheology and flow. J. Geophys. Res., 89: 6003-6015.

Jacoby W.R. and H. Schmeling, 1982. On the effects of the lithosphere on mantle convection and evolution, Phys. Earth Planet. Inter., 9: 305-319.

Jarvis G.T. and D.P. McKenzie, 1980. Convection in a compressible fluid with infinite Prandtl number, J. Fluid Mech,. 96: 515-583.

Landau L.D. and E.M. Livshitz, 1958. Mechanics, London: Pergamon, 136 pp.

Landau L.D. and E.M. Livshitz, 1959. Fluid Mechanics, London: Pergamon, 536 pp.

Lenardic A. and W.M. Kaula, 1994. Tectonic plates, D" thermal structure, and the nature of mantle plumes, J. Geophys.Res., 99: 15,697-15,708.

Lowman J.P. and J.T. Jarvis, 1993. Mantle convection flow reversals due to continental collisions, Geophys. Res. Lett., 20: 2,091-2,094.

Lowman J.P. and J.T. Jarvis, 1995. Mantle convection models of continental collision and breakup incorporating finite thickness plates, Phys. Earth Planet. Inter., 88: 53,068-53,088.

Lowman J.P. and J.T. Jarvis, 1996. Continental collisions in wide aspect ratio and high Rayleigh number two-dimensional mantle convection models, J. Geophys. Res., 101: 25,485-25,497.

Lux R.A., G.F. Davies, and J.H. Thomas, 1979. Moving lithospheric plates and mantle convection, Geophys. J. R. Astron. Soc., 57: 209-228.

Machetel P. and P. Weber, 1991. Intermittent layered convection in a model mantle with an endothermic phase change at $670 \mathrm{~km}$, Nature, 350: 55-57.

Mitrovica J. X. and A.M. Forte, 1997. Radial profile of mantle viscosity: Results from the joint inversion of convecvtion and postglacial rebound observables, J. Geoph. Res., 102: 2751-2769.

Nakakuki T., D.A. Yuen and S. Honda, 1997. The interaction of plumes with the transition zone under continents and oceans, Earth Planet. Sci. Lett., 146: 379391.

Parmentier E.M., C. Sotin and B.J. Travis, 1994. Turbulent 3-D thermal convection in an infinite Prandl number, volumetrically heated fluid; Implication for mantle dynamics, Geophys. J. Int., 116: 241-254.

Rykov V.V. and V.P. Trubitsyn, 1996a. Numerical technique for calculation of threedimensional mantle convection and tectonics of continental plates. In Computational Seismology and Geodynamics ed. by D.K. Chowdhury. Am. Geophys. Un., Washington D.C. 3; 17-22 ( English translation of Vychisliteljnaya seismologiya. Nauka. Moscow).

Rykov V.V and V.P.Trubitsyn, 1996b. 3-D model of mantle convection incorporating 
moving continents, in Computational Seismology and Geodynamics ed. by D.K. Chowdhury. Am. Geophys. Un., Washington D.C., 3: 23-32. (English translation of Vychisliteljnaya seismologiya. Nauka. Moscow).

Samarskii A.A. and E.S. Nikolaev, 1978. Method of solving finite-difference equations (in Russian). Moscow. Nauka. P. 591.

Schubert G., 1992. Numerical models of mantle convection, Ann. Rev. Fluid Mech., 24: 395-394.

Solheim L.P. and W.R., Peltier, 1994. Phase boundary deflections at 660-km depth and episodically layered isochemical convection in the mantle, J. Geophys. Res., 99: 15,861-15,875.

Tackley P.J., 1998. Self-consistent generation of tectonic plates in 3-dimensional mantle convection, Earth Planet. Sci. Lett., 157, 9-22.

Tackley P.J., D.J. Stevenson, G.A. Glatzmaier and G. Schubert, 1994. Effect of multiple phase transitions in three dimension spherical model of convection in Earth's mantle, J. Geophys. Res., 99: 15,877-15,901.

Trubitsyn V.P. and A.M. Bobrov, 1994. Structure evolution of mantle convection after breakup of supercontinent, Izvestiya, Physics of the solid Earth. 29: 768-778. (English translation of Fizika Zemli. Published by American Geophysical Union and Geological Society of America).

Trubitsyn V.P. and A.M. Bobrov, 1996. Thermal and mechanical interaction of continents with the mantle in Computational Seismology and Geodynamics ed. by D.K. Chowdhury. Am. Geophys. Un., Washington D.C, 3: 33-41. (English translation of Vychisliteljnaya seismologiya. Nauka. Moscow.).

Trubitsyn V.P and A. M. Bobrov, 1997. Structure of mantle convection beneath stationary continents, in Computational Seismology and Geodynamics ed. by D.K. Chowdhury Am. Geophys. Un., Washington D.C, 4: 42-53. (English translation of Vychisliteljnaya seismologiya. Nauka. Moscow.).

Trubitsyn V.P., A.M. Bobrov and V.V. Kubyshkin, 1993. Influence of continental lithosphere on structure of mantle thermal convection, Izvestiya, Physics of the solid Earth. 29: 377-385. (English translation of Fizika Zemli. Published by American Geophysical Union and Geological Society of America).

Trubitsyn V.P. and A.S. Fradkov, 1985. Convection under continents and oceans, Izvestiya, Physics of the solid Earth. 21: 491-498. (English translation of Fizika Zemli. Published by American Geophysical Union and Geological Society of America).

Trubitsyn V.P. and A.S. Fradkov, 1986. The viscous drag on the oceanic lithosphere, Izvestiya, Physics of the solid Earth. 22: 103-116. (English translation of Fizika Zemli. Published by American Geophysical Union and Geological Society of 
America).

Trubitsyn V. P. and V.V. Rykov, 1995. A 3-D numerical model of the Wilson cycle, J. Geodynamics, 20: 63-75.

Trubitsyn V. P. and V.V. Rykov, 1997. Mechanism of formation of an inclined subduction zone. Izvestiya, Physics of the solid Earth, 33: 427-433. (Official English translation of Fizika Zemli. Interperiodica Publishing, Russia).

Trubitsyn V. P. and V.V. Rykov, 1998a. Global tectonics of floating continents and oceanic lithospheric plates, Doklady Russian Academy of Sciences 359: 109-111.

Trubitsyn V. P. and V.V. Rykov, 1998b. Self-consistent 2-D mode of mantle convection with floating continent, Russian J. Earth's Sciences (electronic), 1, No.1, July (in translation into English), http://eos.wdcb.rssi/ru/rjes/rje98001/rje98001.html

Trubitsyn V. P. and V.V. Rykov, 1999, Mantle convection and global tectonics of the Earth, Russian J. Earth's Sciences (electronic), 1, No.1, January (in translation into English), http://www.scgis.ru/russian/cp 1251/dgggms/198/main.html

Trubitsyn V.P., Yu.F. Belavina and V.V. Rykov, 1993. Thermal and mechanical interaction of mantle and continental lithosphere, Izvestiya, Physics of the solid Earth. 29: 933-945. (English translation of Fizika Zemli. Published by American Geophysical Union and Geological Society of America).

Zalesak S.T., 1979. Fully multidimensional flux-corrected transport algorithms for fluids, J.Comp. Phys., 31: 335-361.

Zharkov V.N. and V.P. Trubitsyn, 1979. Physics of planetary interiors. Arizona: Pachart Publ., 380 pp. 


\section{LIST OF FIGURES}

Fig.1.1 -1.17 2-D numerical model for evolution of mantle convection with one freefloating continent with an effective Rayleigh number $\mathrm{Ra}=210^{5}$

Fig. 1.1 and 1.4 - calculated temperature and flow for developed non-stationary mantle convection for the time when the continent is emplaced on the mantle. Elongated box $X: Z=10: 1$. Dimensional time and color scale for the temperature are shown on the left. Upper curve - calculated dimensionless (Nusselt number) heat flow distribution

Fig. 1.2-1.3 - calculated dimensionless temperature and viscosity as functions of the depth: $\mathrm{Z}$ axis directed upwards, $\mathrm{X}$ axis is temperature and logarithm of viscosity

Fig. 1.4-1.17 show positions of floating continent and changes of mantle convection.

Fig. 2.1 -2.12 Calculated evolution of mantle convection with five floating continents with $\mathrm{Ra}=10^{6}$ for dimensionless variables. Temperature is shown by color, velocity of mantle flow and continents are shown by arrows (see scale on the left).

Fig. 2.1 - initial positions for continents on a convecting mantle.

Fig. 2.11 - time when all continents assembled.

Fig. 2.12 - time when continents dispersed.

Fig. 3.1 -3.14 Lateral variations of temperature for various depths, calculated from tomographic data and used as the initial temperature distribution for calculation of mantle convection. The scale for temperature variation is shown on the left.

Fig. 3.15 The initial positions of six continents and two islands on the cold viscous sphere. The continents are shown in brown. 
Fig. 3.16 -3.30 Calculated mantle flow and continent velocities, and heat flow for the various times in the evolution of mantle convection with floating continents for the time from the present time $(t=0)$ until 1.2 By in the future. The continents are shown in brown, and arrows show vector velocities (scale is on the left). The values of calculated heat flow are shown by color.

Fig. 4.1 The depth distribution of temperature $T(r, t=0)$ in the Earth, taken as the initial conditions for the calculations. The blue curve is the adiabatic temperature, the red curve is the full temperature, and the black curve is the over-adiabatic (potential) temperature, the evolution of which is calculated in the Boussinesq approximation. The vertical axis is depth $(\mathrm{km})$, the horizontal axis is temperature $\left({ }^{0} \mathrm{C}\right)$.

Fig. 4.2 The depth distribution of viscosity $\eta(p, T, t=0)$ in the Earth, calculated by formulas $(36,37)$, using the initial full temperature for the Earth.

Fig. 4.3 Cross-section of the mantle at latitude $\varphi=15^{\circ}$ at the initial time $\mathrm{t}=0$. The continents Antarctic (bottom), Africa (right), Eurasia (West Europe and Scandinavia in the upper right) and Alaska (in the upper-left) are pictured by the color brown. Lateral variations of the potential temperature are calculated from tomographic data. The green color corresponds to a cold lithosphere, the red color to a hot giant anomaly under the Pacific and Africa. The black spherical curve shows the 670-km upper-lower mantle boundary.

Fig. 4.4-4.28 The calculated evolution of the mantle convection with floating continents for the present time $(t=0)$ until $195 \mathrm{My}$ into the future. The arrows show the calculated mantle flow and the continental velocities. The scales for temperature and velocities are shown on the left. Also, a maximum and minimum calculated heat flow is shown. 


\section{BIOGRAPHICAL SKETCHES}

NAME: Valery Trubitsyn

ADDRESS: Institute of Physics of the Earth

Russian Academy of Sciences

B.Gruzinskaya 10, 123810, Moscow, Russia

TELEPHONE: (095) 254-9235
EMAIL: trub@uipe-ras.scgis.ru

DATE OF BIRTH: Sept. 5, 1930

EDUCATION:

1963 Dr. Sci. Institute of Physics of the Earth RAS

1971 Dr.-Prof. Institute of Physics of the Earth RAS

\section{EMPLOYMENT:}

1954 Post-graduate student Institute of Physics of the Earth RAS

1957 Research Fellow, Institute of Physics of the Earth RAS

1966 Senior Research Scientist, Institute of Physics of the Earth RAS

1982 Professor, Institute of Physics of the Earth RAS

1980- Head of Laboratory of Theoretical Geodynamics,

present Institute of Physics of the Earth RAS

\section{FIELD AND MAJOR SCIENTIFIC RESULTS}

1. 1960-1963: Quantum mechanics of solids: Using quantum theory, HartreeFock and mathematical theory, Trubitsyn created the theory for the calculation of electronic conductivity in solids. High-pressure lids to level the overlap and transition of any material into a metallic phase were developed. The calculations of the critical pressure for silicates were found to be a few tens of Mbar. This work proved that Earth's core must consists of iron, and not of metallic silicate (as most scientists thought at that time).

2. 1963-1966: High-pressure physics: Solid hydrogen is a classic subject for study, and frozen deuterium could be a compact fuel for spaceships. There was an unknown low for Van-der-Vaalse forces at high pressure. They increase to infinity as distances between atoms are reduced. Landau proposed to neglect the Van-der-Vaalse forces, and all scientists did so. Trubitsyn found that the Van-der-Vaalse law changes 
at high pressure and that these forces play a great role. The neglecting of these forces in the input caused results to be off by about $900 \%$ ! Trubitsyn found the equations describing molecular and metallic hydrogen, helium and other elements, including all repulsion and attraction forces. The equation of solid hydrogen was confirmed by special experiments at the Livermore Laboratory under E. Teller. Until the present, this equation has only slightly been modified.

3. 1966-1972: Physics of Solar System: Trubitsyn was the first scientist to find that Jupiter is a liquid planet and not solid (as all scientists thought at that time). Jointly with V.N. Zharkov he created the first models of the liquid interiors for Jupiter, Saturn, Uranus and Neptune.

4. 1970-1979: Figures and gravity of rotating stars and planets: In the nineteenth century, Poisson determined that the well-known theory of the celestial rotating bodies of Laplace is wrong. Many scientists believed Poisson tried to create a new theory. In fact, a Russian mathematician Lyapunov created a new theory, but this theory was not used due to its complexity. Trubitsyn proved that all divergent terms in all the infinite systems of Laplace's equations sum to zero. Jointly with V. N. Zharkov, he analytically found the integer-differential equations for ten harmonics and calculated the figure and gravity of Jupiter. American spaceships confirmed these results and confirmed the liquid state of Jupiter and the other giant planets

5. 1990-present: Magma chamber processes: Trubitsyn created a new theory for the heterogeneous differentiation in a magma chamber. This theory of mass transfer is similar to the theory of Rayleigh for heat transfer, but there is a difference in that conductive heat flow is proportional to the gradient of the temperature, whereas conductive mass transfer (Stokes settling) is proportional to mass concentration. Trubitsyn found critical numbers and critical cells for the onset of convective mass transfer. When limited to small sizes of heterogeneity, this theory supports the wellknown theory of the Rayleigh-Taylor instability, but with large heterogeneity this theory describes Stokes settling. Also, Trubitsyn wrote a system of equations for heat and mass transfer that join the theories of Rayleigh-Benard, Rayleigh-Taylor, and Stokes to find critical numbers for the onset of thermo-compositional convection.

6. 1995-present: Compaction and magma migration: Jointly with $\mathrm{M}$. Rabinovich and G. Khodakovsky, Trubitsyn investigated a new type of wave migration of magma in a medium of variable viscosity. Known compaction waves (McKenzie, Richter, Stevenson and others) can move up only through a medium with an inversion in the density. The waves of the new type move anywhere, (e.g. in a magma cumulus), where porosity decreases.

7. 1979-present: Mantle convection: Numerical modeling of mantle convection with variable viscosity. Trubitsyn (jointly with V.V. Rykov) input Euler's solid body equations to equations of mantle convection. Numerical modeling of mantle convection 
with floating continents allowed us to make advances in the full theory of oceanic and continental tectonics.

\section{RELEVANT PUBLICATIONS}

Trubitsyn V.P. and A.M. Bobrov A.M. 1994. Structure evolution of mantle convection after breakup of supercontinent, Izvestiya, Physics of the solid Earth. 29: 768778. (English translation of Fizika Zemli. Published by American Geophysical Union and Geological Society of America).

Trubitsyn V. P. and V.V. Rykov, 1995. A 3-D numerical model of the Wilson cycle, J. Geodynamics, 20: 63-75.

Trubitsyn V. P., 1997. The role of continents in global Earth's tectonics, Izvestiya, Physics of the Solid Earth, 34: 1-7 (Official english translation of Fizika Zemli. Interperiodica Publishing, Russia).

Trubitsyn V. P. and V.V. Rykov, 1998b. Selfconsistent 2-D model of mantle convection with floating continent, Russian J. Earth's Sciences

(electronic), 1, No.1, July (in translation into English), http://eos.wdcb.rssi/ru/rjes/rje98001/rje98001.htm

Zharkov V.N. and V.P. Trubitsyn, 1979. Physics of planetary interiors. Arizona: Pachart Publ., 380 pp.

\section{OTHER SIGNIFICANT PUBLICATIONS}

Trubitsyn V.P., 1966. Equation state of solid hydrogen at high pressures. Physics of solids.

Trubitsyn V.P., 1972. Adiabatic model of Jupiter, Astron. Journal.

Trubitsyn V.P., 1974. The solution of problem of Cleorou-Laplace- Lyapunov, Physics of the Solid Earth.

Zharkov V.N. and V.P. Trubitsyn, 1975. Theory of figures of rotating bodies, Astron. Journal.

Trubitsyn V. P. and V.V. Rykov, 1999. Mantle convection and global tectonics of the Earth, Russian J. Earth's Sciences (electronic), 1, No.1, January (in translation into English), http://www.scgis.ru/russian/cp1251/dgggms/198/main.html

POSTDOCTORAL FELLOWS: A. M. Bobrov, A. S. Fradkov, Yu. F. Belavina, S. G. Schlessberg, E. V. Kharybin, A. B. Makalkin, I. A. Tcharevskiy, G.I. Khodakovskiy, A.A. Karasev. 


\section{BIOGRAPHICAL SKETCHES}

NAME: Vitali Rykov

ADDRESS: Institute of Physics of the Earth

Russian Academy of Sciences

B.Gruzinskaya 10,

123810, Moscow, Russia

TELEPHONE: (095) 254-9235

EMAIL:vrykov@worldbank.org

DATE OF BIRTH: Jun. 25, 1955

EDUCATION:

1985 Dr. Sci. Computer Center Russian Academy of Science

EMPLOYMENT:

1978 Research Fellow, Computer Center Russian Academy of Science

1992 Senior Research Scientist, Institute of Geosystem

1993 Senior Research Scientist, Institute of Physics of the Earth RAS

\section{FIELD AND MAJOR SCIENTIFIC RESULTS:}

1993-present: Numerical modeling of mantle convection: Numerical modeling mantle convection with variable viscosity. Rykov (jointly with Trubitsyn) input Euler's solid body equations to equations of mantle convection. Rykov developed an original numerical technique for solving the system of coupled equations of mantle convection and floating continents. Also, Rykov created the original graphics for presentation of the results from the $3-\mathrm{D}$ models.

\section{RELEVANT PUBLICATIONS}

Rykov V.V., Numerical modeling of the non-stationary flows of viscous incompressible fluid, Computational Mathematics and Mathematical Physics, 1985, No. 25, p. 94-97. 
Rykov V.V., Numerical simulation of non-uniform motion of a body in a viscous fluid. In book: Modern problems in computational aero-hydrodynamics, Mir, Moscow, London, 1992, p. 131-145.

Rykov V.V. and V.P. Trubitsyn, Numerical technique for calculation of threedimensional mantle convection and tectonics of continental plates. In Computational Seismology and Geodynamics ed. by D.K. Chowdhury. Am. Geophys. Un., Washington D.C., 1996, 3; 17-22. (English translation of Vychisliteljnaya seismologiya. Nauka. Moscow.)

Rykov V.V and V.P.Trubitsyn, 3-D model of mantle convection incorporating moving continents, in Computational Seismology and Geodynamics ed. by D.K. Chowdhury. Am. Geophys. Un., Washington D.C., 1996, 3: 23-32. (English translation of Vychisliteljnaya seismologiya. Nauka. Moscow.).

Trubitsyn V. P. and V.V. Rykov, 1995. A 3-D numerical model of the Wilson cycle, J. Geodynamics, 20: 63-75.

\section{OTHER SIGNIFICANT PUBLICATIONS}

Trubitsyn V. P. and V.V. Rykov, 1998. Global tectonics of floating continents and oceanic lithospheric plates, Doklady Russian Academy of Sciences, 359: 109-111.

Trubitsyn V. P. and V.V. Rykov, 1998. Selfconsistent 2-D model of mantle convection with floating continent, Russian J. Earth Sciences (electronic), 1, No.1, July (in translation into English), http://eos.wdcb.rssi/ru/rjes/rje98001/rje98001.htm

Trubitsyn V. P., V.V. Rykov and W. Jacoby, 1999. The angle of downflow under overriding continent, J. Geodynamics, 28: 00-00 (in press).

Trubitsyn V. P. and V.V. Rykov, 1999. Mantle convection and global tectonics of the Earth, Russian J. Earth Sciences (electronic), 1, No.1, January (in translation into English), http://www.scgis.ru/russian/cp1251/dgggms/198/main.html 

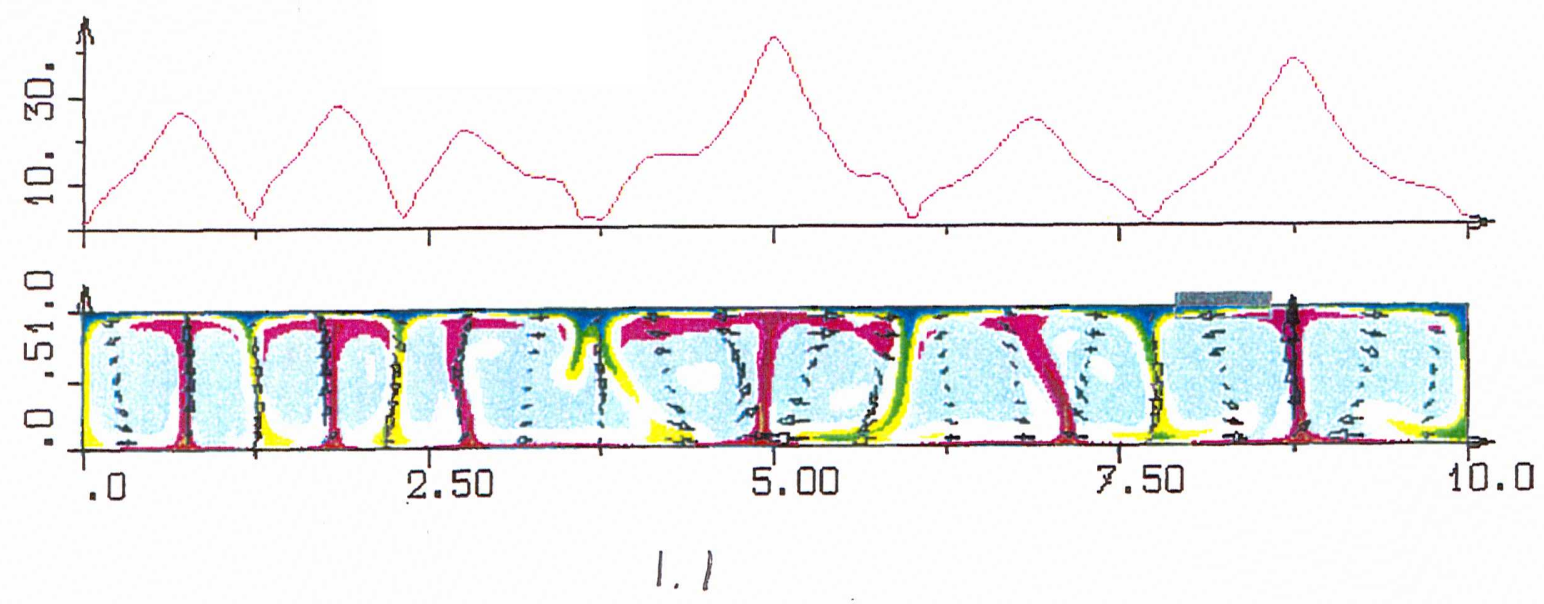

t $2.5565490 \mathrm{e}-02$ Czoss section: $Y=5.0000 \mathrm{e}-02$ Isolines: $\mathrm{TH}$ Min: $1.3003 e-05$ Max: $9.9998 \mathrm{e}-01$

$\rightarrow \quad 1.3942 e+03$

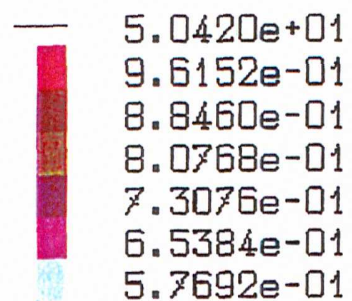

5. $0000 e-01$ 4. $2308 e-01$

$3.4616 e-01$

$2.6923 e-01$

1. $9231 e-01$

$1.1539 e-01$

$3.8473 e-02$

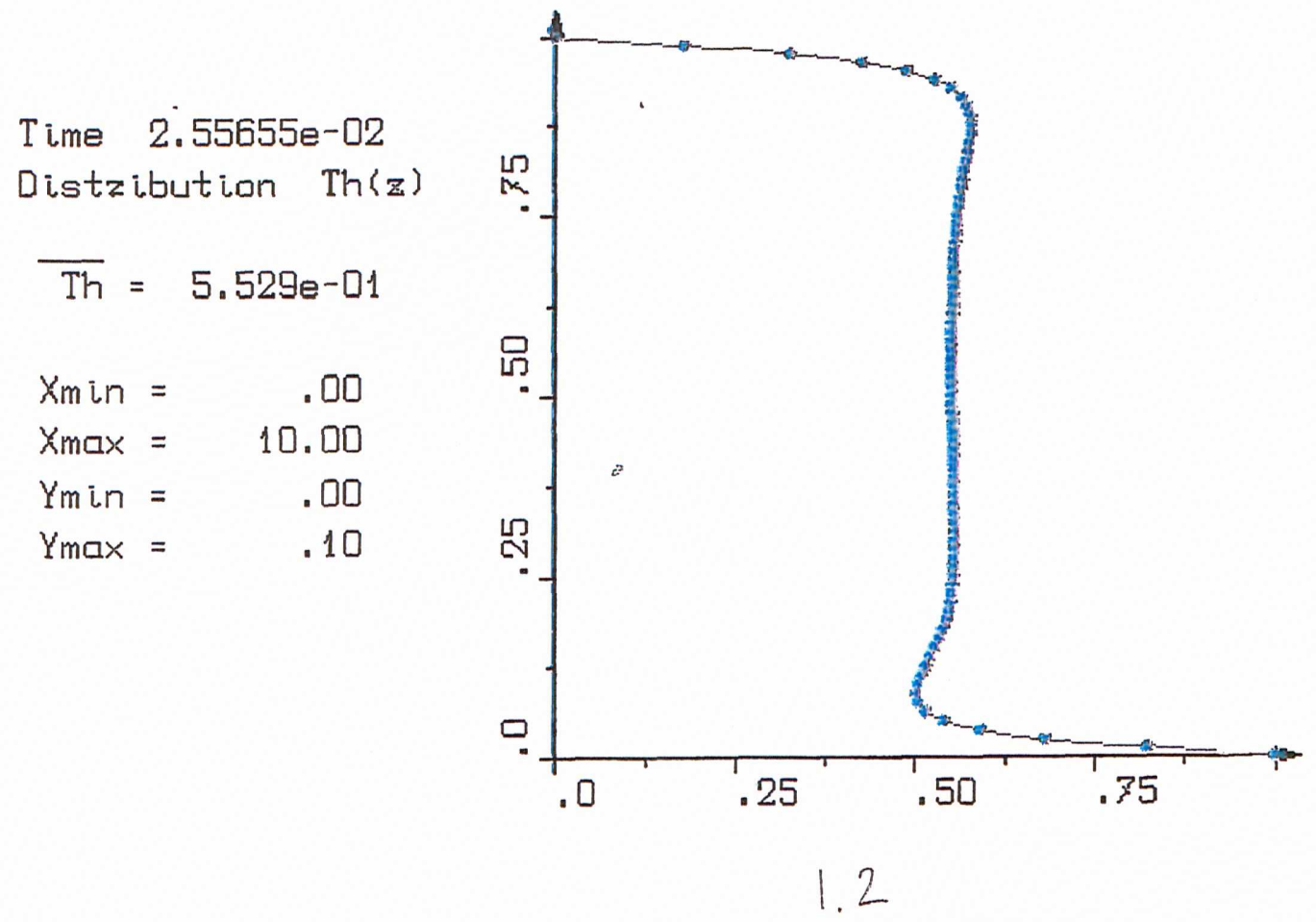


Time 2.55655e-02 Distzibution Lg(Sv)

$\begin{array}{lr}\overline{L_{9}}= & -8.872 e-01 \\ X_{\text {min }}= & .00 \\ X_{\text {max }}= & 10.00 \\ Y_{\text {min }}= & .00 \\ Y_{\text {max }}= & .10\end{array}$
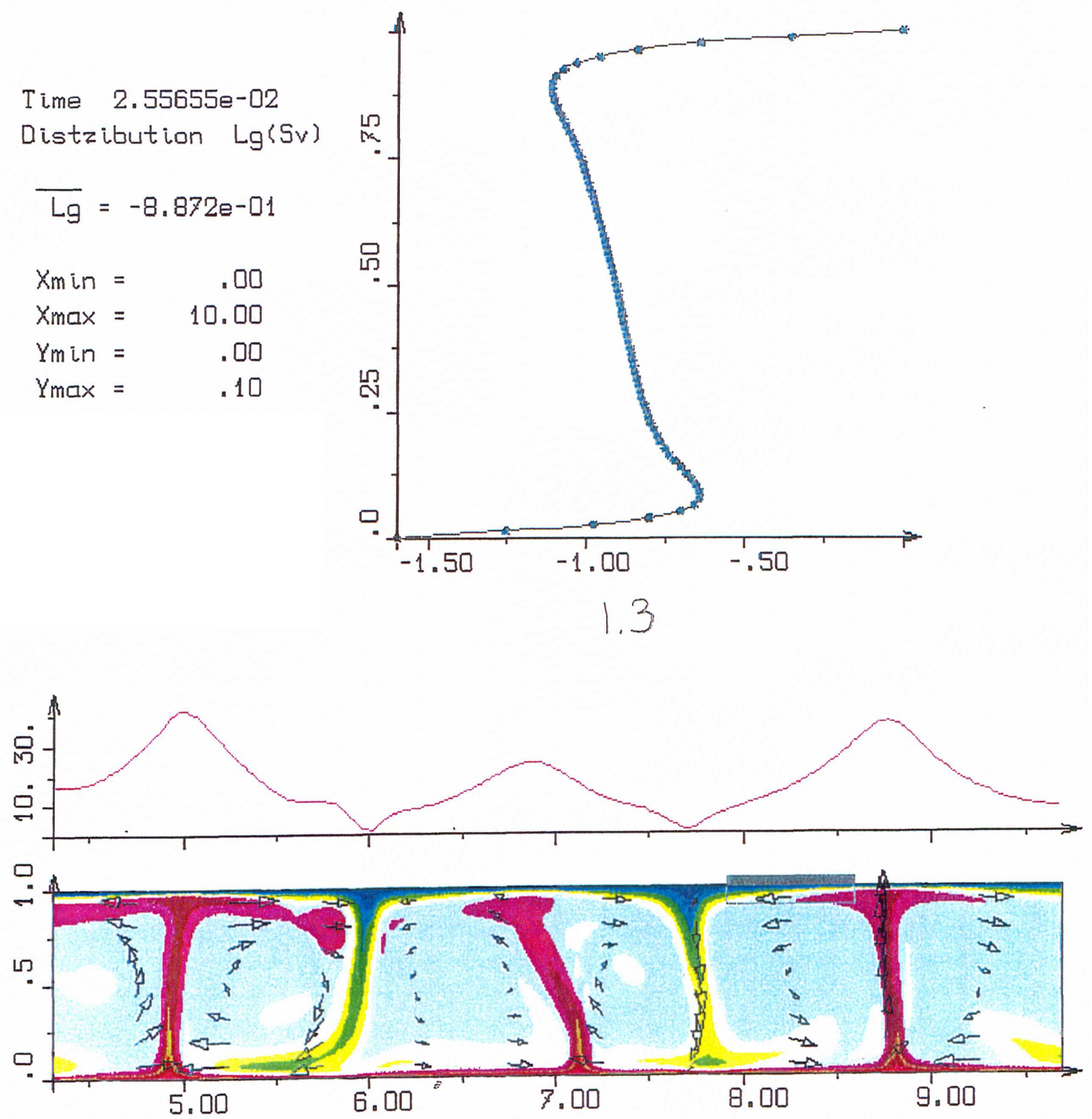

1. 4
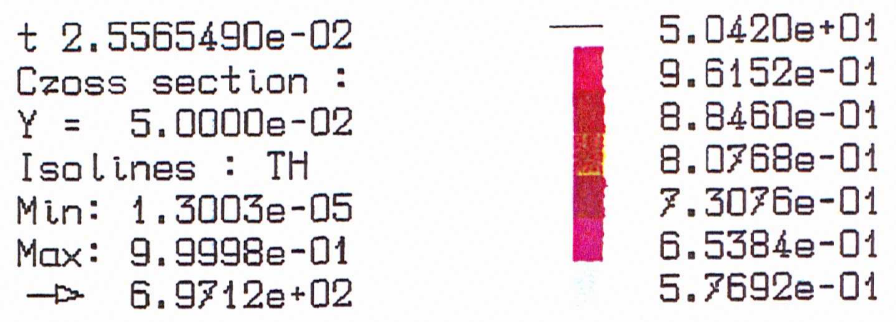

$5.0000 e-01$

4. $2308 e-01$

3. $4616 e-01$

$2.6923 e-01$

$1.9231 e-01$

$1.1539 e-01$

3. 8473e-02 

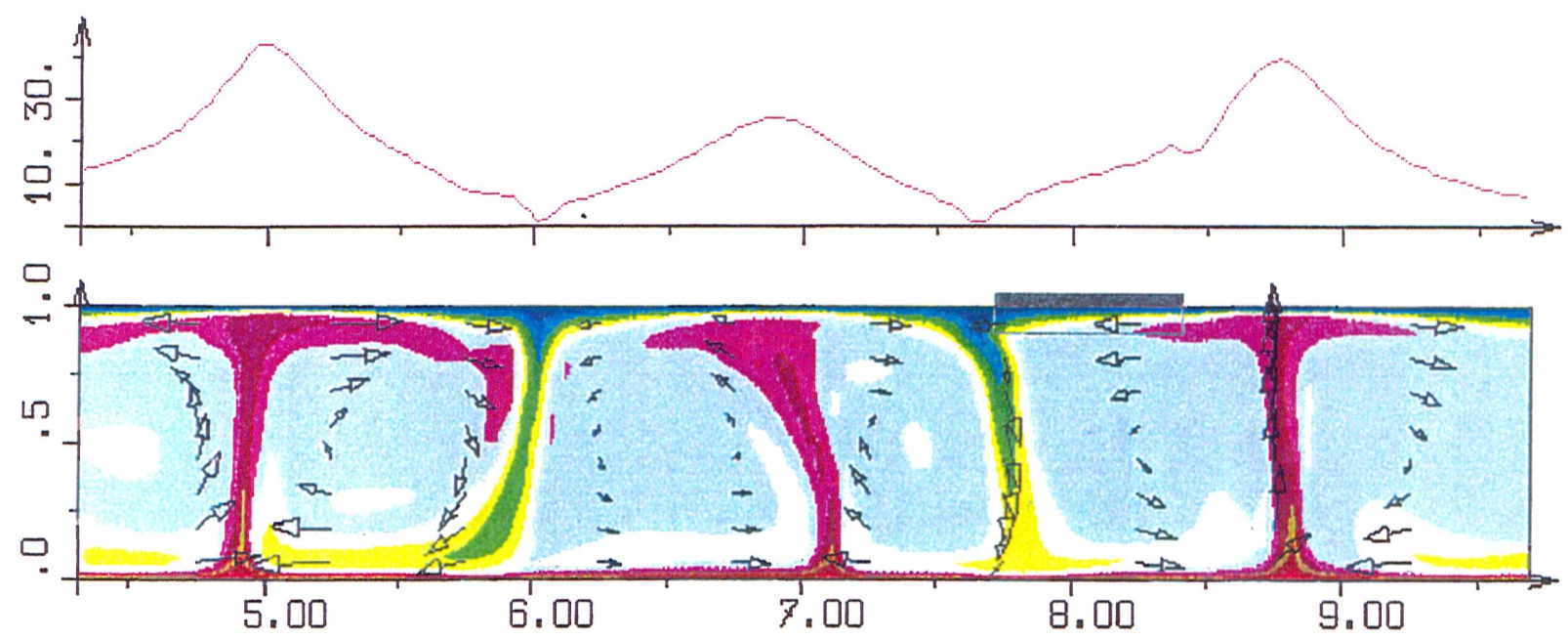

1.5

t $2.5900840 e-02$

Czoss section :

$Y=5.0000 \mathrm{e}-02$

Isalines : $\mathrm{TH}$

Min: 1.1056e-05

Max: 9.9998e-01

$\rightarrow \quad 6.9097 e+02$

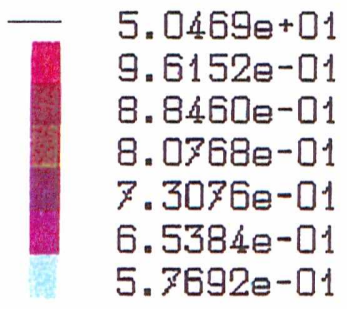

$5.0000 e-01$

4. $2307 e-01$

3. $4615 e-01$

$2.6923 e-01$

$1.9231 e-01$

$1.1539 e-01$

$3.8471 e-02$
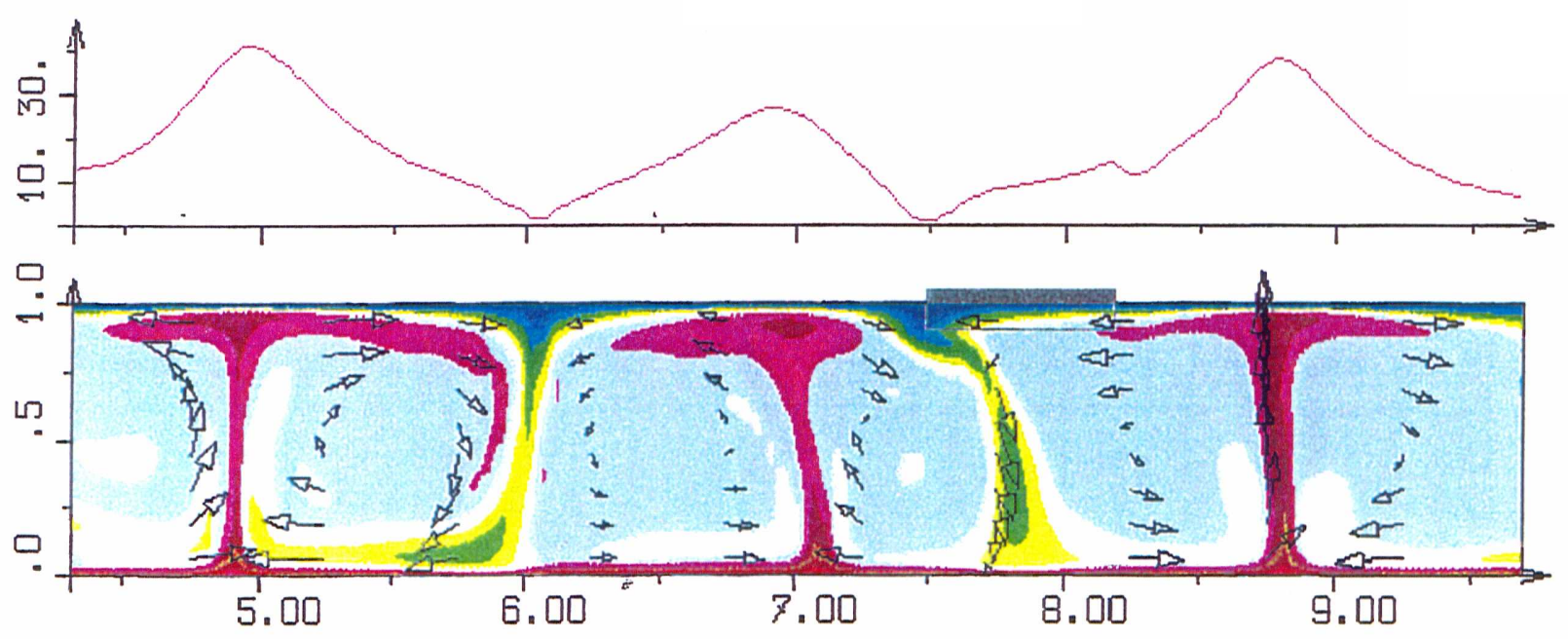

1.6

t 2.6301500e-02

Czoss section :

$Y=5.0000 e-02$

Isolines : $\mathrm{TH}$

Min: $1.4451 e-05$

Max: $9.9998 e-01$

$\rightarrow \quad 6.1477 \mathrm{e}+02$
$5.0502 e+01$

$9.6152 e-01$

$8.8460 e-01$

$8.0768 e-01$

$7.3076 e-01$

$6.5383 e-01$

$5.7691 e-01$
4. $99999-01$

4. $2307 e-01$

3. $4615 e-01$

$2.6923 \theta-01$

1. $9231 \theta-01$

$1.1539 \theta-01$

$3.8474 e-02$ 

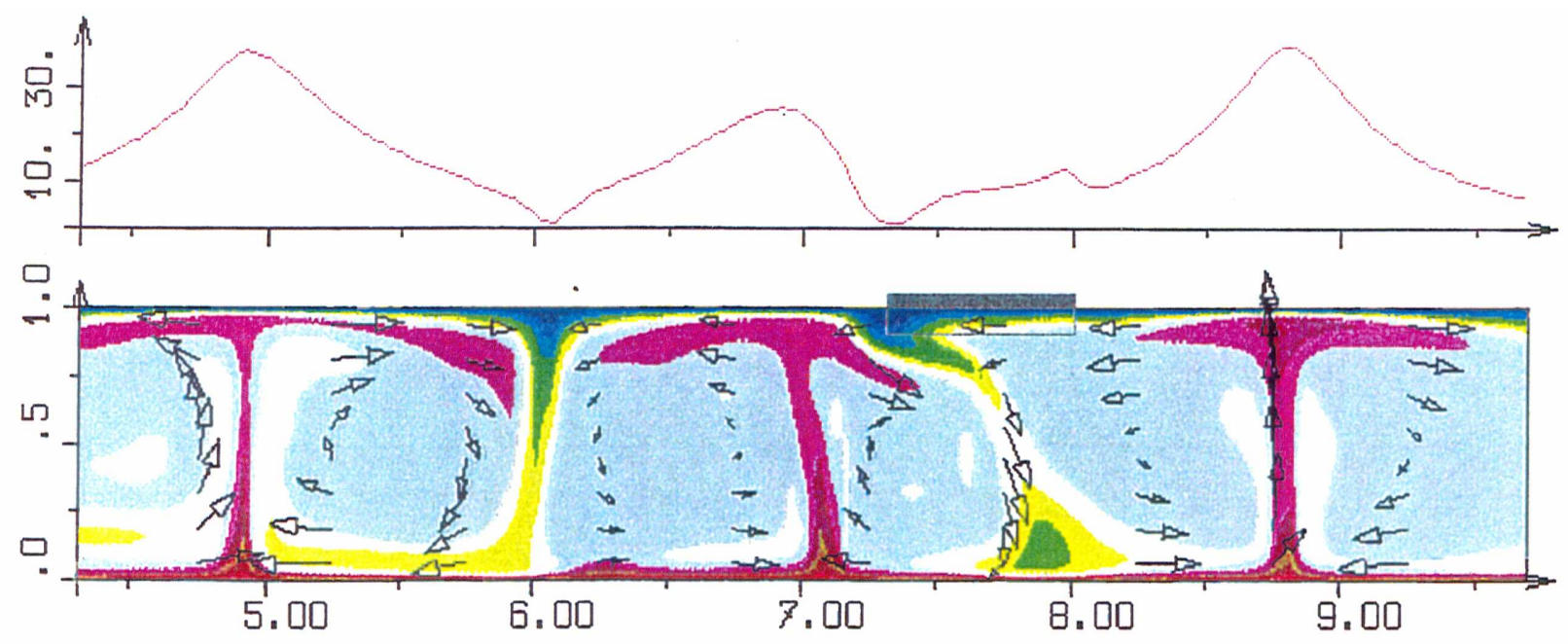

1.7

t $2.6701320 e-02$

Czoss section :

$Y=5.0000 e-02$

Isalines : $\mathrm{TH}$

Min: $1.5770 \mathrm{e}-05$

Max: 9.9998e-01

$\rightarrow 5.5791 e+02$
$5.0500 e+01$

9. $6152 e-01$

8. 8460e-01

8. $0768 e-01$

$7.3076 e-01$

6.5384e-01

$5.7692 e-01$
$5.0000 e-01$

4. $2308 \theta-01$

3. $4616 \theta-01$

$2.6924 e-01$

1. $9232 \theta-01$

$1.1540 \mathrm{e}-01$

$3.8476 e-02$
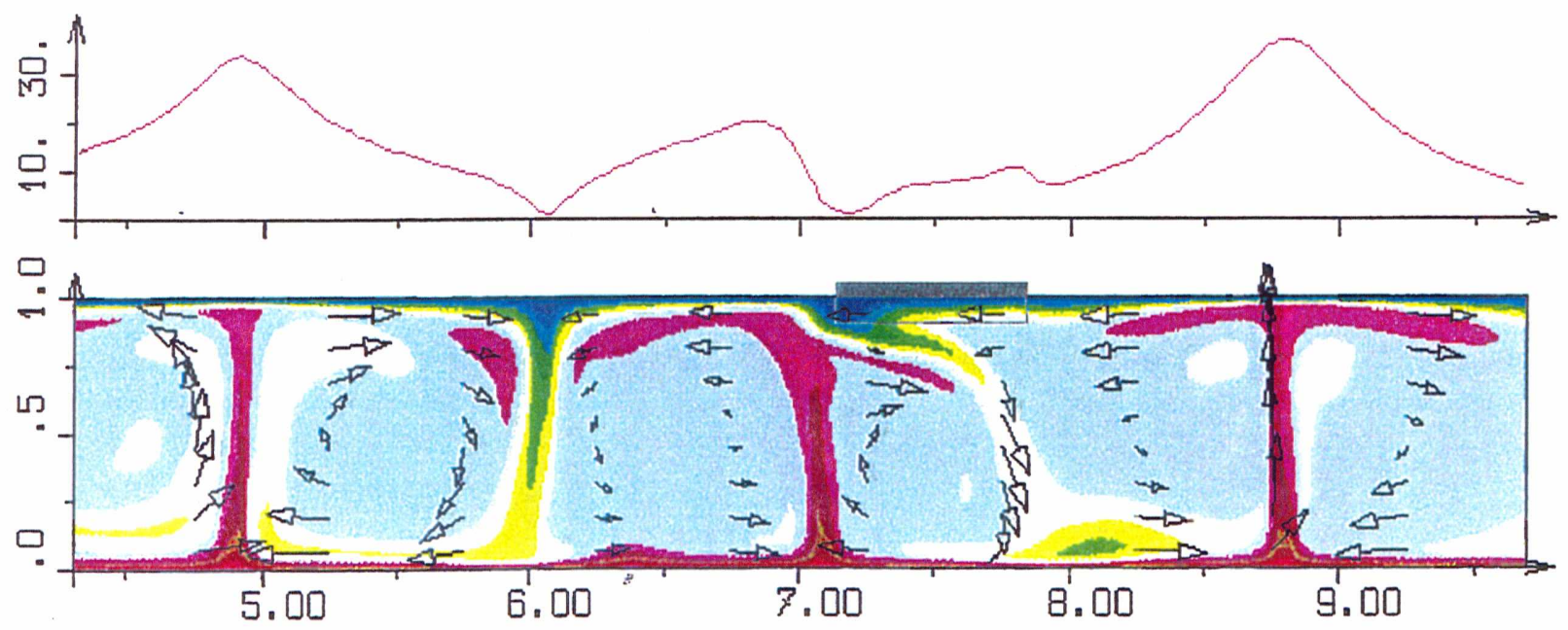

1.8

t 2.7100430e-02

Czoss section :

$Y=5.0000 \mathrm{e}-02$

Isolines : $\mathrm{TH}$

Min: $1.3979 e-05$

Max: 9.9997e-01

$\rightarrow \quad 5.1382 e+02$
$5.0502 e+01$

9.6151e-01

8.8459e-01

9.0767e-01

$7.3075 e-01$

6. $5383 e-01$

$5.7691 \theta-01$
4. $9999 e-01$

4. $2307 e-01$

3. $4615 e-01$

2.6923e-01

$1.9231 e-01$

$1.1539 e-01$

$3.84740-02$ 

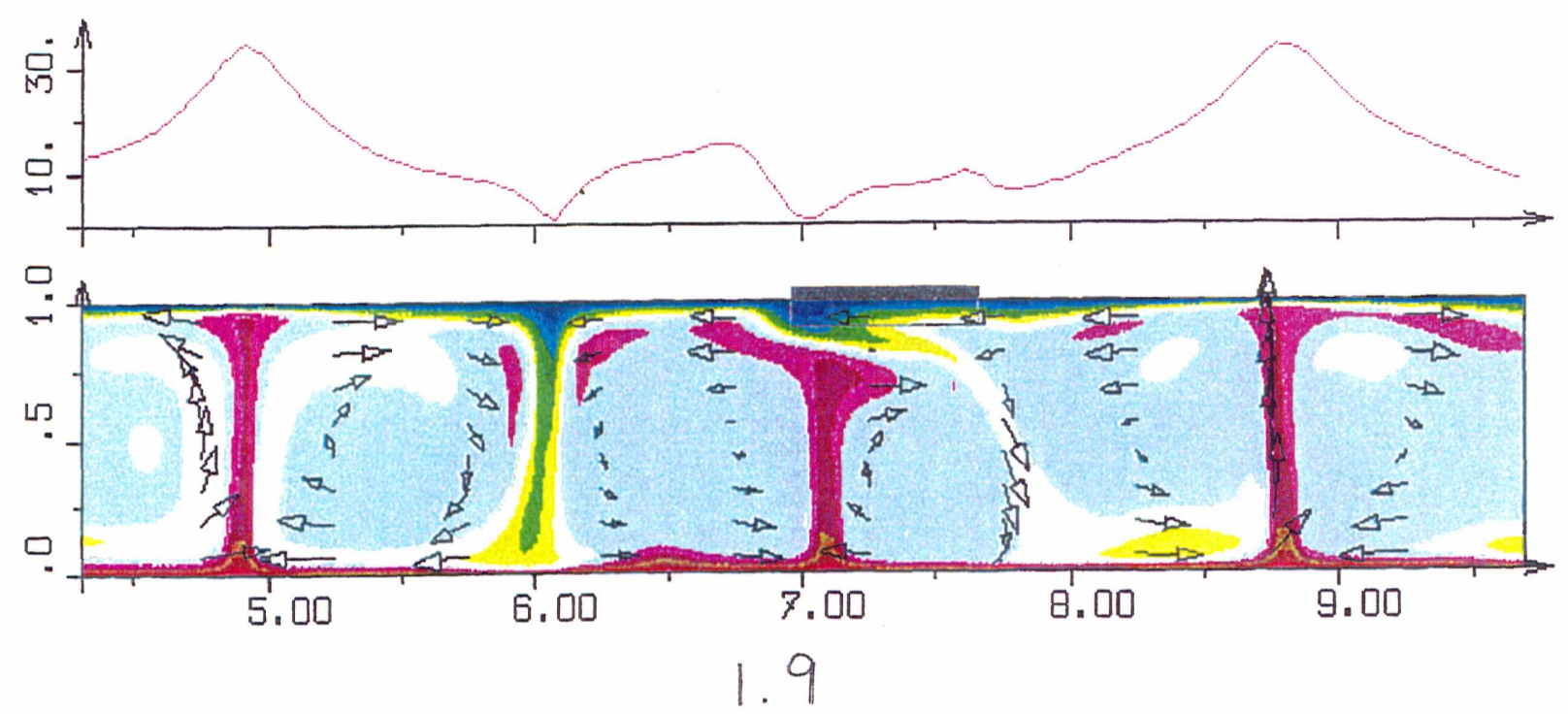

t 2.7502420e-02 Czoss section : $Y=5.0000 e-02$ Isolines : $\mathrm{TH}$ Min: $1.2969 e-05$ Max: $9.9998 \mathrm{e}-01$ $\rightarrow 5.2780 \mathrm{e}+02$

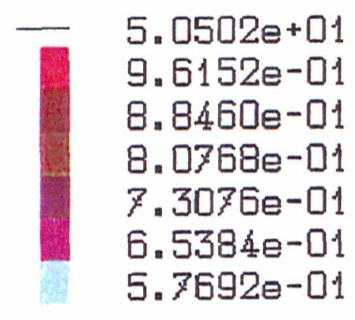

$5.0000 e-01$

4. $2308 e-01$

3. $4615 e-01$

$2.6923 e-01$

1. $9231 e-01$

$1.1539 \mathrm{e}-01$

$3.8473 e-02$
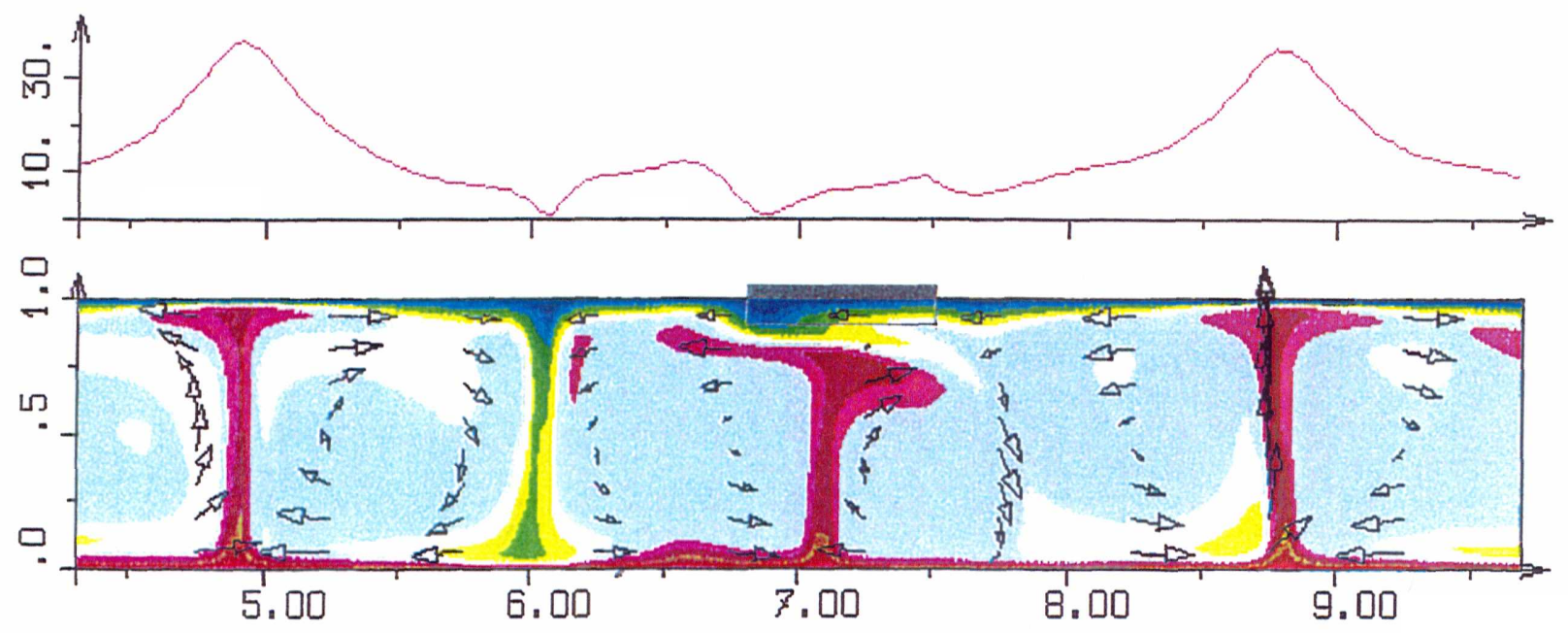

1.10

t 2.7902200e-02 Czoss section : $Y=5.0000 e-02$ Isolines : $\mathrm{TH}$ Min: $1.3581 e-05$ Max: $9.9997 e-01$ $\rightarrow 5.5046 e+02$

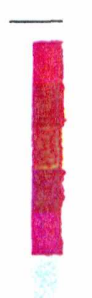

4. $9999 e-01$ 4. $2307 \mathrm{e}-01$ 3. $4615 e-01$ $2.6923 e-01$ $1.9231 \mathrm{e}-01$ $1.1539 e-01$ $3.8473 e-02$ 

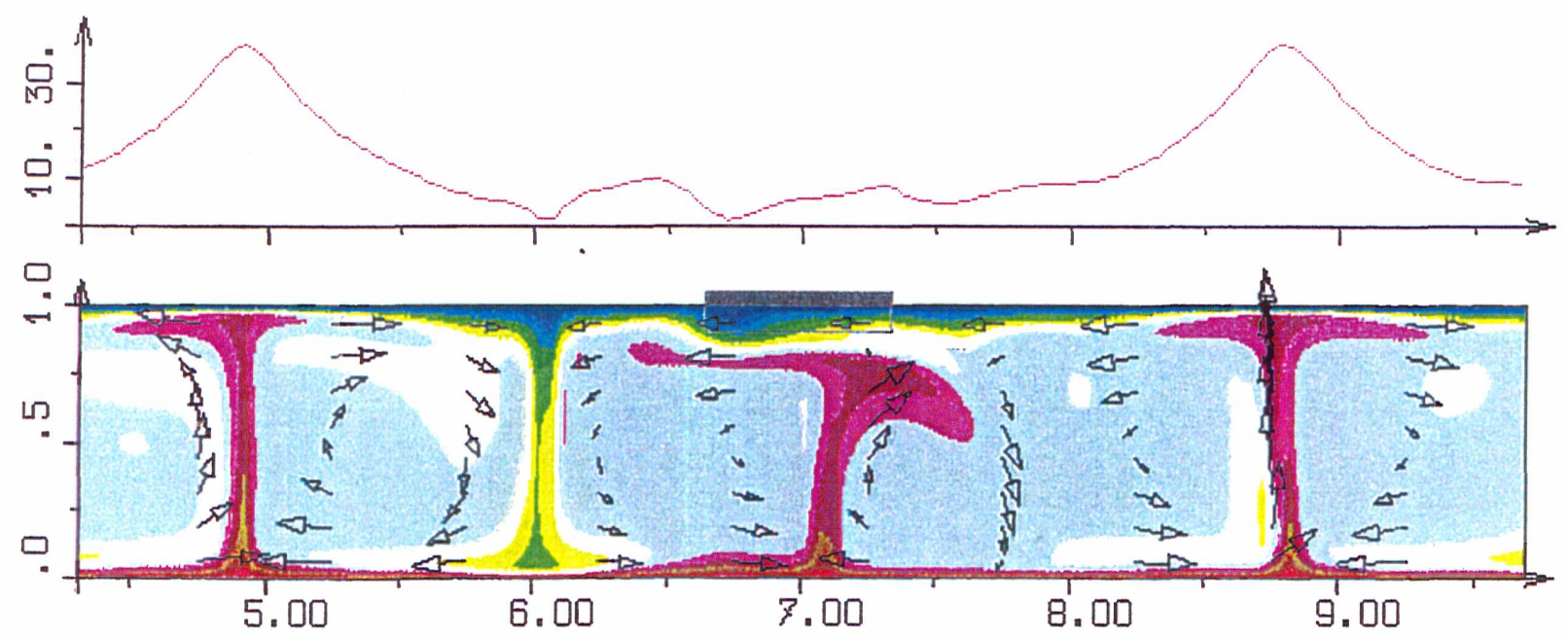

1.11

t 2.8300310e-02

Czoss section :

$Y=5.0000 e-02$

Isolines: $\mathrm{TH}$

Min: $1.5430 \mathrm{e}-05$

Max: $9.9998 e-01$

$\rightarrow \quad 5.2684 e+02$

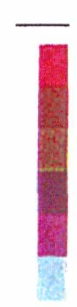

$5.0496 e+01$

9.6152e-01

8.8460e-01

8. $0768 \mathrm{e}-01$

7.3076e-01

6. $5384 \mathrm{e}-01$

$5.7692 e-01$
$5.0000 e-01$

4. $2308 e-01$

$3.4616 e-01$

$2.6924 e-01$

1. $9232 e-01$

$1.1540 e-01$

$3.8475 e-02$
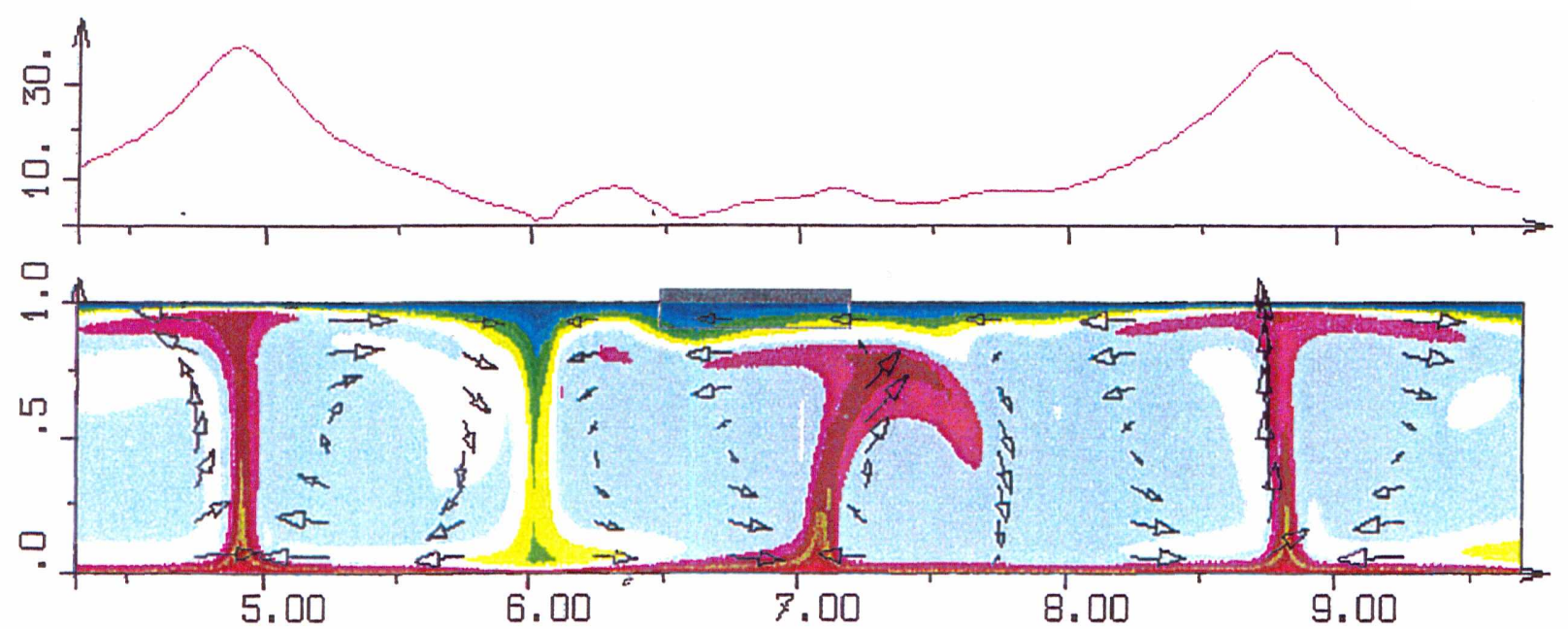

1.12

t 2.8700880e-02

Czoss section :

$Y=5.0000 \mathrm{e}-02$

Isalines : $\mathrm{TH}$

Min: $1.6340 \mathrm{e}-05$

Max: $9.9998 \mathrm{e}-01$

$\rightarrow \quad 5.5961 e+02$
5. $0492 e+01$

9.6152e-01

8. 8460e-01

8. $0768 \mathrm{e}-01$

7.3076e-01

$6.5384 e-01$

$5.7692 e-01$
5. 0000e-01

4. $2308 e-01$

3. $4616 e-01$

$2.6924 \mathrm{e}-01$

1. $9232 e-01$

1. $1540 \mathrm{e}-01$

$3.8477 e-02$ 

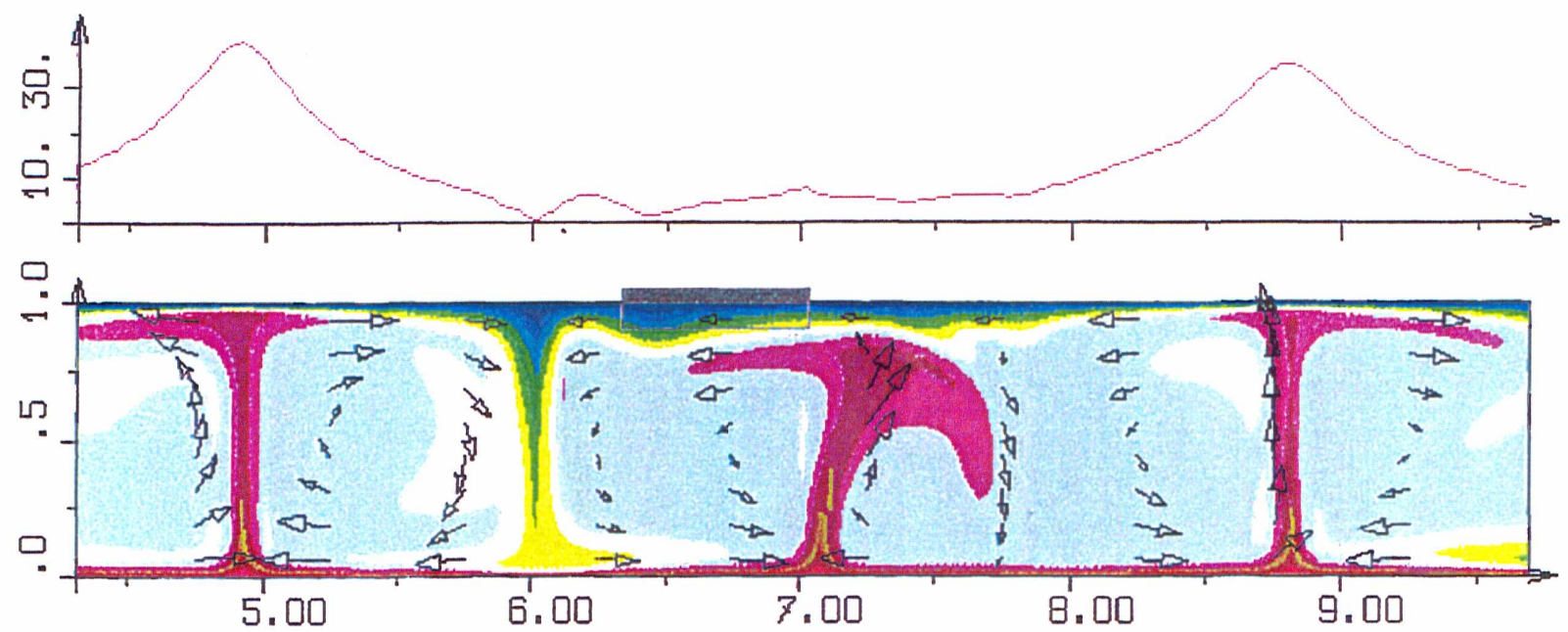

1.13

t 2.9100720e-02

Czoss section :

$Y=5.0000 e-02$

Isolines : $\mathrm{TH}$

Min: $1.1722 \mathrm{e}-05$

Max: 9.9998e-01

$\rightarrow \quad 5.6701 e+02$

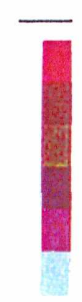

5. $0490 e+01$

9.6152e-01

8.8460e-01

8. $0768 e-01$

7. 3076e-01

6.5384e-01

$5.7692 e-01$

4.9999e-01

4. $2307 e-01$

3. $4615 \theta-01$

2. 6923e-01

1.9231e-01

1. 1539e-01

$3.8472 \theta-02$
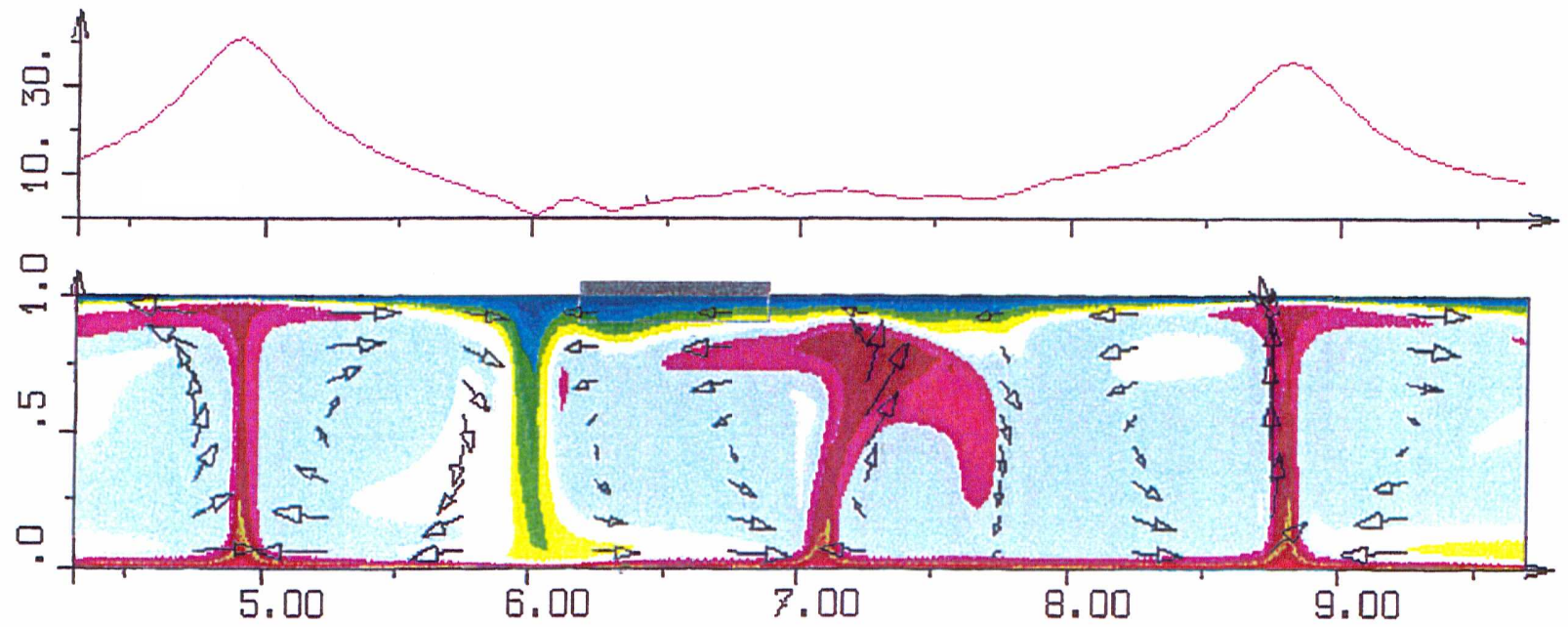

1.14

t $2.9502040 e-02$

Czass section :

$Y=5.0000 e-02$

Isalines : $\mathrm{TH}$

Min: $1.1559 e-05$

Max: $9.9998 e-01$

$\rightarrow \quad 5.4749 e+02$

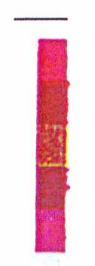

$5.0488 e+01$

9.6152e-01

8.8460e-01

8. $0768 e-01$

7.3076e-01

6. 5384e-01

$5.7691 e-01$
4. $9999 e-01$

4. $2307 e-01$

3. $4615 e-01$

2.6923e-01

1. $9231 e-01$

1. 1539e-01

$3.8472 e-02$ 

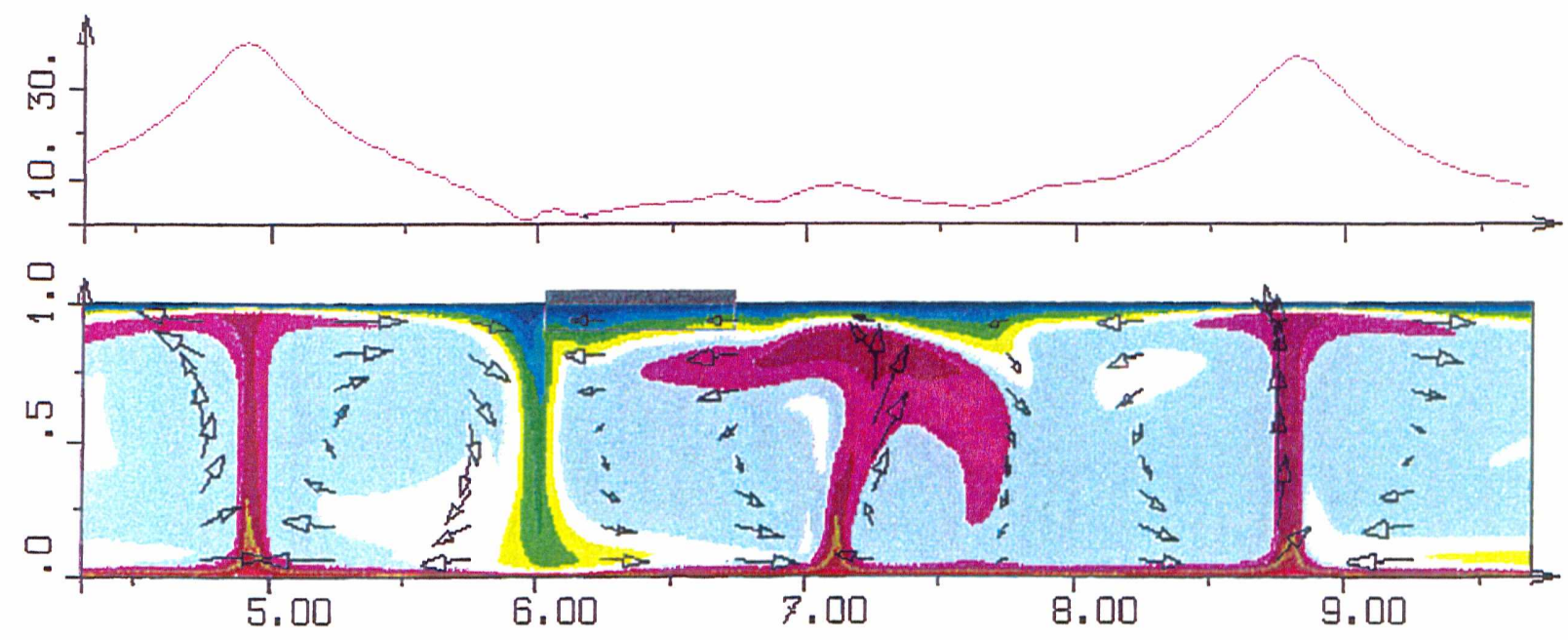

1.15

t 2.9900540e-02

Czoss section :

$Y=5.0000 e-02$

Isolines : $\mathrm{TH}$

Min: $1.2819 e-05$

Max: 9.9998e-01

$\rightarrow \quad 5.6219 e+02$
$5.0491 e+01$
9.6152e-01
8. 8460e-01
8. $0768 \mathrm{e}-01$
$7.3076 e-01$
6. $5384 e-01$
$5.7692 e-01$

4. $9999 e-01$

4. $2307 e-01$

3. $4615 e-01$

$2.6923 e-01$

$1.9231 \mathrm{e}-01$

$1.1539 e-01$

$3.8473 e-02$
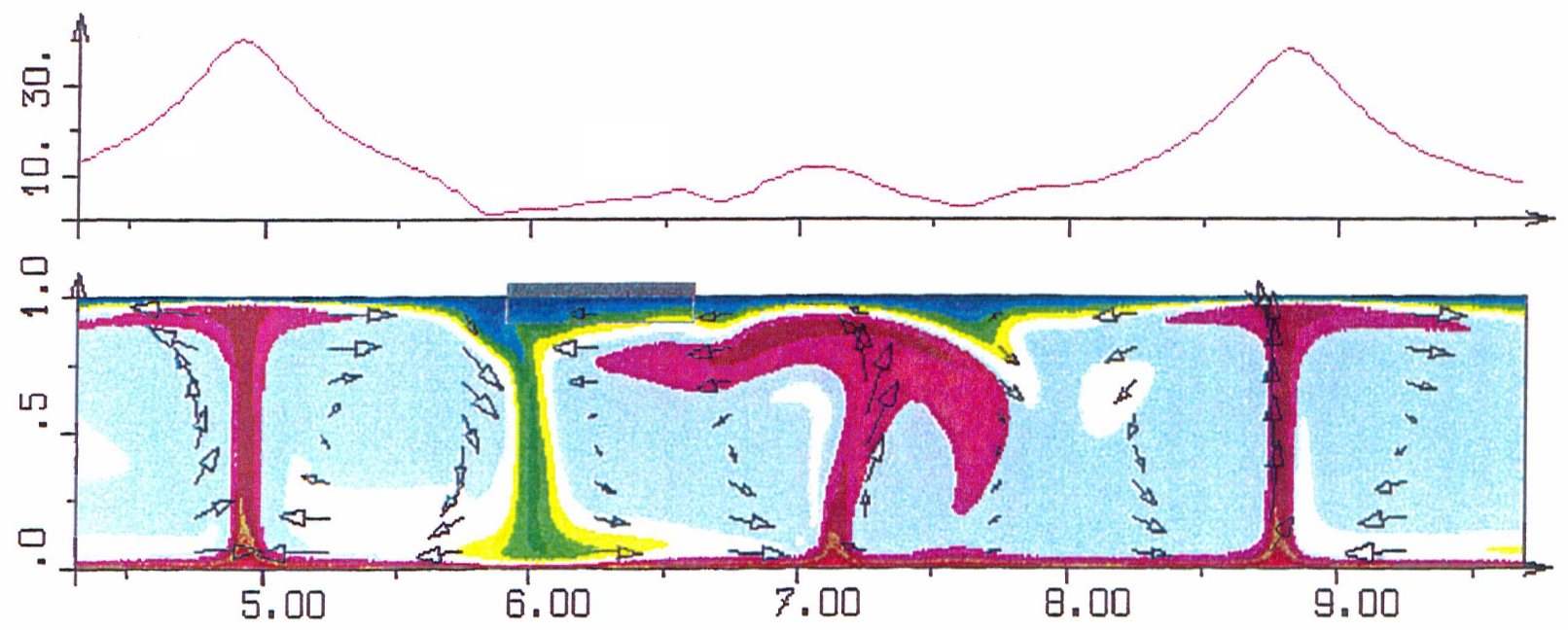

1.16

t 3.0300830e-02

Czoss section :

$Y=5.0000 \mathrm{e}-02$

Isolines : $\mathrm{TH}$

Min: $1.4816 e-05$

Max: 9.9997e-01

$\rightarrow$ 6.0236e+02
5. $0492 e+01$

$9.6151 e-01$

8. $8459 e-01$

$8.0767 e-01$

7.3075e-01

6. $5383 e-01$

$5.7691852^{-1}$
4. $9999 e-01$

4. $2307 e-01$

$3.4615 e-01$

2.6923e-01

$1.9231 \mathrm{e}-01$

1. $1539 e-01$

$3.8475 e-02$ 

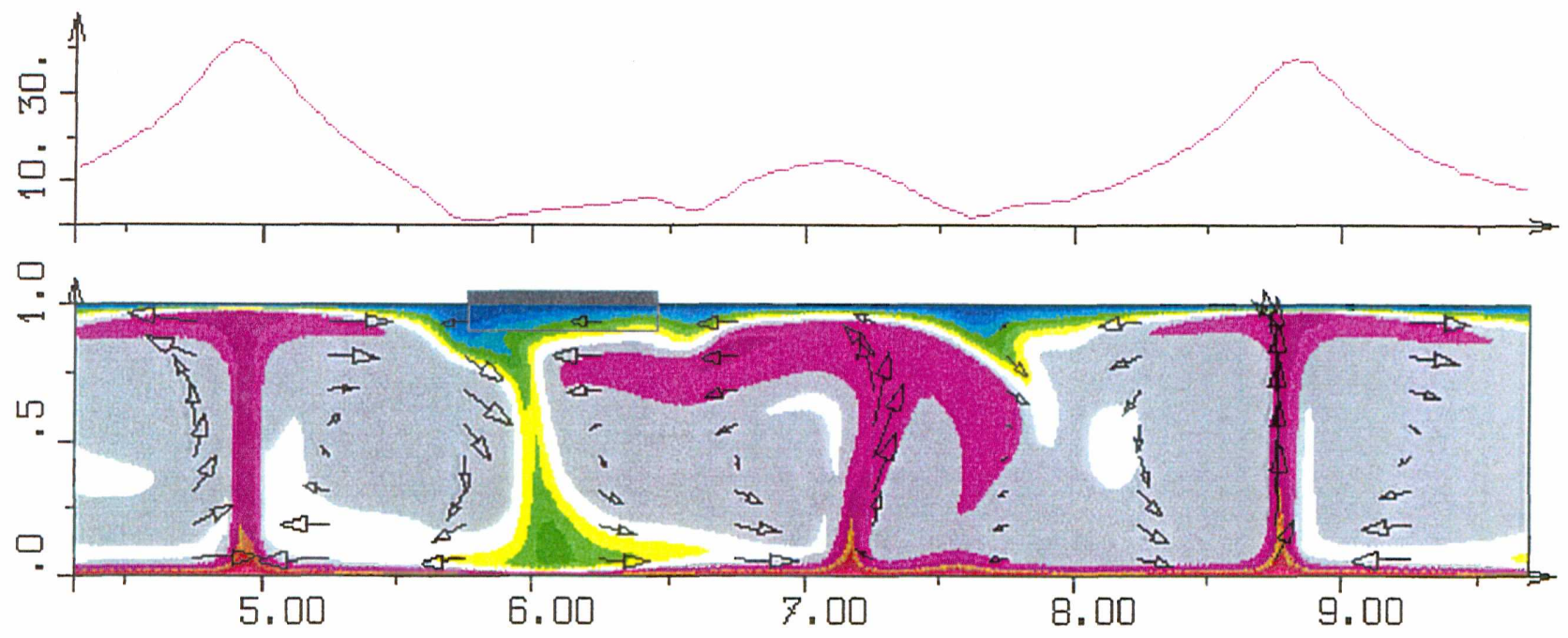

1.17

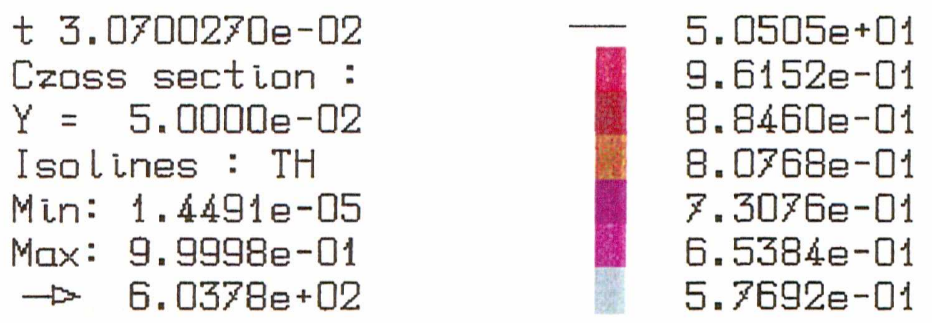

$5.0000 e-01$

4. $2308 e-01$

3. $4616 e-01$

2.6924e-01

1. $9231 e-01$

$1.1539 e-01$

$3.8474 \mathrm{e}-02$ 
$t=1 .: 0167[[E+[1$

CroEs $\mathrm{P}=1.000$

190.000: 120.000 ।

Scale = 1. DULE+[D

velas ity vectoze

$\rightarrow=:-128 E+] 2$

$H_{\text {U1 }}+F$ low

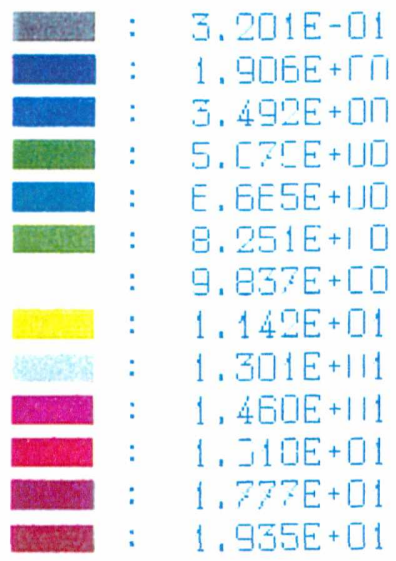

$\imath=1$. [ $1 E G[I D E+[1$

Czcse $P=1.000$

(95. 000; 120,000)

Sor le = 1.200E+00

Velozity vectoze

$\rightarrow$ - : $9.933 E+012$

Heat Flow

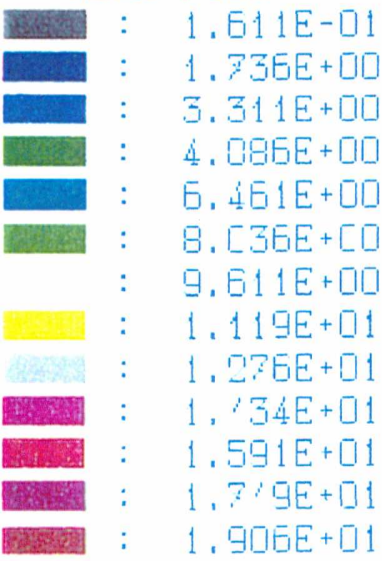
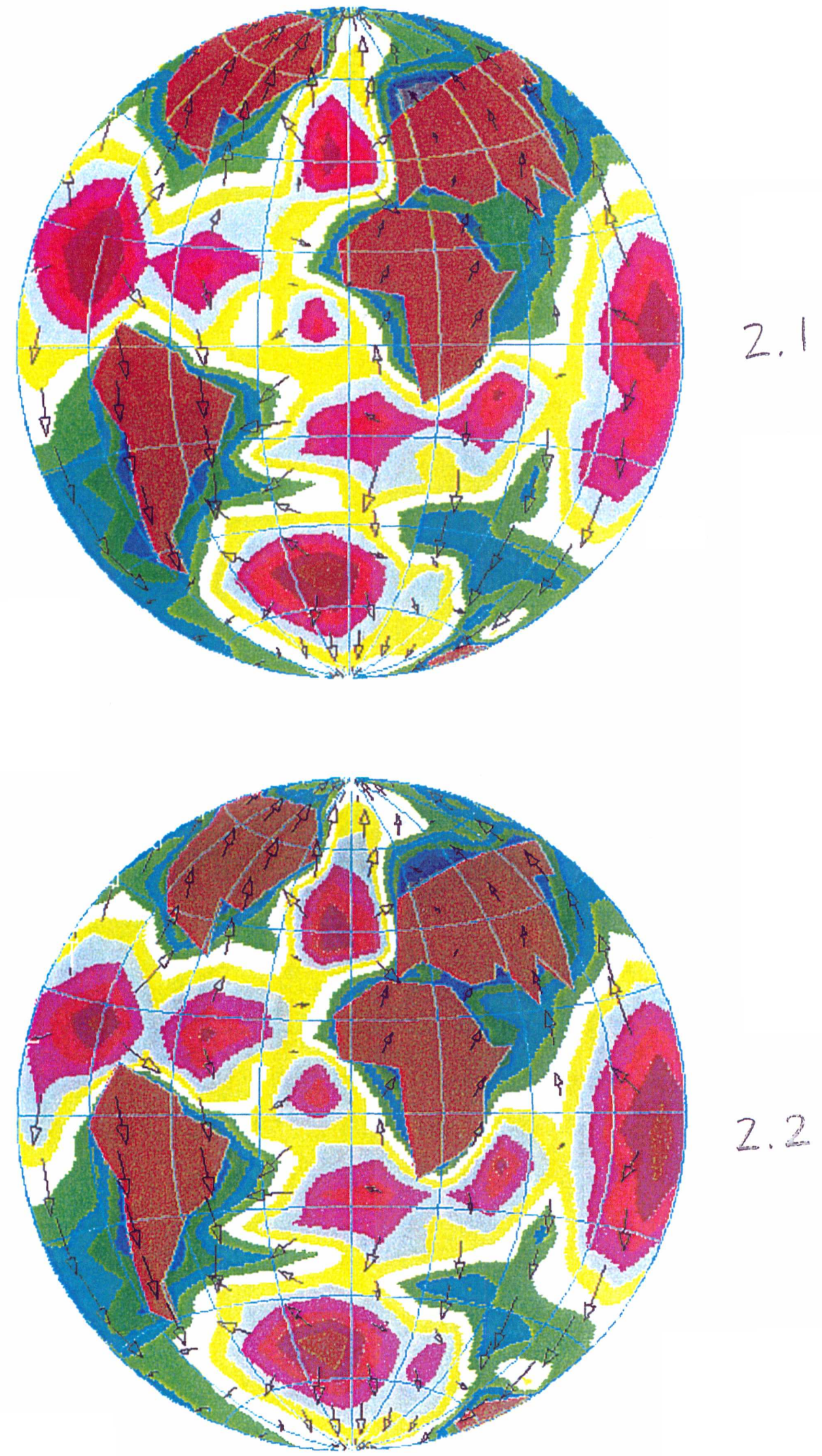

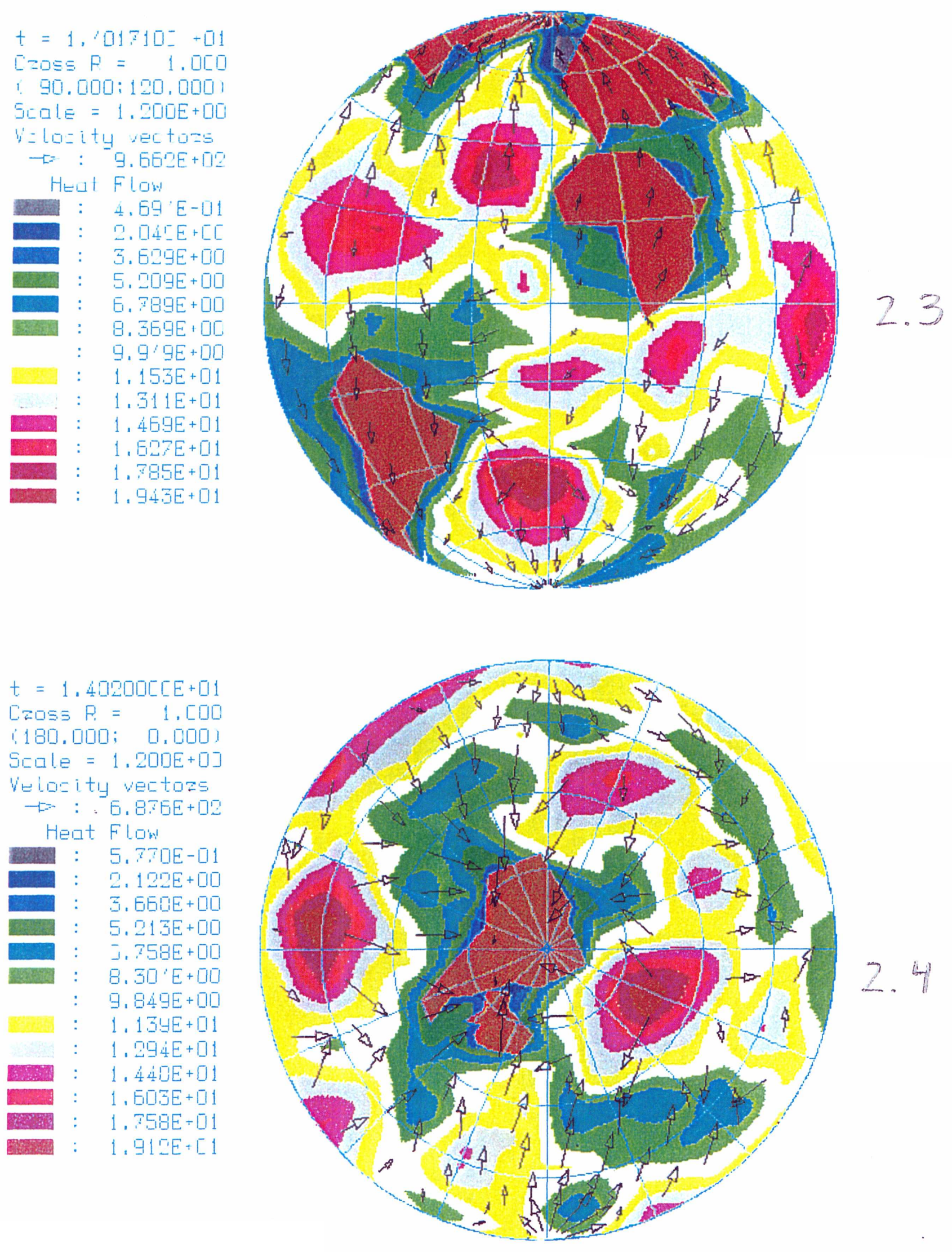
$t=1.0 \square-40[0 E+\Pi 1$

Crose $F=1 .[-]$

i. $135.0[0] 330,0001)$

Stal.e = $1.200 E+00$

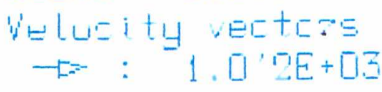
Heat Flow

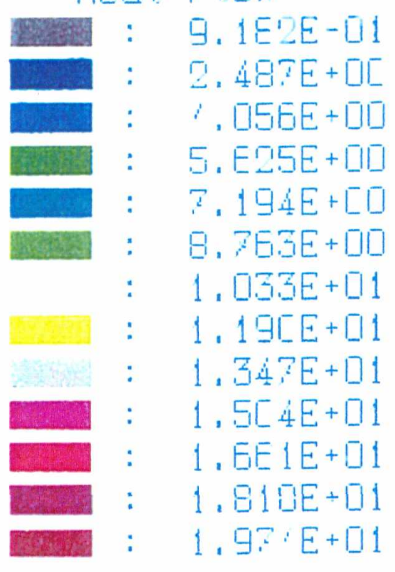

$t=1,402 E O O D E+[1$ Lrase $\mathrm{F}=1.000$ (135. 0100; 3.30.000) Scale = 1.200E+口0 Velazity vectors

$\rightarrow=: 1,145 E+[13$ Heat Flow

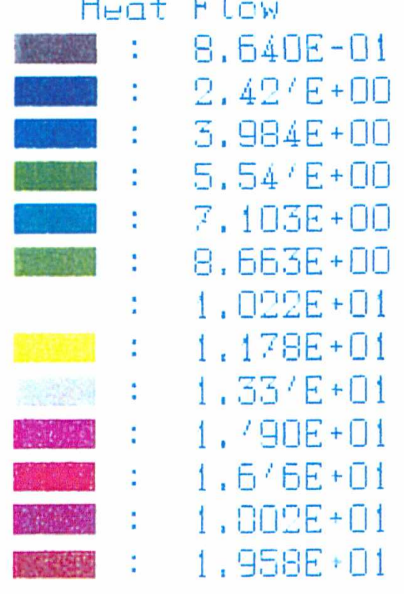

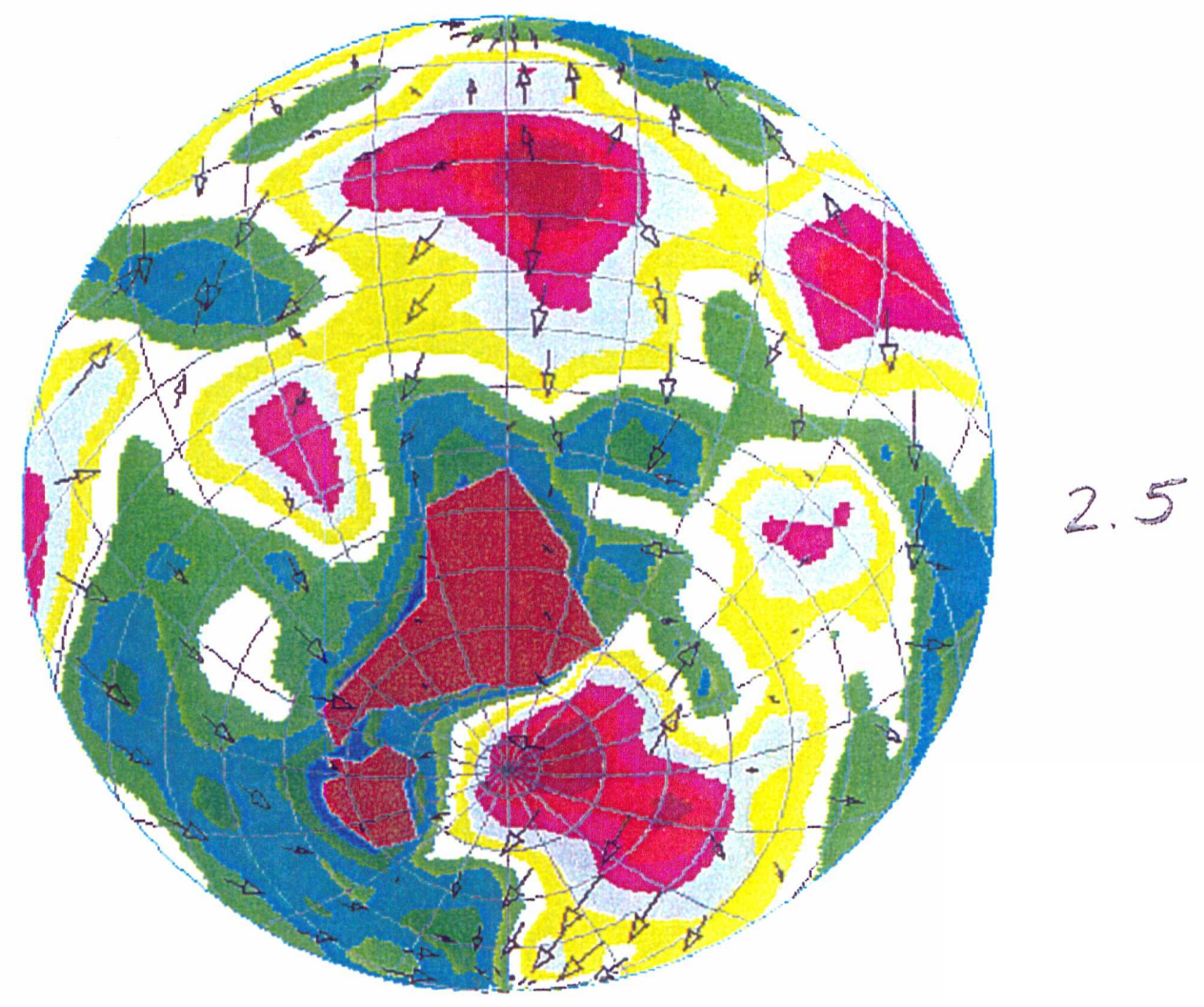

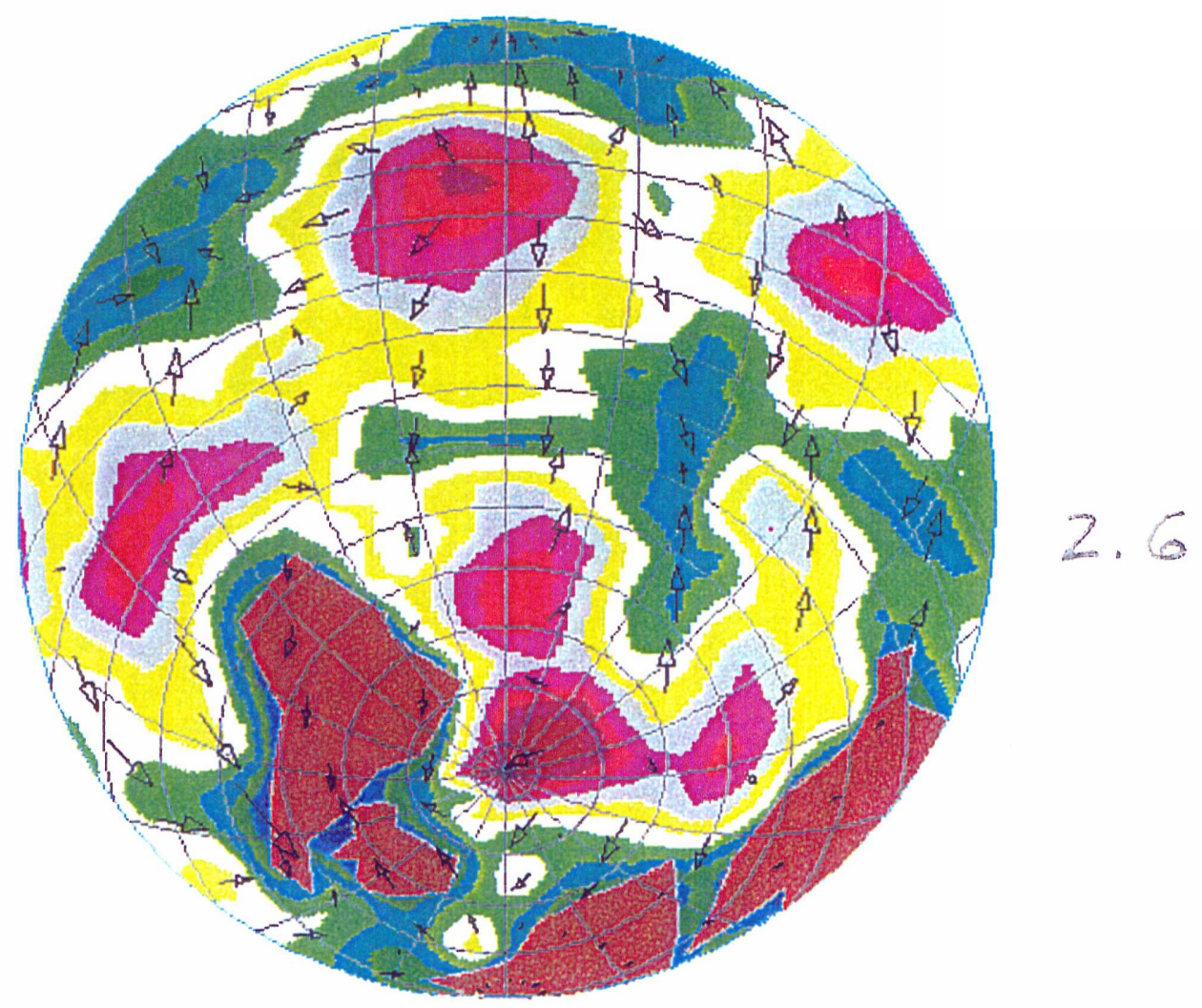


$t=1,4008000 \mathrm{E}+[1$

$[\approx 0 \equiv \equiv F=1.0001$ 135.0001; 330.0001 5сロIE = 1. DOUE+[OU velozitu velozi

$\rightarrow$ : 1. $284 \mathrm{E}+[13$ Heat Flow

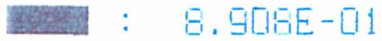

: $2.391 E+00$

: $3 . \theta_{-1 E+00}^{1}$

: $5.391 \mathrm{E}+[10$

: E. $091 \mathrm{E}+00$

ㅁ. $0.391 \mathrm{E}+00$ ‥ $891 \mathrm{E}+[\mathrm{\square}$ $1.139 E+\square 1$ 1. 밀 + 1 $1,4.99 E+\square 1$ $1.599 E+[1$ $1,739 E+\square 1$ 1. $89 ! E E+[1$
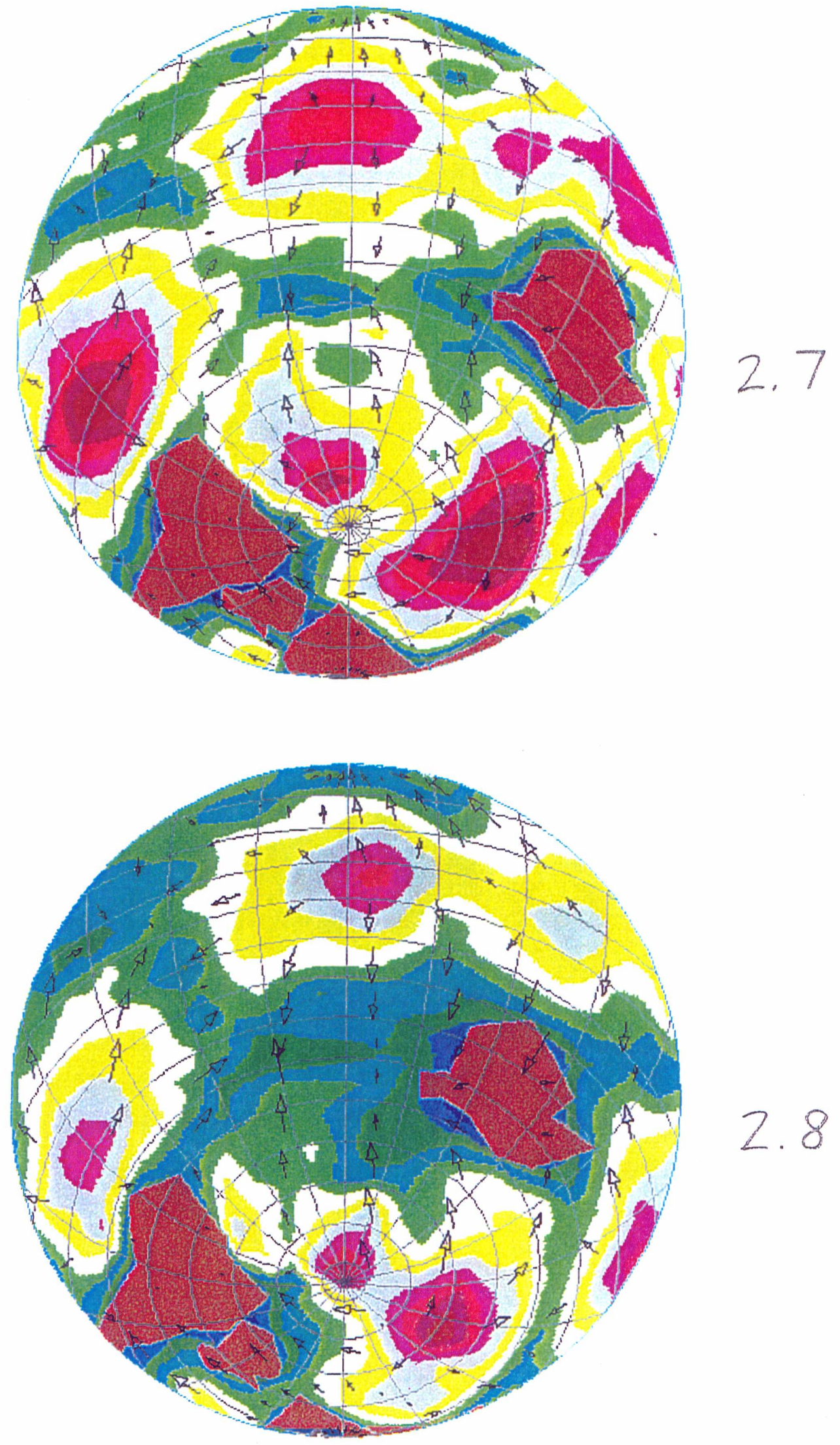

$t=1,401295010 \mathrm{E}+[1$ Czoss! = 1.0[0] (135. 0100; 330. 0001 Scale = 1.2010E+ [OD veláty vertazs

$\rightarrow:: 1,16.5 E+0.5$ Heat Flow

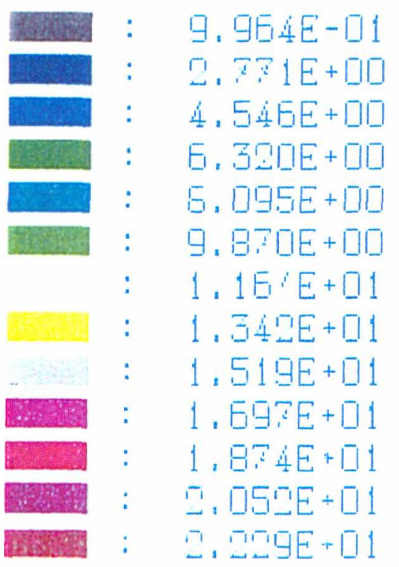


$t=1,4031100 E+\square 1$

[z0es $\mathrm{P}=1.000$ (135.01010; 330.000 i Scבl上 = 1. $20 \square E+[\square$ yelagity v-ctors

$\rightarrow$ : $9.7[5 E+[1]$ Heat Flow

E. $739 E-[1$

2. $16.5 E+\square 0$

3. $65 E E+[D$

$5.14 . ? E+[D$

E. $5.39 E+\square D$

ด. 13IDE+DI

G. $6 \Omega 1 E+[\square$

1. $111 E+\square 1$

1. $260 \mathrm{DE}+01$

$1.409 E+\square 1$

$1.559 E+[1$

1. $7 \square \square E+\square 1$

1. $.5,2 E+\square 1$
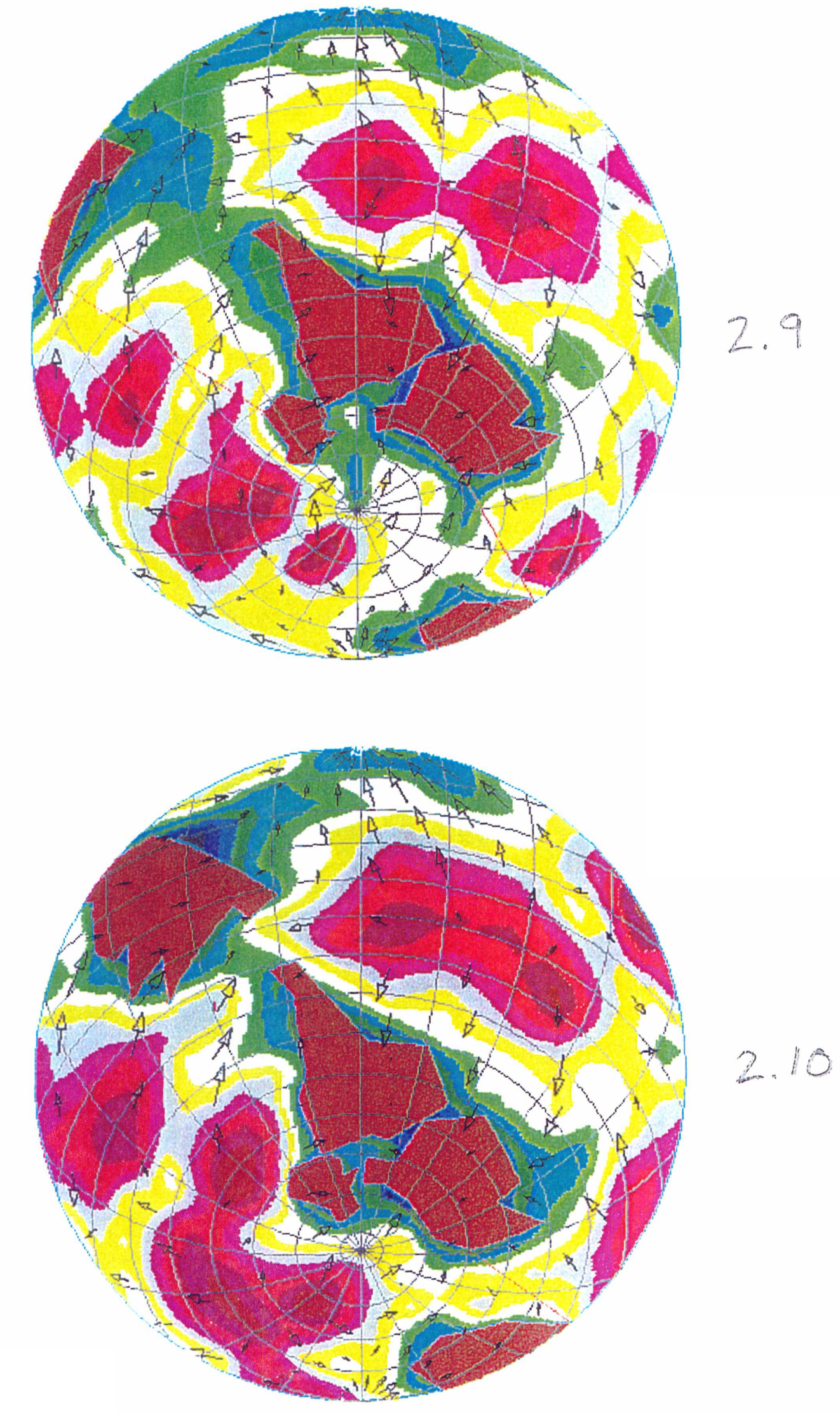

$t=1.4031700 E+11$

Czoss $\mathrm{P}=1.000$ (135. 1000; 330, 000) Scale = 1.2010E+00 velacity vertazs

$\rightarrow=: 1.09 ? E+0.3$ Heat Flow

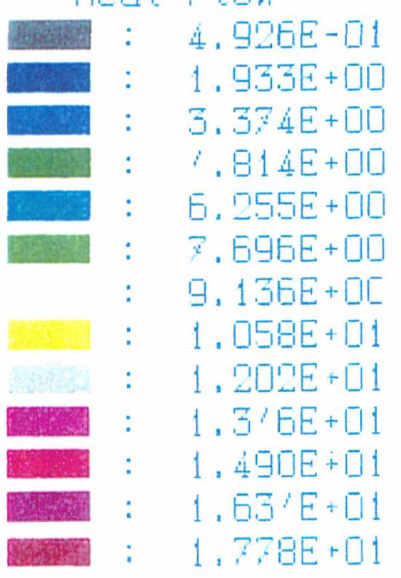


$t=1.4033050 E+01$

$[=0 \equiv \equiv=1.00[0$ 135. [1001; 330. 000 ) SEDLE = 1.20DE+ [D Velazity vertaze

$\rightarrow=: 1.21 \mathrm{BE}+[1.5$ Heat Flow

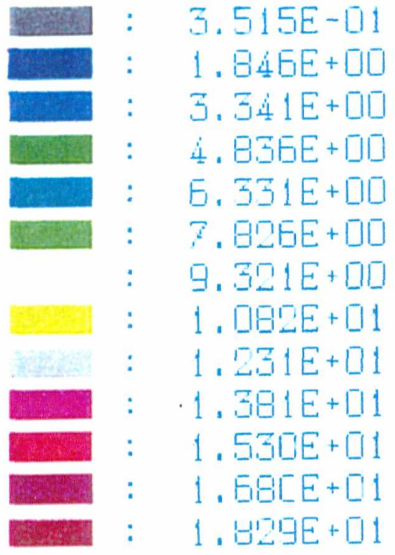

$t=1.4036100 E+[1$ LzIss $\mathrm{P}=1 . \mathrm{D}=\mathrm{D}$ (135. 1001; 330. 000) Scale = 1.20DE+口D Velacity vectozs

$\multimap:: 1.044 E+[3$ Hent Flow

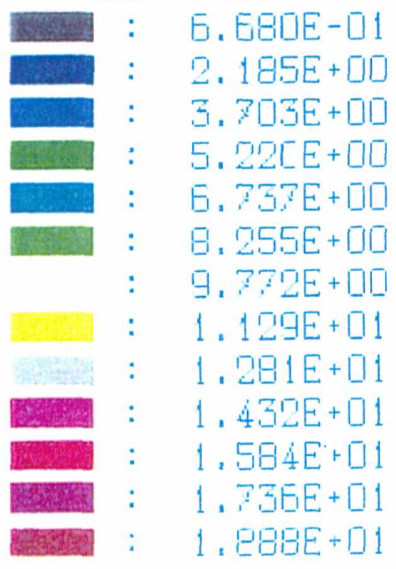

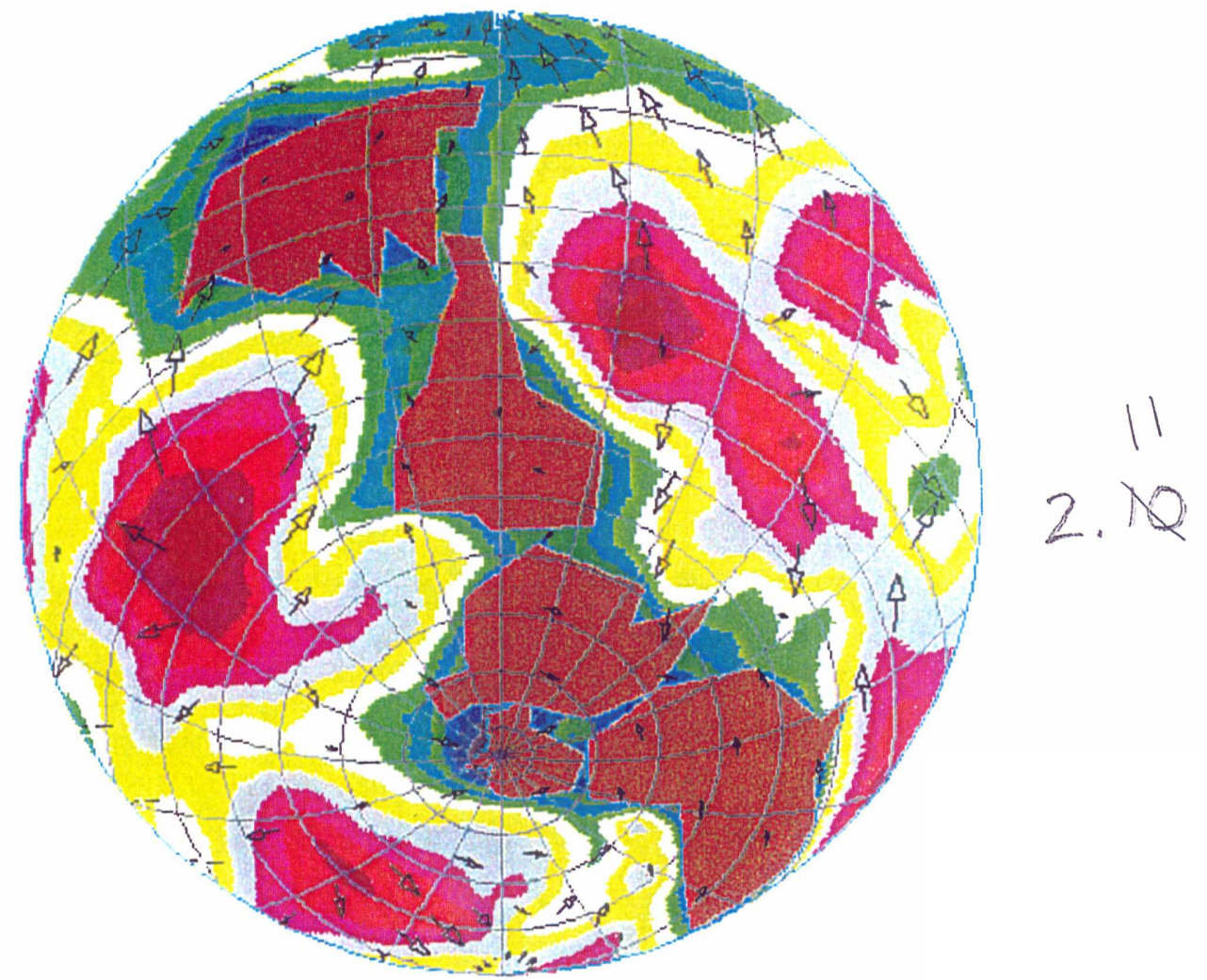

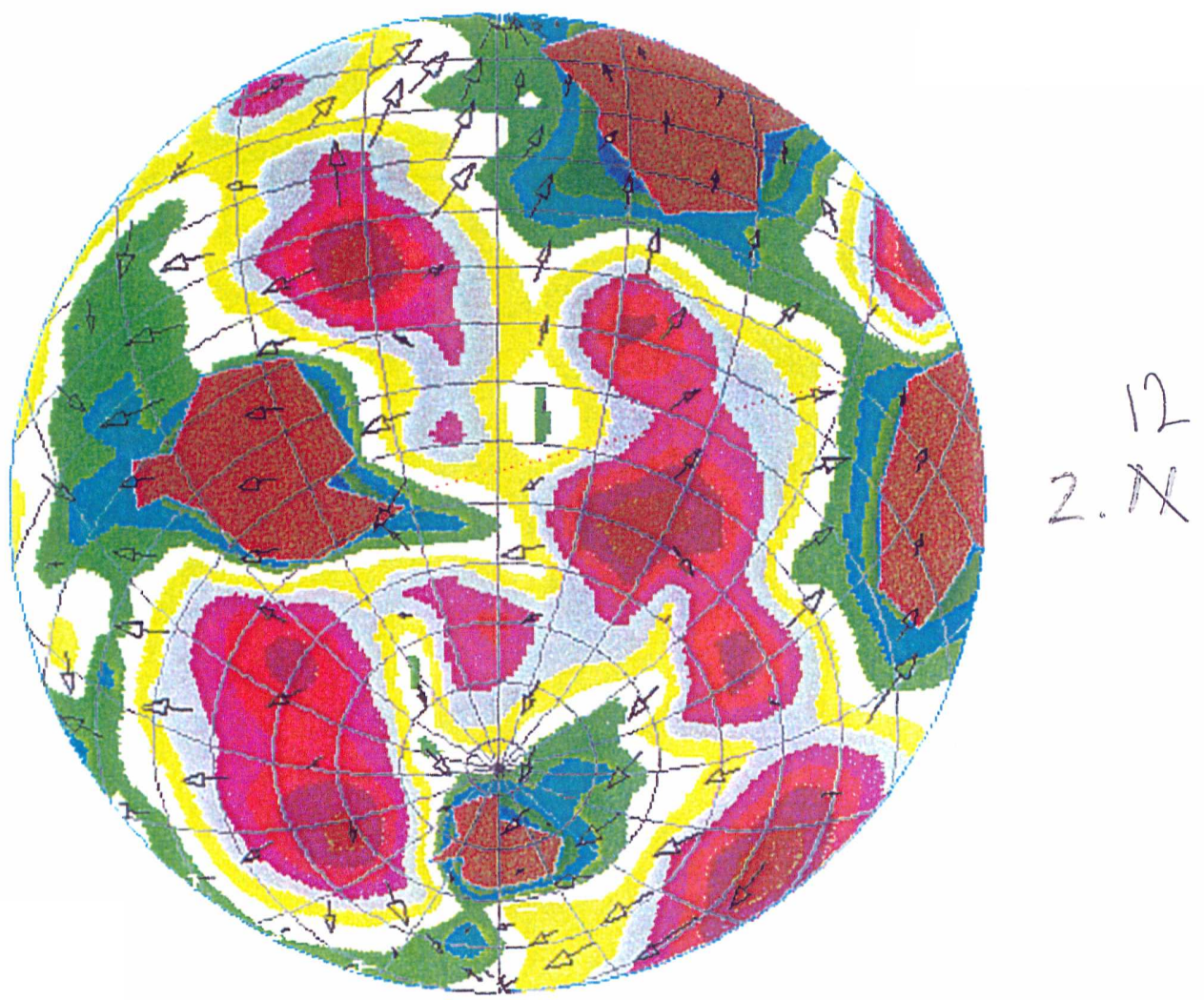


T ime 0.0065000 Ma Depth $200.000 \mathrm{~km}$ (90.000;315.000) Scale 1.000

Tempezatuze (C)

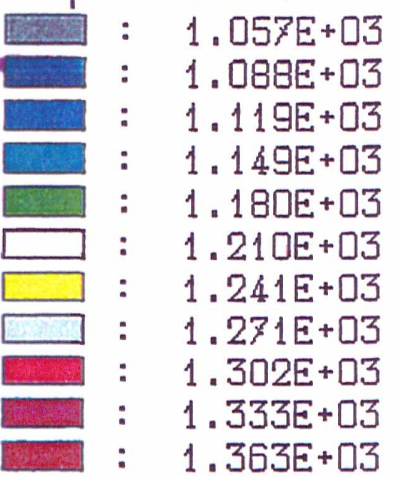

Time 0.0065000 Ma Depth $400.000 \mathrm{~km}$ ( 90.000;315.000) Scale 1.000

Tempezatuze (C)

\begin{tabular}{|c|c|c|}
\hline & : & $1.213 E+03$ \\
\hline & : & $1.237 E+03$ \\
\hline & : & $1.261 E+03$ \\
\hline & : & $1.285 E+03$ \\
\hline & : & $1.310 E+03$ \\
\hline & : & $1.334 \mathrm{E}+03$ \\
\hline & : & $1.358 E+\square 3$ \\
\hline & : & $1.382 E+\square 3$ \\
\hline & : & 1. $407 E+\square$ \\
\hline & : & $431 E$ \\
\hline & : & $1.455 E+03$ \\
\hline
\end{tabular}
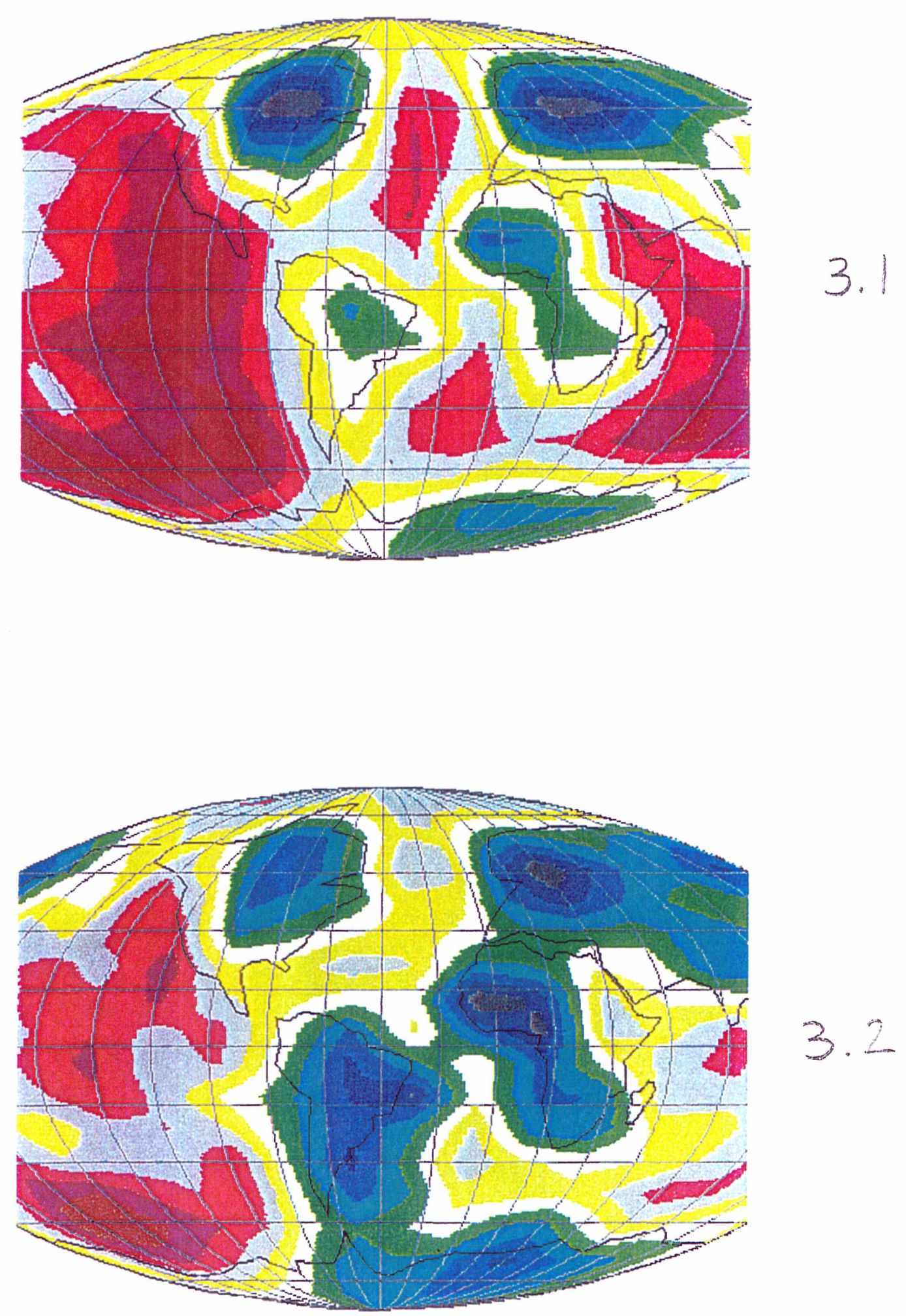
Time 0.0065000 Ma Depth $600.000 \mathrm{~km}$ (90.000;315.000) Scale 1.000

Tempezatuze (C)

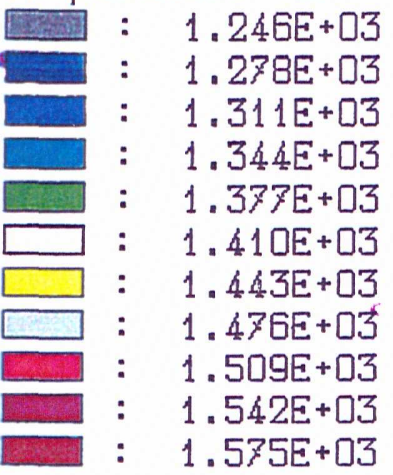

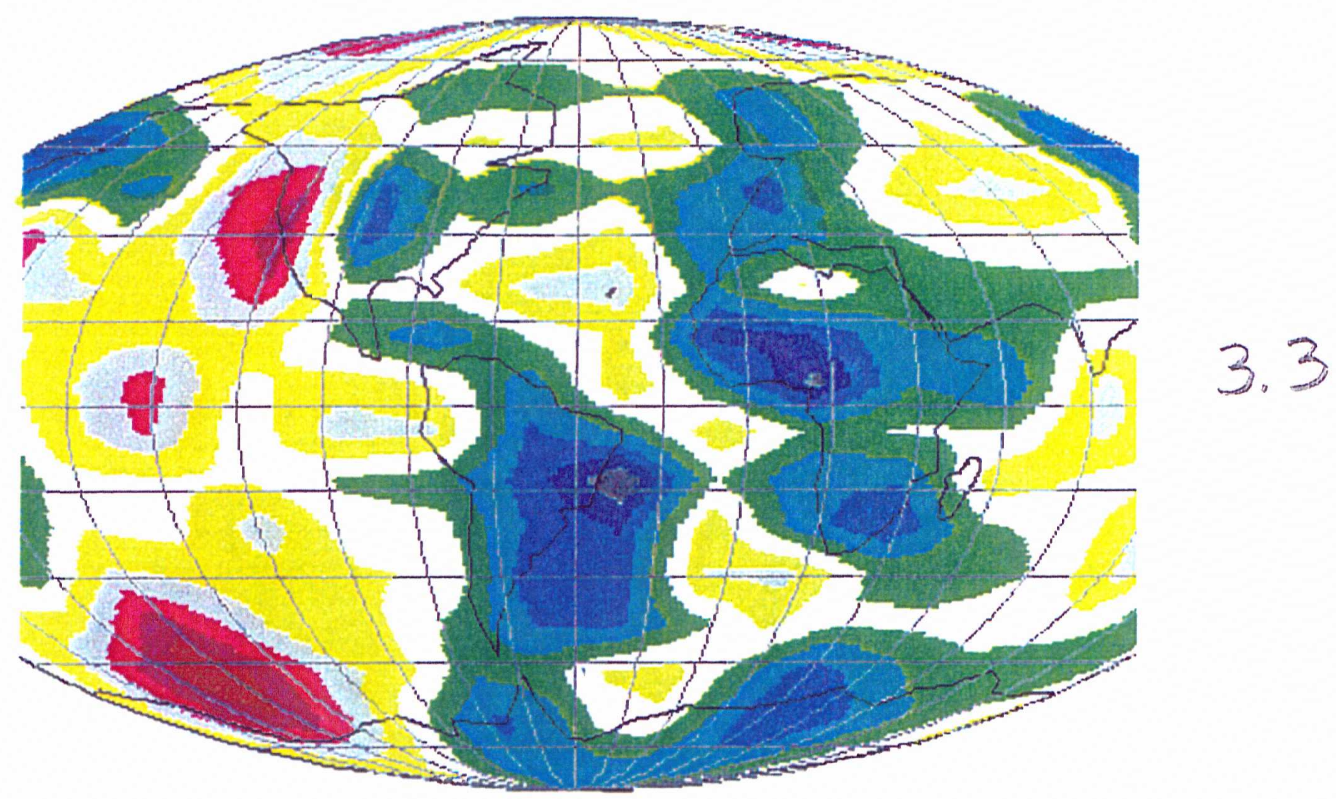

Time $0.0065000 \mathrm{M}$ Depth $800.000 \mathrm{~km}$ (90.000;315.000) Scale 1.000

Tempezatuze (C)

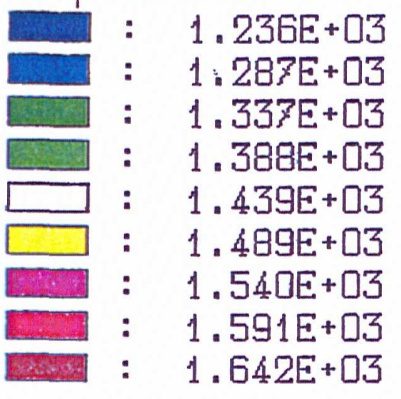

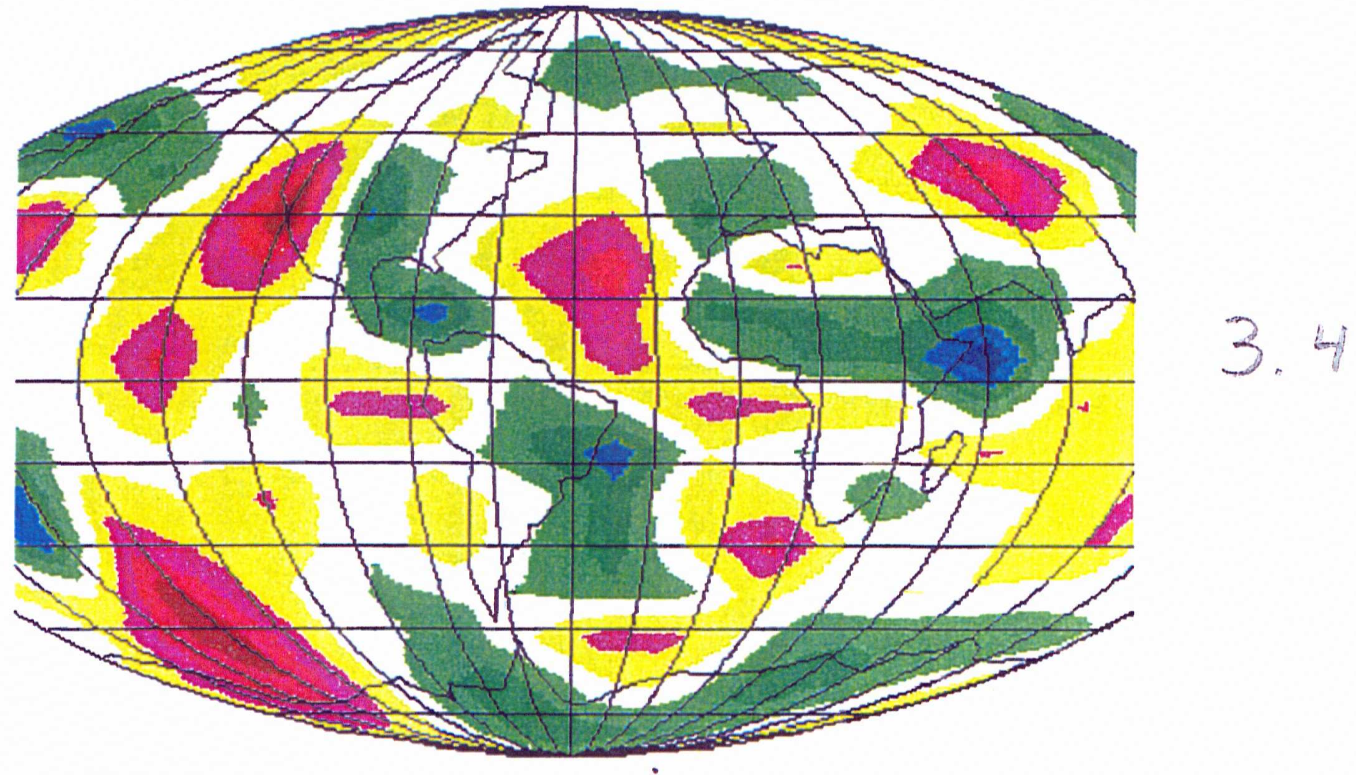


Time 0.0065000 Ma Depth $1000.000 \mathrm{~km}$ (90.000;315.000\} Scale 1.000

Tempezatuze (C)

\begin{tabular}{|c|c|c|}
\hline & : & 1.170 \\
\hline & & 1. \\
\hline & & $1.281 E$ \\
\hline & & $\begin{array}{l}1.332 \mathrm{E} \\
1.3935\end{array}$ \\
\hline & & $1.434 \mathrm{E}$ \\
\hline & & 1. $4 \mathrm{BGE}$ \\
\hline & & $1.537 \mathrm{E}$ \\
\hline & & $1.588 \mathrm{E}$ \\
\hline & & 1 \\
\hline
\end{tabular}

Time 0.0065000 Ma Depth $1200.000 \mathrm{~km}$ (90.000;315.000) Scale 1.000

Tempezatuze (C)

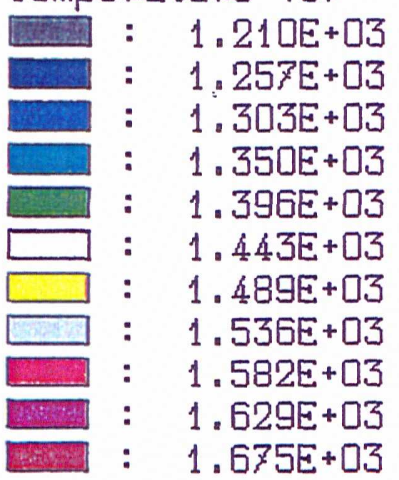
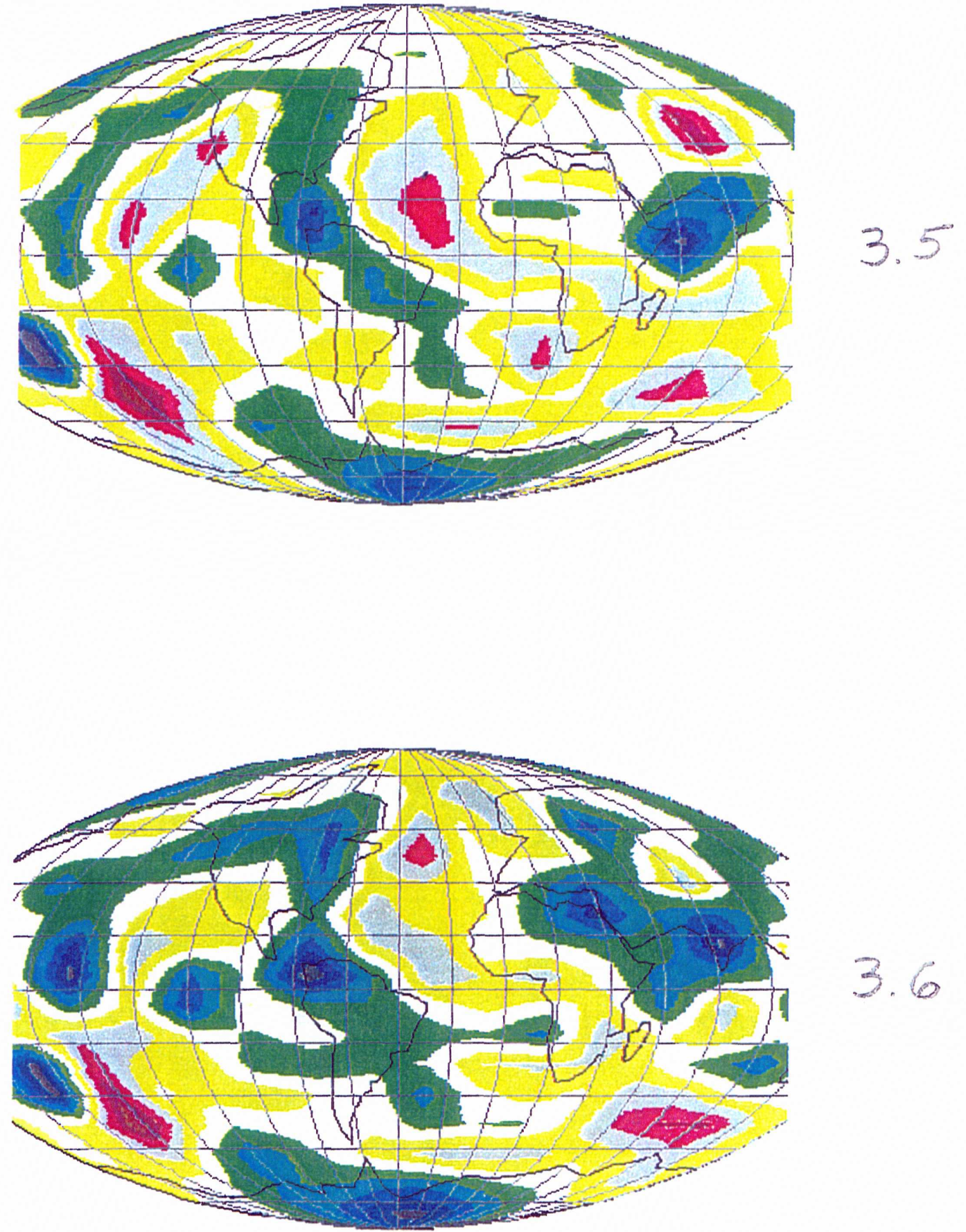
Time 0.0065000 Ma Depth 1400.000 km ( 90.000;315.000) Scale 1.000

Tempezatuze (C)

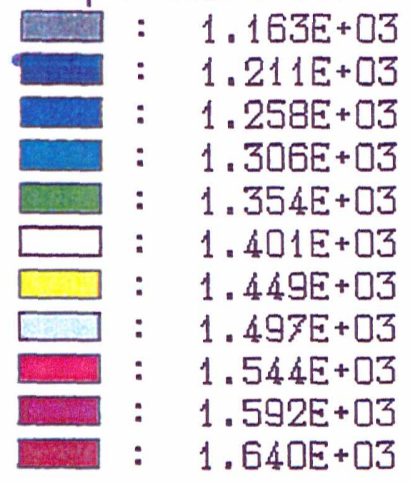

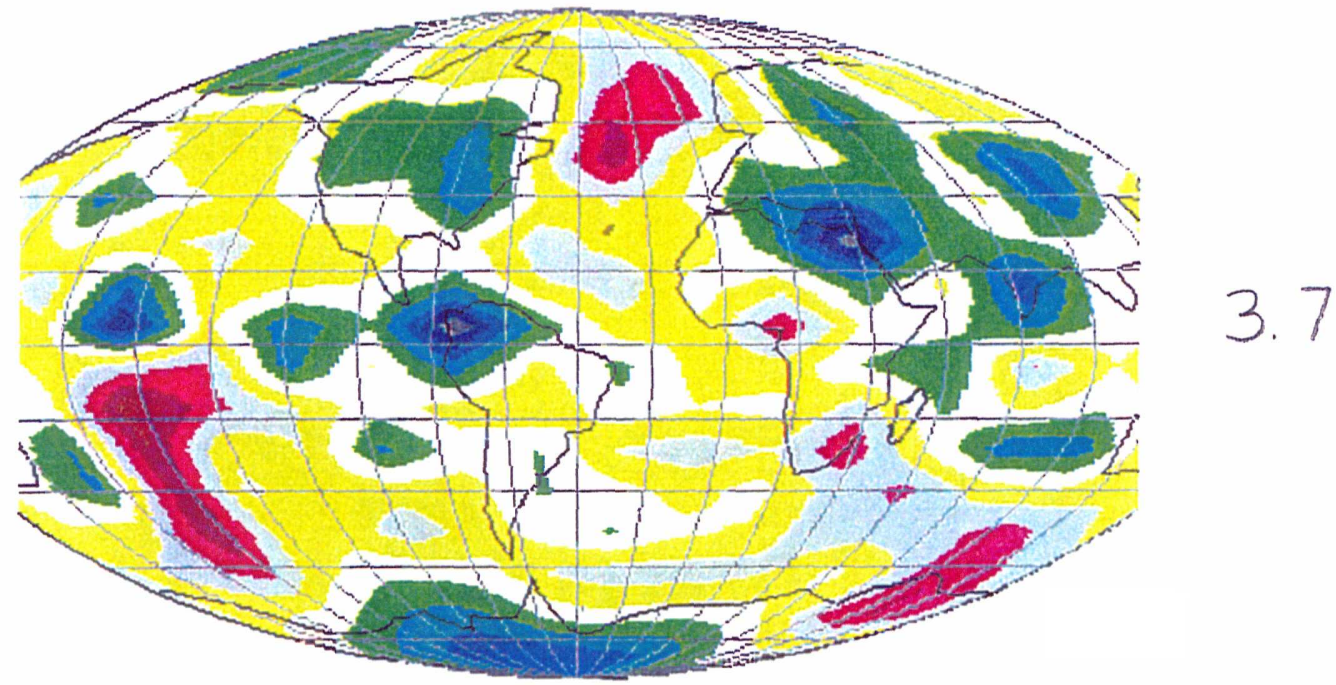

Time 0.0065000 Ma Depth $1600.000 \mathrm{~km}$ ( 90.000;315.000) Scale 1.000

Tempezatuze (C)

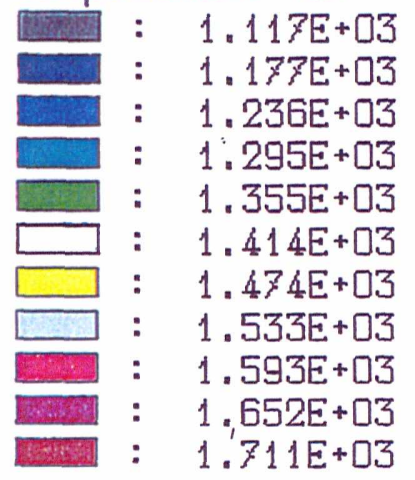

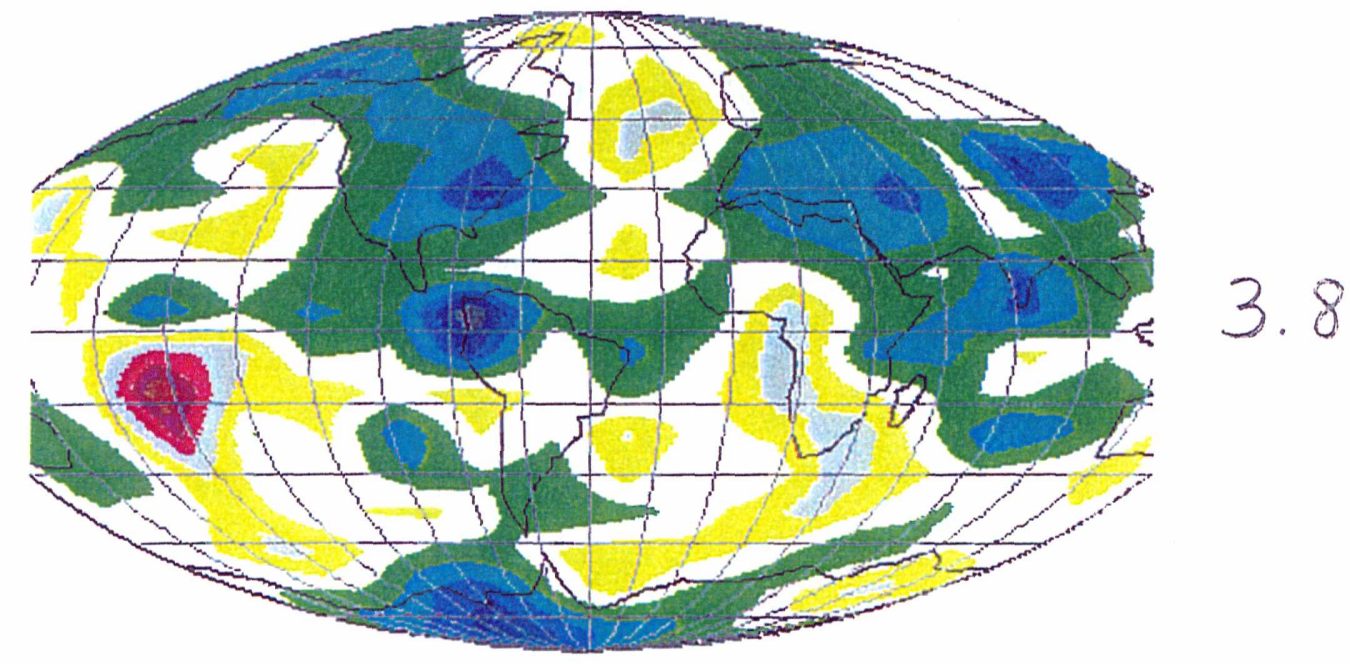


Time 0.0065000 Ma Depth $1800.000 \mathrm{~km}$ (90.000;315.000) Scale 1.000

Tempezatuze (C)

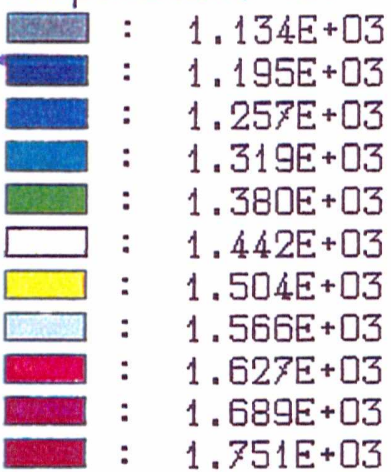

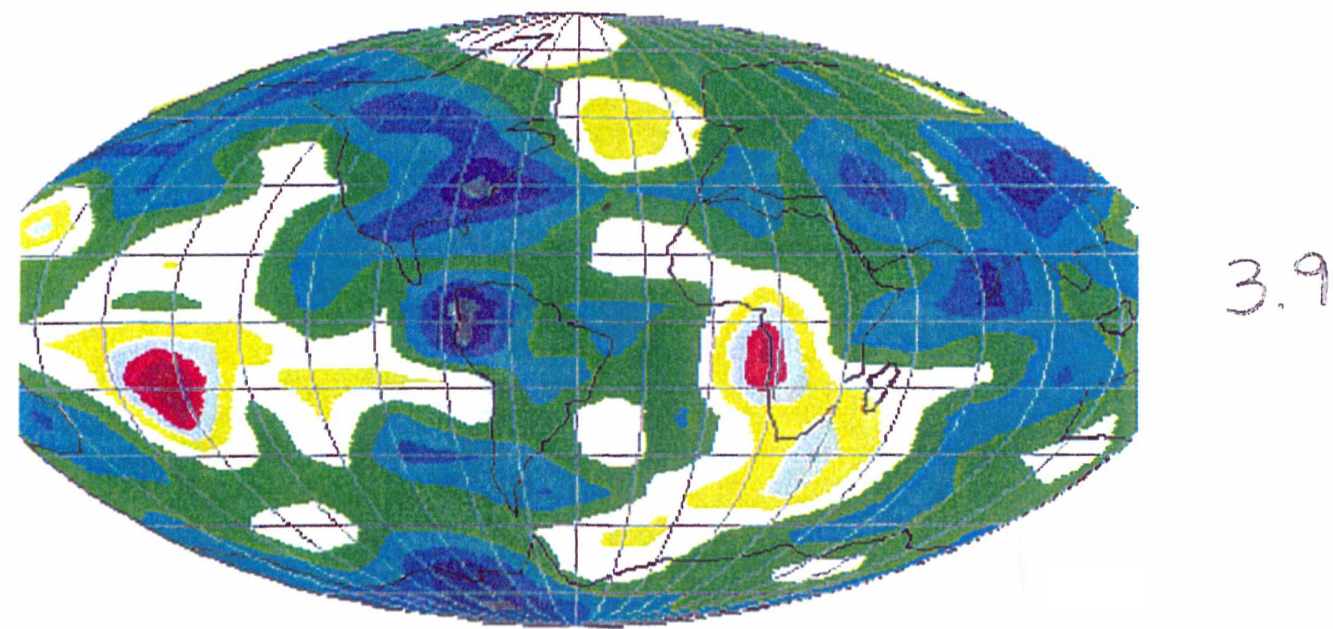

Time 0.0065000 Ma Depth 2000.000 km ( 90.000;315.000) Scale 1.000

Tempezatuze (C)

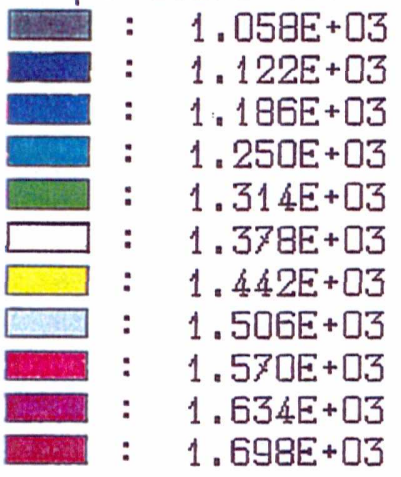

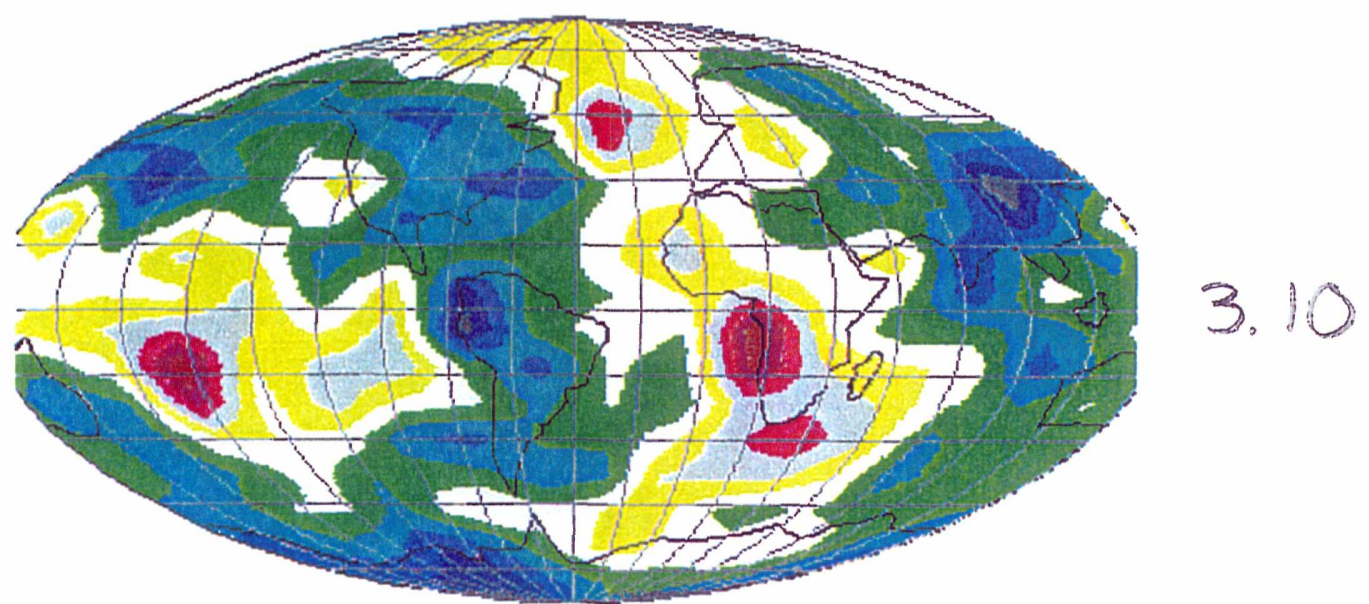


Time 0.0065000 Ma Depth $2200.000 \mathrm{~km}$ (90.000;315.000) Scale 1.000

Tempezatuze (C)

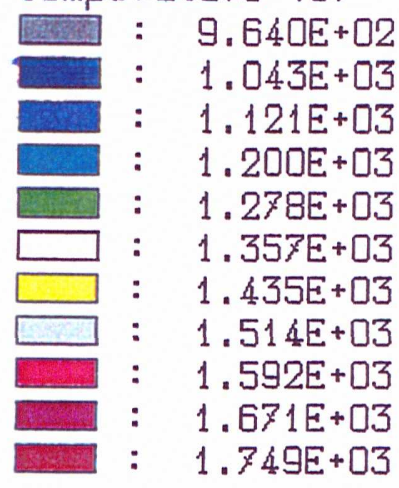

Time 0.0065000 Ma Depth $2400.000 \mathrm{~km}$ (90.000;315.000) Scale 1.000

Tempezatuze (C)

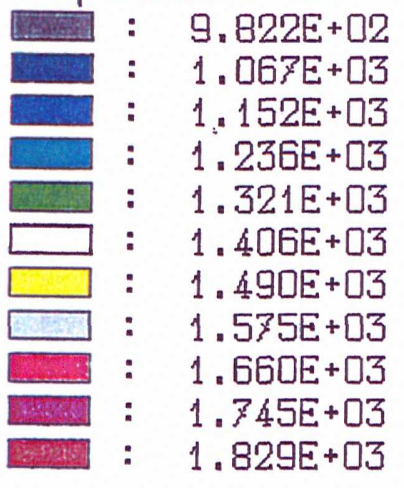
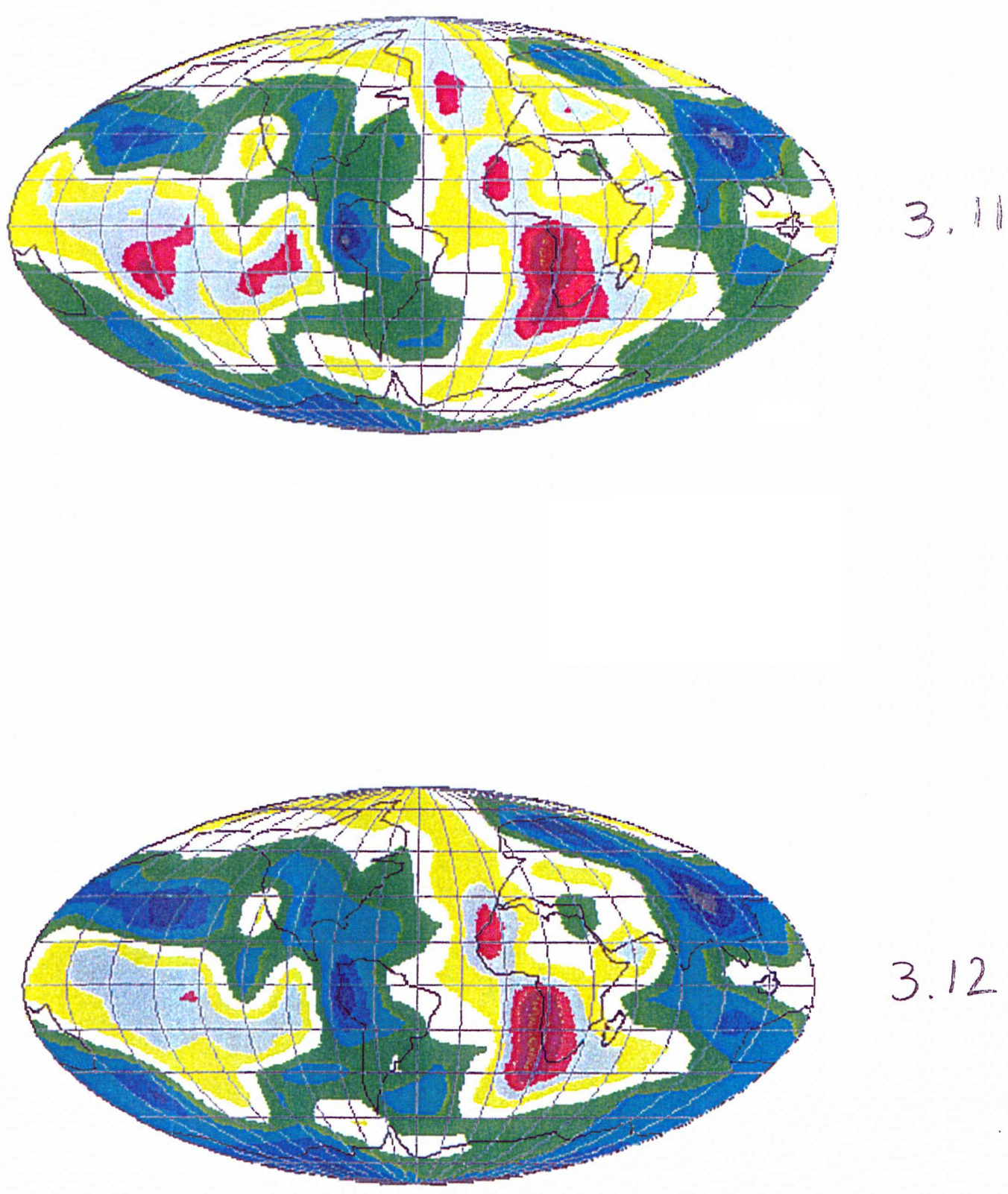
Time 0.0065000 Ma Depth $2600.000 \mathrm{~km}$ (90.000;315.000) Scale 1.000

Tempezatuze (C)

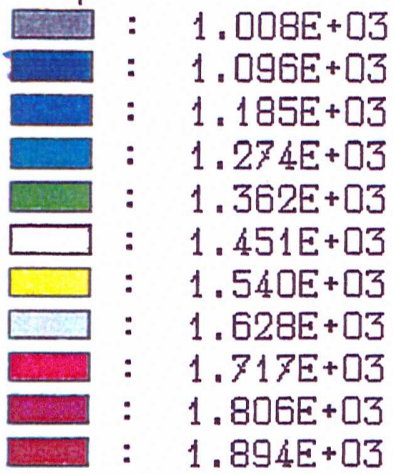

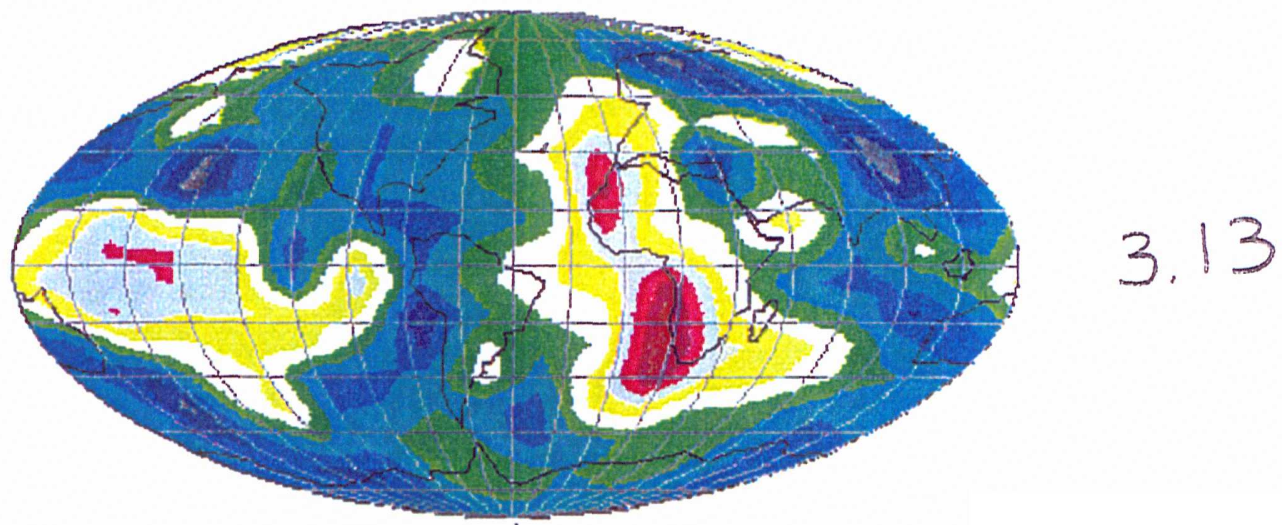

Time 0.0065000 Ma Depth $2800.000 \mathrm{~km}$ ( 90.000;315.000) Scale 1.000

Tempezatuze (C)

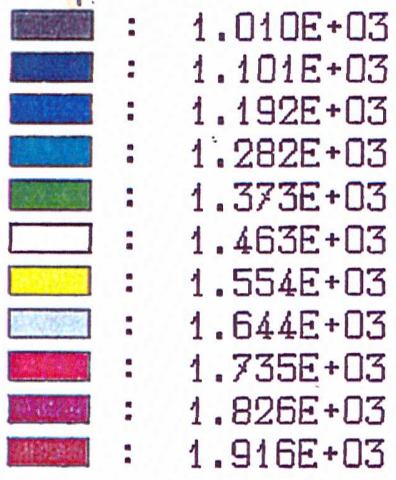

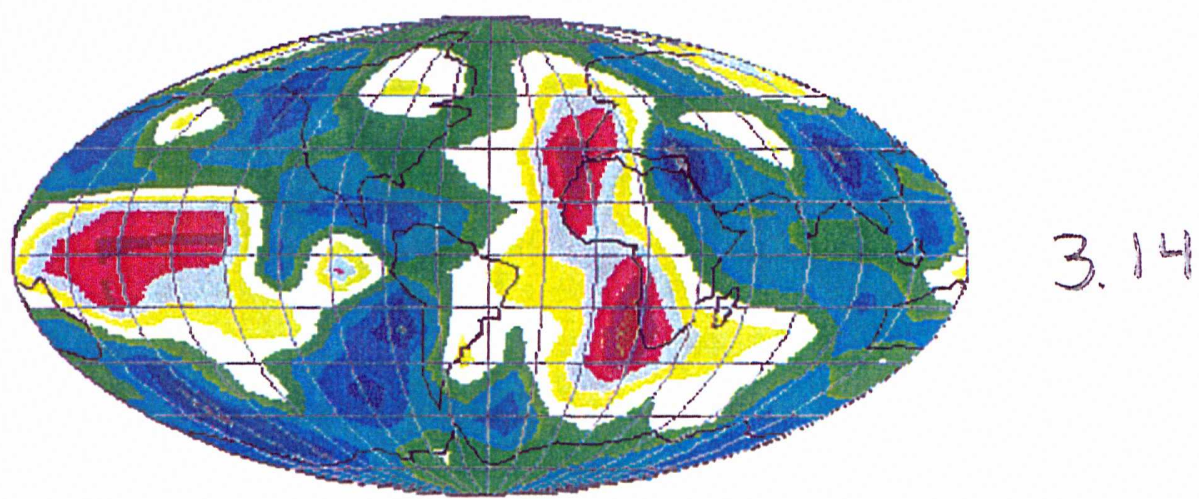


Time 0.0000000 Mם

Depth $\quad .000 \mathrm{~km}$

(90.000; 0.000)

Scale $\quad .800$

Heat Flow $\{\mathrm{mW} / \mathrm{m} 2\}$

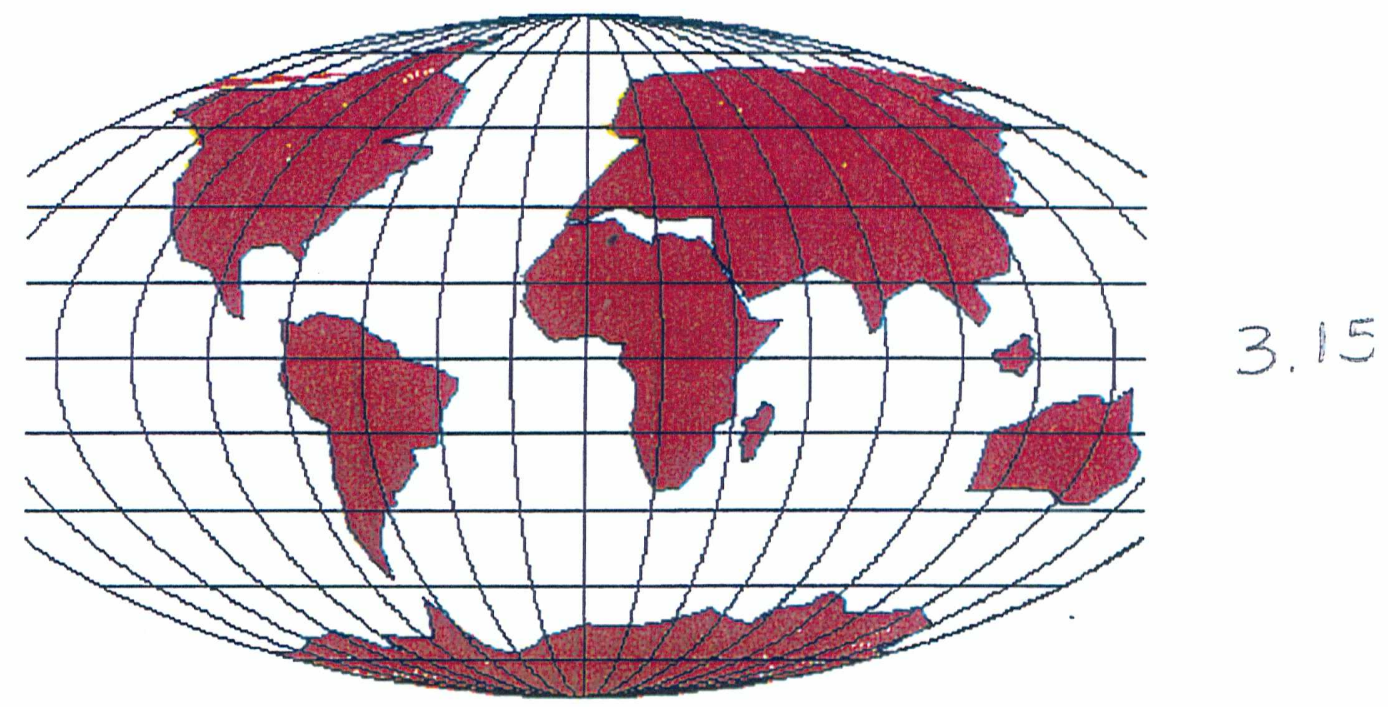

Time 0.0065000 Ma

Depth $\quad .000 \mathrm{~km}$

(90.000; 0.000)

Scale $\quad 800$

Velocity $(\mathrm{cm} / \mathrm{y}$ )

$\rightarrow: 4.217 \mathrm{E}-01$

Heat Flow (m/ $/ \mathrm{m} 2)$

: $4.888 \mathrm{E}+01$

: $5.241 \mathrm{E}+01$

: $: 5.595 \mathrm{E}+01$

: $\quad 5.948 \mathrm{E}+01$

$\square: \quad 6.302 \mathrm{E}+01$

$\square: 6.655 \mathrm{E}+01$

: $7.009 E+01$

E: $7.362 \mathrm{E}+01$

: $7.716 \mathrm{E}+01$

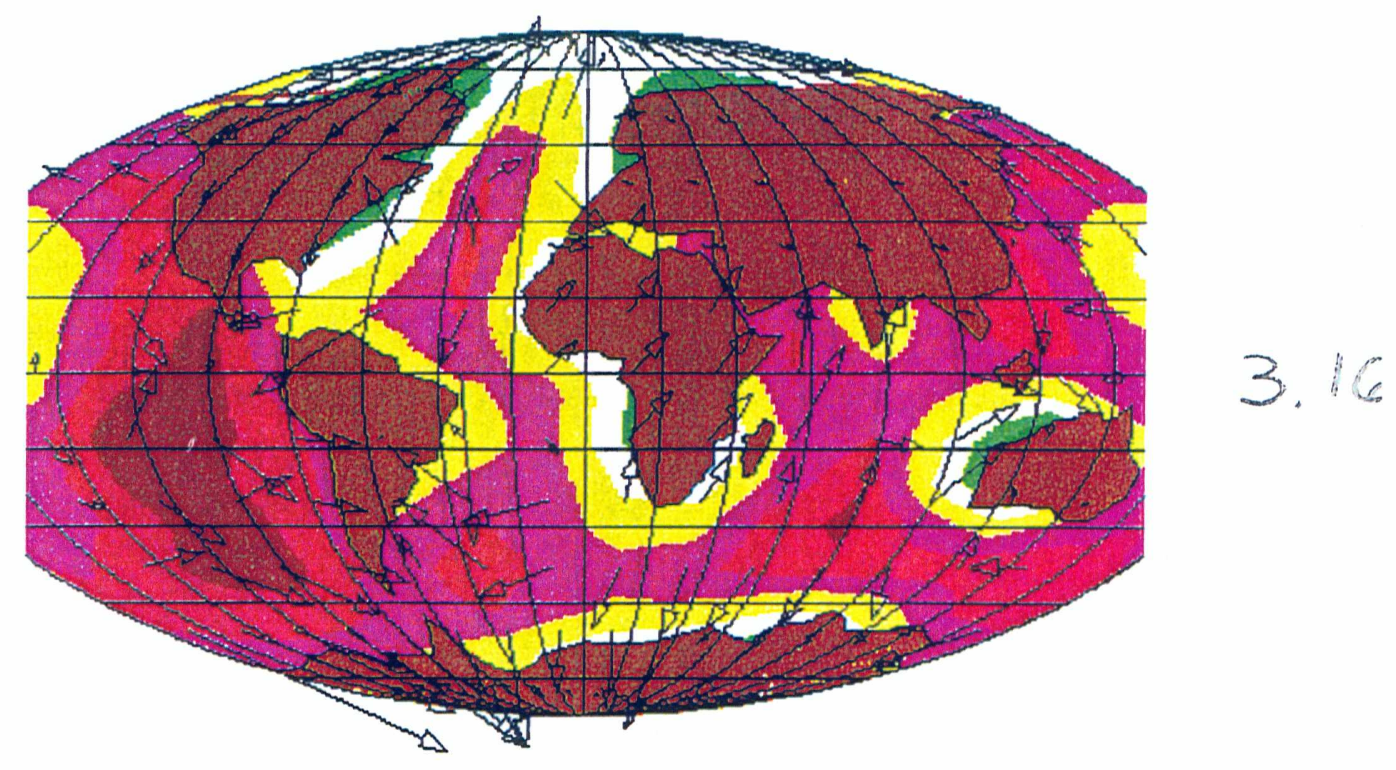


Time $130.21260 \mathrm{Ma}$

Depth $\quad .000 \mathrm{~km}$

(90.000; 0.000)

Scale .800

Velocity $\{\mathrm{cm} / \mathrm{y}\}$

$\rightarrow: 1.205 \mathrm{E}+00$

Heat Flow $\{\mathrm{mW} / \mathrm{m} 2\}$

[: $2.685 E+01$

$: 3.515 \mathrm{E}+01$

: $\quad 4.345 \mathrm{E}+01$

: $5.175 \mathrm{E}+01$

: $6.005 E+01$

$\square: 6.835 \mathrm{E}+01$

$\square: 7.665 \mathrm{E}+01$

$=1.016 \mathrm{E}+02$

$: 1.099 \mathrm{E}+02$ $\square: 8.495 \mathrm{E}+01$

$=9.325 \mathrm{E}+01$

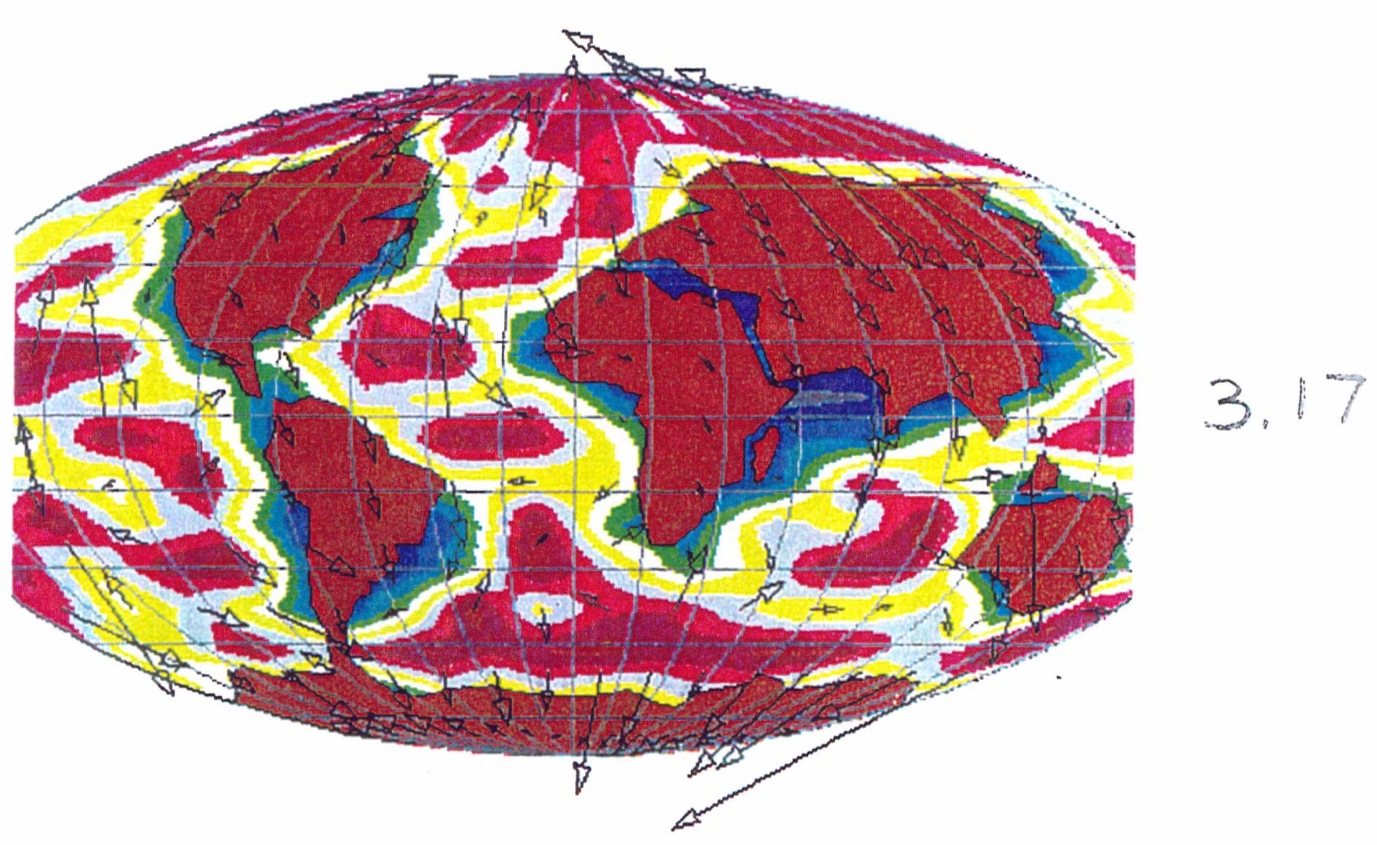

Time 260.21290 Ma

Depth $\quad .000 \mathrm{~km}$

(90.000; 0.000)

Scale .800

Velocity $(\mathrm{cm} / \mathrm{s}$ )

$\rightarrow: 1.913 \mathrm{E}+00$

Heat F low ( $\mathrm{m}$ W/m2)

: $1.870 E+01$

: $2.730 \mathrm{E}+01$

: $: 3.589 \mathrm{E}+01$

D $\quad 4.448 E+01$

: $: 5.307 \mathrm{E}+01$

$\square: \quad 0.166 \mathrm{E}+01$

$\square: 7.026 \mathrm{E}+01$

$\square: 7.885 \mathrm{E}+01$

: $8.744 \mathrm{E}+01$

: 9.603E+01

: $1.046 \mathrm{E}+02$

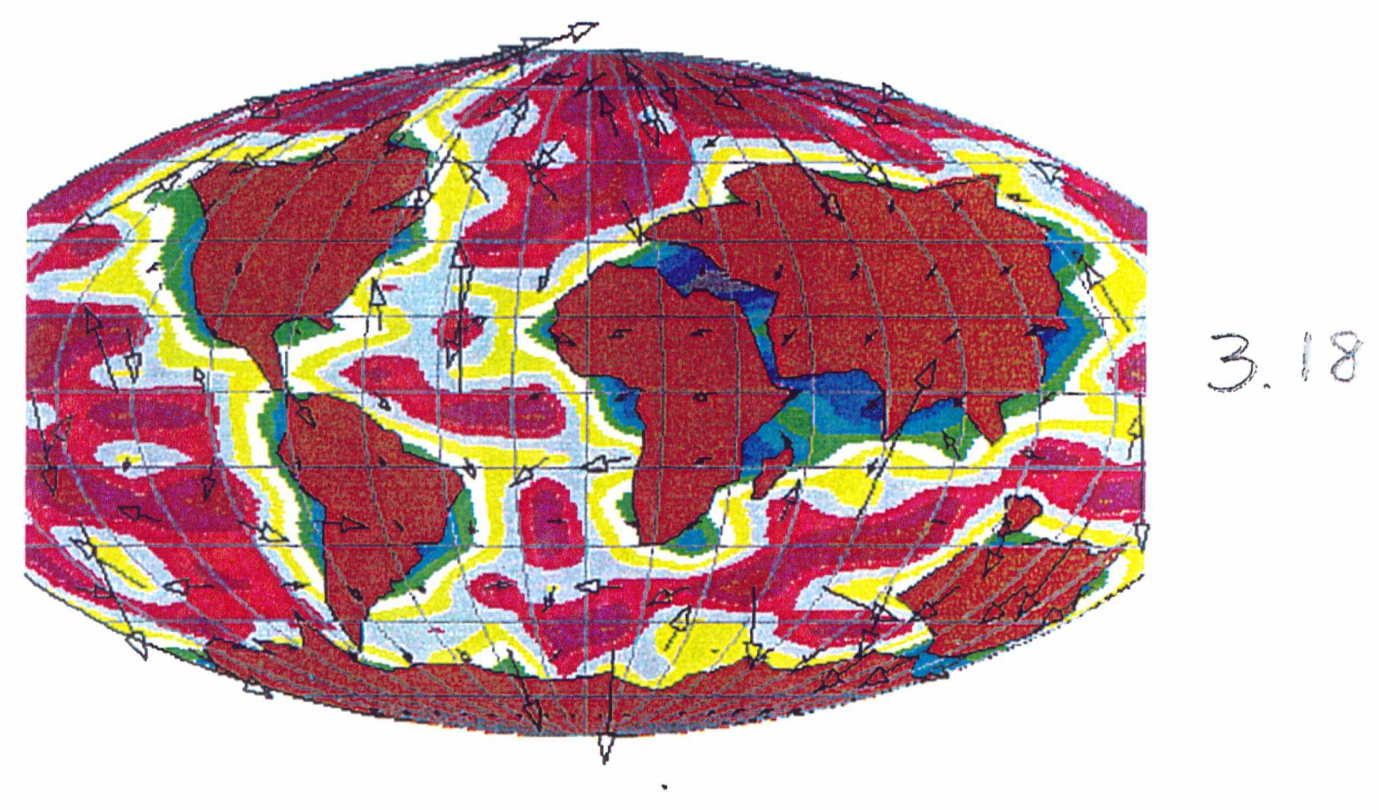


Time 195.42220 Ma

Depth $\quad .000 \mathrm{~km}$

(90.000; 0.000)

Scale $\quad 800$

Velocity $(\mathrm{cm} / \mathrm{y})$

$\rightarrow: 1.080 E+00$

Heat $\mathrm{F}$ low $\{\mathrm{mW} / \mathrm{m} 2\}$

E. $2.160 \mathrm{E}+01$

: $2.973 \mathrm{E}+01$

ㄴ. $3.785 \mathrm{E}+01$

: $4.597 \mathrm{E}+01$

: $5.409 \mathrm{E}+01$

$\square: \quad 6.222 \mathrm{E}+01$

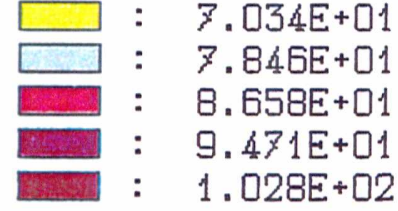

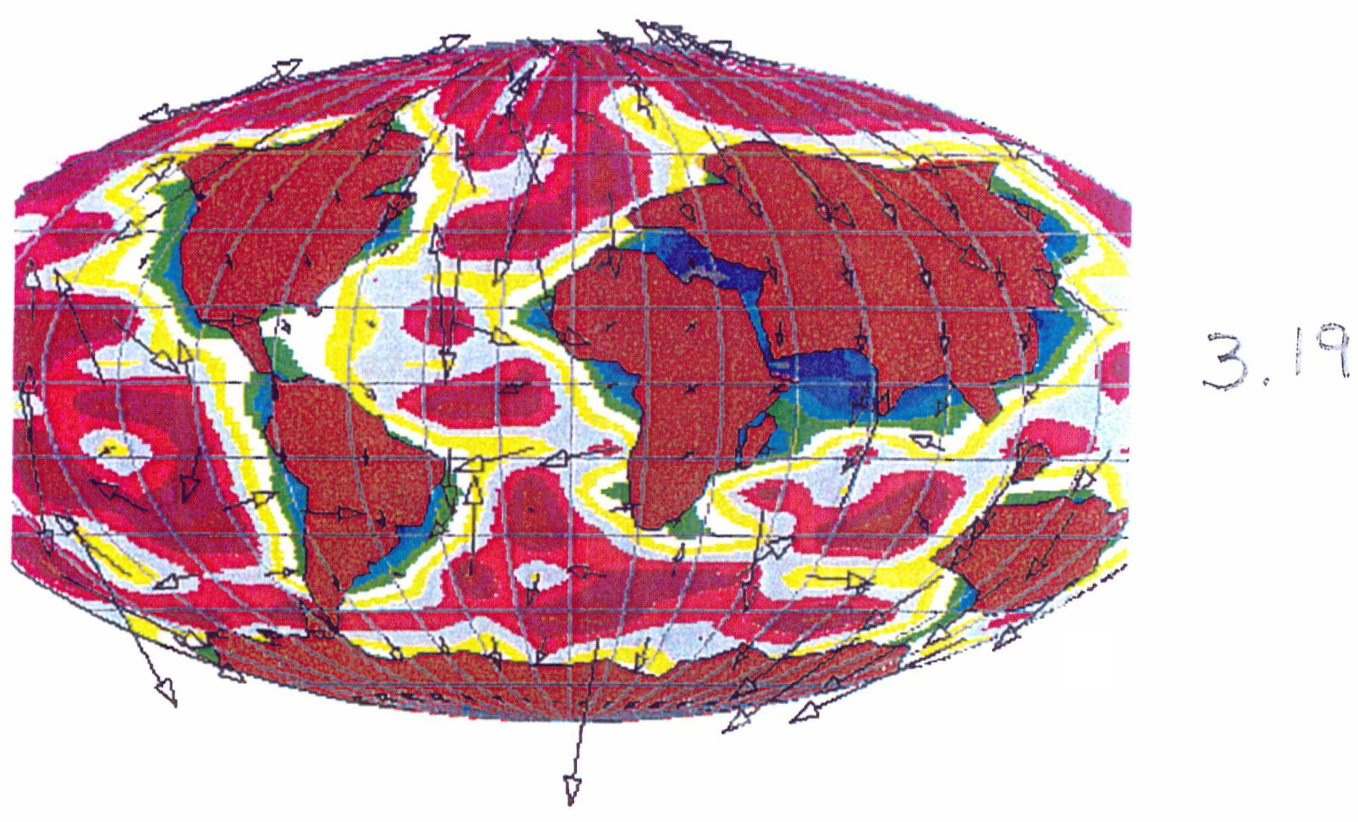

Time $325.07420 \mathrm{Ma}$ Depth $\quad .000 \mathrm{~km}$ (90.000; 0.000) Scale $\quad .800$ Velocity $(\mathrm{cm} / \mathrm{y})$ $\rightarrow: 2.251 \mathrm{E}+00$ Heat Flow ( $\mathrm{m} / \mathrm{m} / \mathrm{m} 2$ )
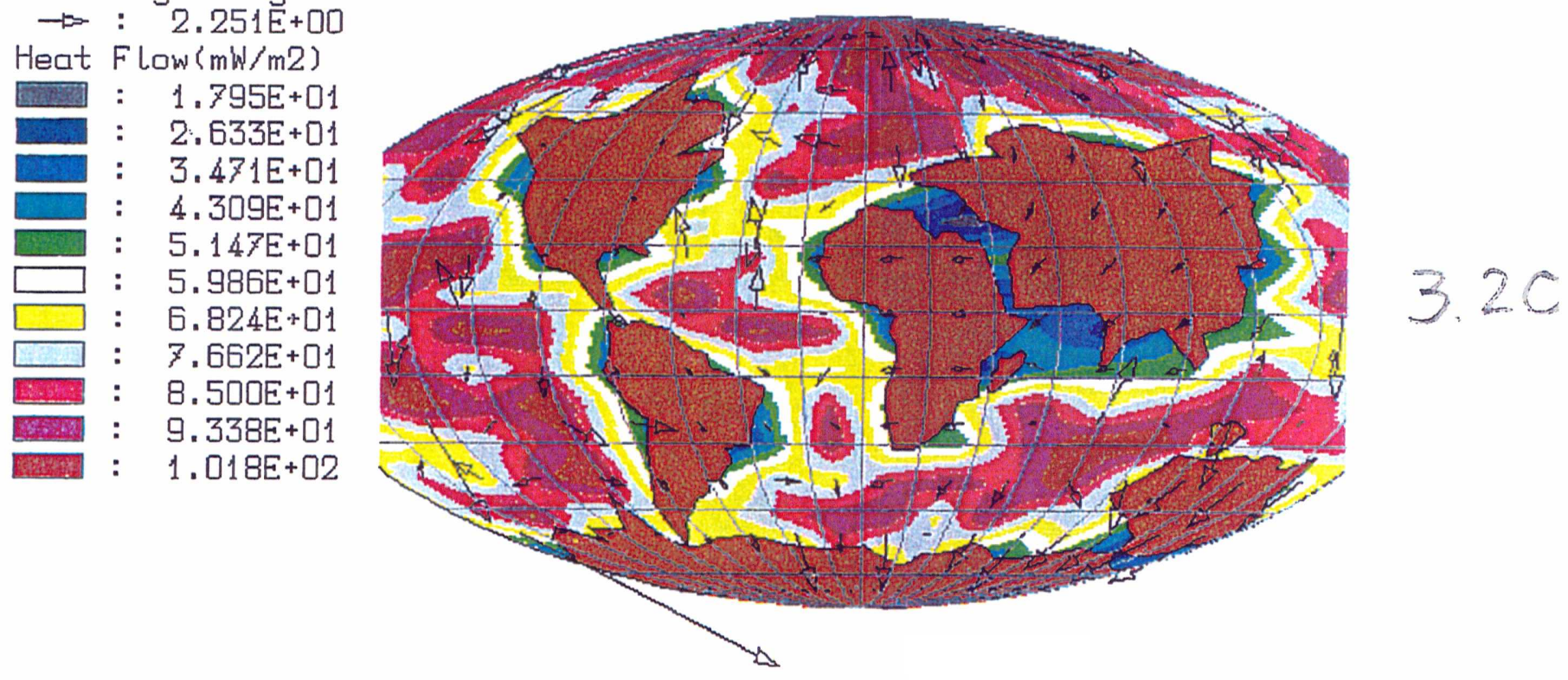
Time 455.08170 Ma Depth .000 km ( 90.000; 0.000) Scale .800 Velocity $(\mathrm{cm} / \mathrm{y}$ ) $\rightarrow$ : $2.589 \mathrm{E}+00$ Heat Flow (m/ $/ \mathrm{m} 2$ )

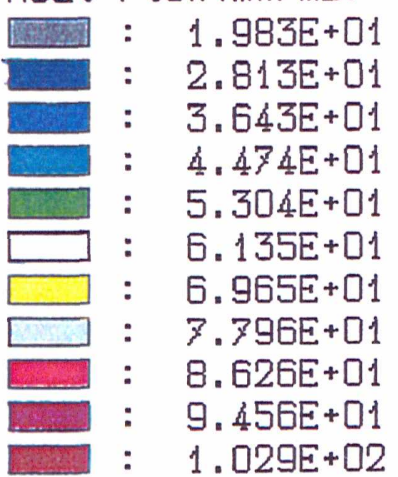

Time 520.01630 Ma Depth $.000 \mathrm{~km}$ (90.000; 0.000) Scale $\quad .800$ Velocity (cm/y) $\rightarrow$ : 1.994E+00 Heat $F$ low $(\mathrm{m} / \mathrm{m} / \mathrm{m}$ )

\begin{tabular}{|c|c|c|}
\hline & & $1.833 E+01$ \\
\hline & & $2.724 E+01$ \\
\hline & & $3 ; 615 E+01$ \\
\hline & : & $4.505 E+01$ \\
\hline & : & $5.396 \mathrm{E}+01$ \\
\hline & : & $6.287 E+01$ \\
\hline & : & $7.178 E+01$ \\
\hline & : & 8. $069 E+0$ \\
\hline & & $960 E+01$ \\
\hline & & $9.850 E+\square$ \\
\hline & & 1.074E+02 \\
\hline
\end{tabular}
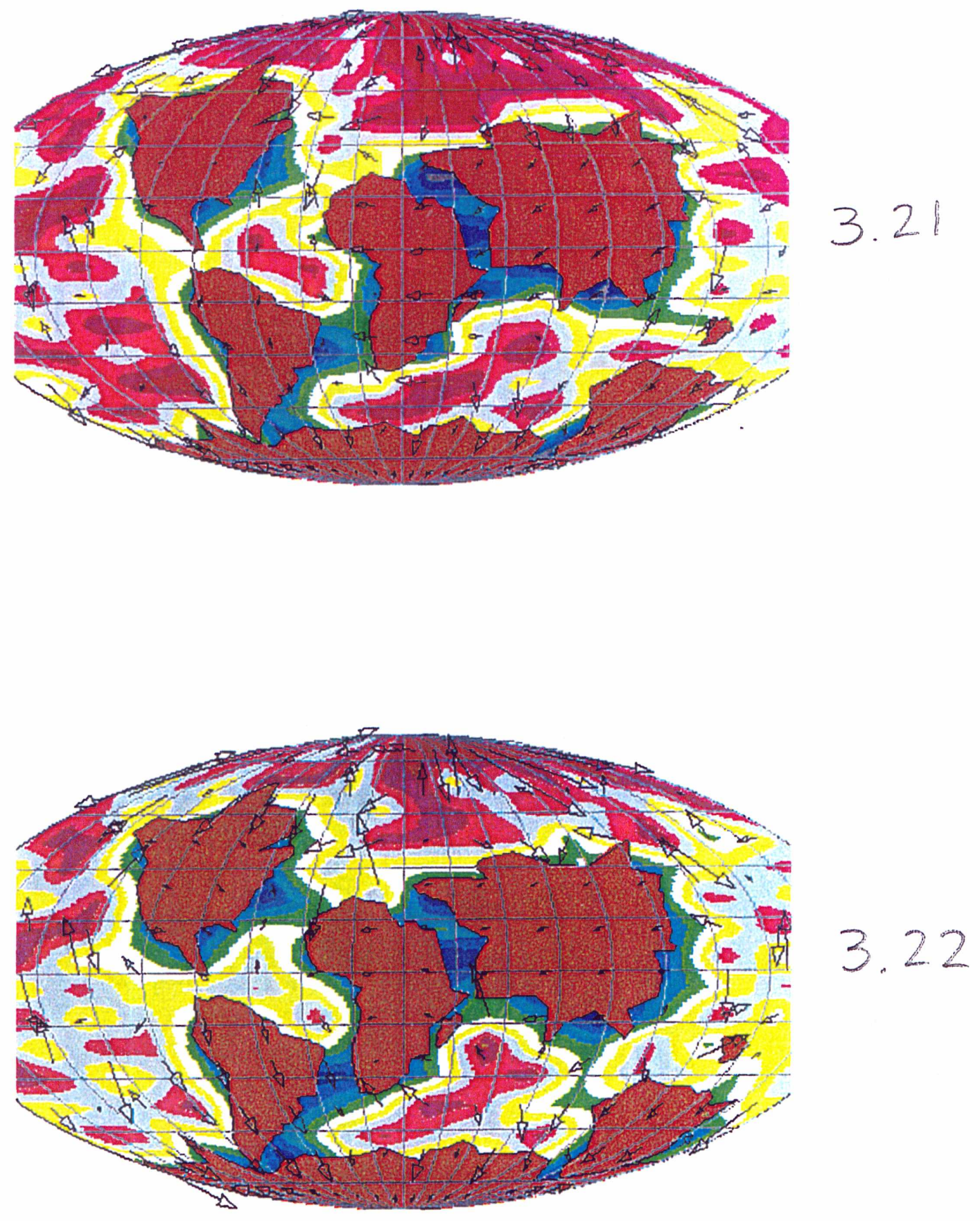
Time 585.31640 Ma

Depth $\quad .000 \mathrm{~km}$

(90.000; 0.000)

Scale $\quad 800$

Velocity (cm/y)

$\rightarrow: 1.786 \mathrm{E}+00$

Heat Flow $(\mathrm{m} W / \mathrm{m} 2)$

: $1.832 E+01$

: $2.653 \mathrm{E}+01$

: $\quad 3.474 \mathrm{E}+01$

— $\quad 4.296 \mathrm{E}+01$

: $5.117 \mathrm{E}+01$

$\square: 5.938 E+01$

$\square: 6.759 \mathrm{E}+01$

$\square: 7.581 \mathrm{E}+01$

: $8.402 \mathrm{E}+01$

: $9.223 \mathrm{E}+01$

: $: 1.004 \mathrm{E}+02$

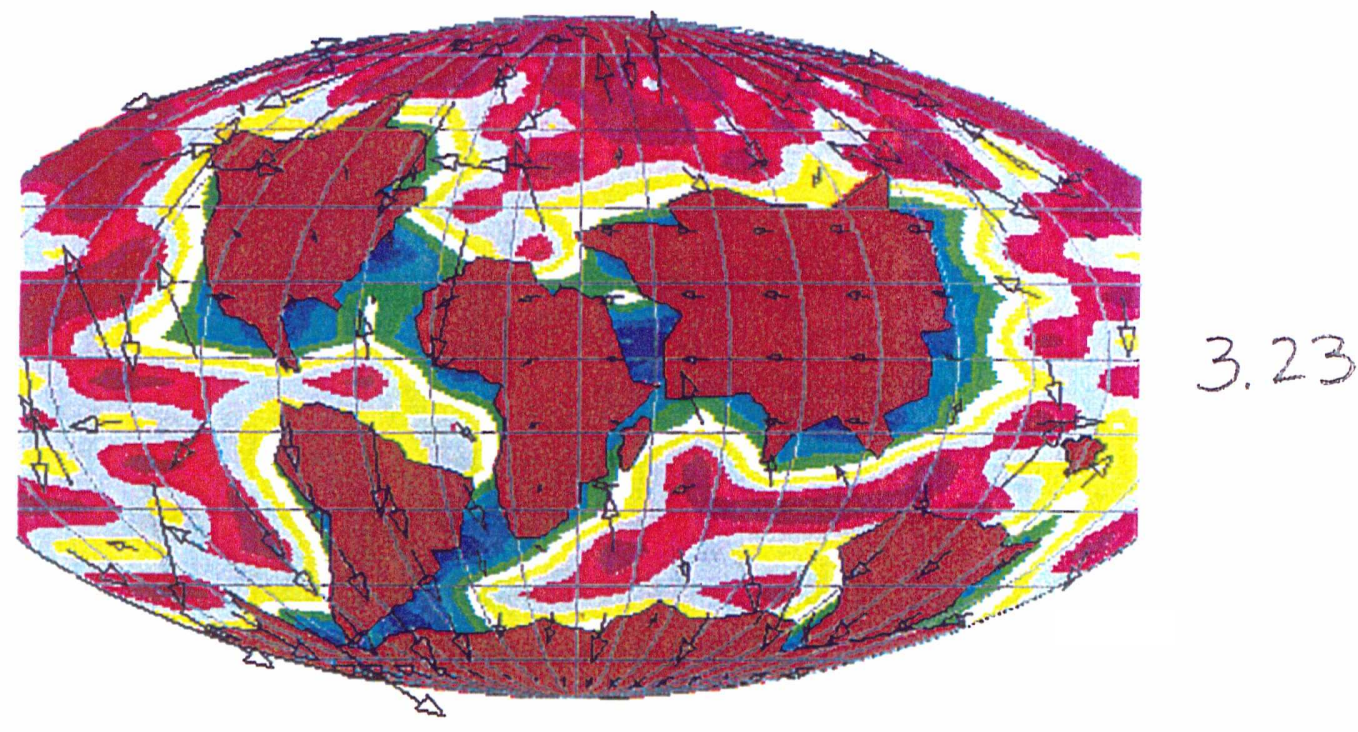

Time 650.43760 Ma

Depth . .000 km (90.000; 0.000) Scale $\quad 800$

Velocity (cm/y)

$\rightarrow: 2.131 \mathrm{E}+00$

Heat F low $(\mathrm{mW} / \mathrm{m} 2)$

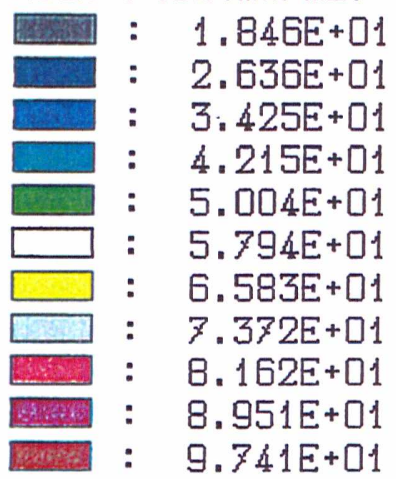

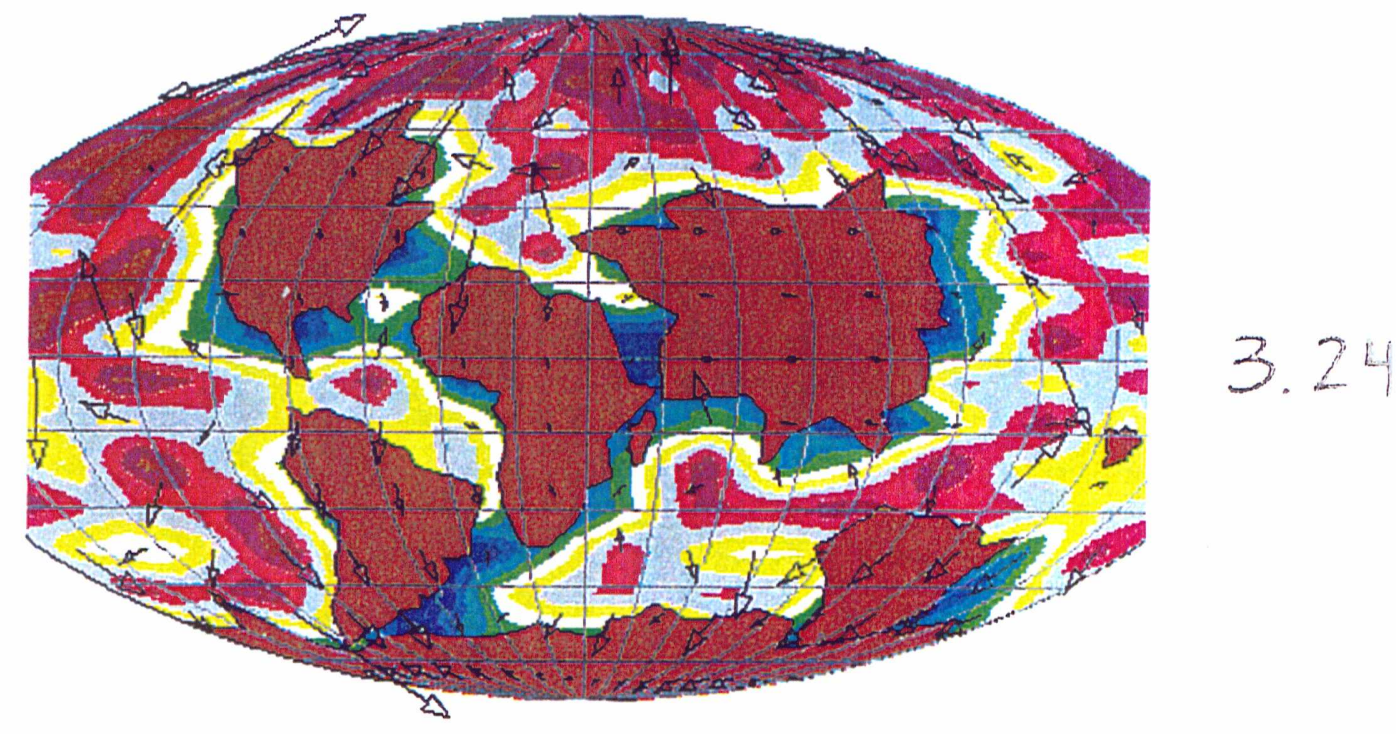


Time $715.03980 \mathrm{Ma}$ Depth $\quad .000 \mathrm{~km}$ \{ 90.000;0.000\} Scale $\quad .800$ Velocity $\{\mathrm{cm} / \mathrm{y}\}$ $\rightarrow: 2.462 \mathrm{E}+00$ Heat Flow $\{\mathrm{mW} / \mathrm{m} 2\}$

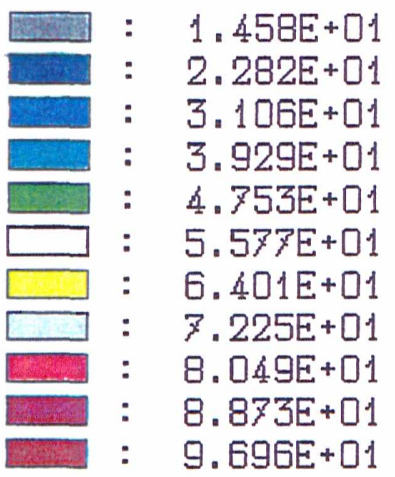

Time 845.32100 Ma Depth $\quad .000 \mathrm{~km}$ (90.000; 0.000) Scale $\quad .800$ Velocity $\{\mathrm{cm} / \mathrm{y}$ \} $\rightarrow: 1.681 \mathrm{E}+00$ Heat F low $(\mathrm{m} / \mathrm{m} / \mathrm{m} 2)$

: $1.979 \mathrm{E}+01$ : $2.874 \mathrm{E}+01$ : $3.770 \mathrm{E}+01$ [- $\quad 4.665 \mathrm{E}+01$ : : $5.560 \mathrm{E}+01$ $\square: 6.456 \mathrm{E}+01$ $\square: 7.351 \mathrm{E}+01$ $\square: 8.246 \mathrm{E}+01$ : $9.142 \mathrm{E}+01$ : $: 1.004 \mathrm{E}+02$ : $1.093 \mathrm{E}+02$
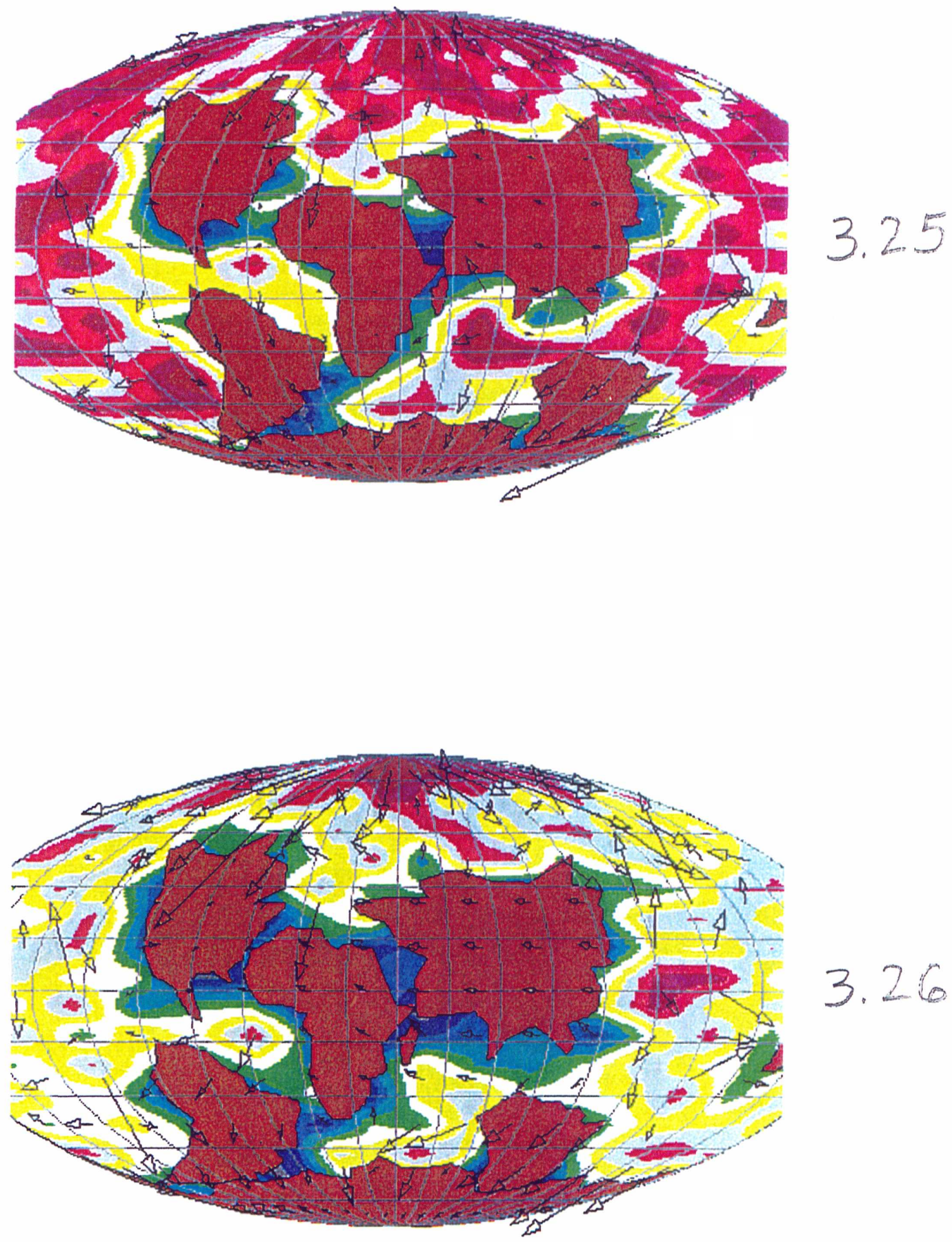
Time 910.29280 Ma Depth $\quad .000 \mathrm{~km}$ \{90.000;0.000\} Scale $\quad 800$ Velocity (cm/s) $\rightarrow: 2.824 \mathrm{E}+00$ Heat Flow $\{\mathrm{mW} / \mathrm{m} 2\}$

ㄴ: $1.883 \mathrm{E}+01$ : $2.652 \mathrm{E}+01$ - $: 3.422 \mathrm{E}+01$ : $4.192 \mathrm{E}+01$ : $: 4.961 \mathrm{E}+01$ $\square: 5.731 E+01$ $\square: 6.501 \mathrm{E}+01$ $\square: 7.270 \mathrm{E}+01$ : $8.040 \mathrm{E}+01$ : $8.810 \mathrm{E}+01$ : $9.579 \mathrm{E}+01$

Time 1040.0160 Ma Depth $.000 \mathrm{~km}$ (90.000;0.000) Scale $\quad .800$ Velocity $(\mathrm{cm} / \mathrm{y}$ ) $\rightarrow: 4.124 \mathrm{E}+00$ Heat Flow $\{\mathrm{m} / \mathrm{m} / \mathrm{m} 2\}$

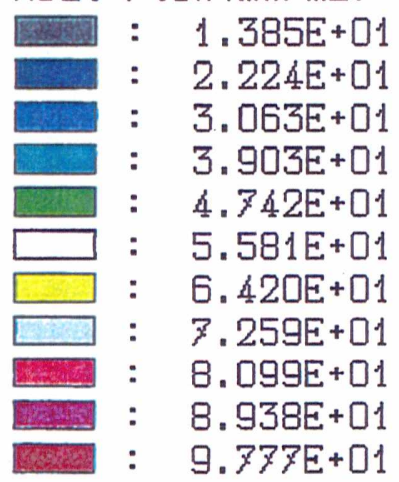

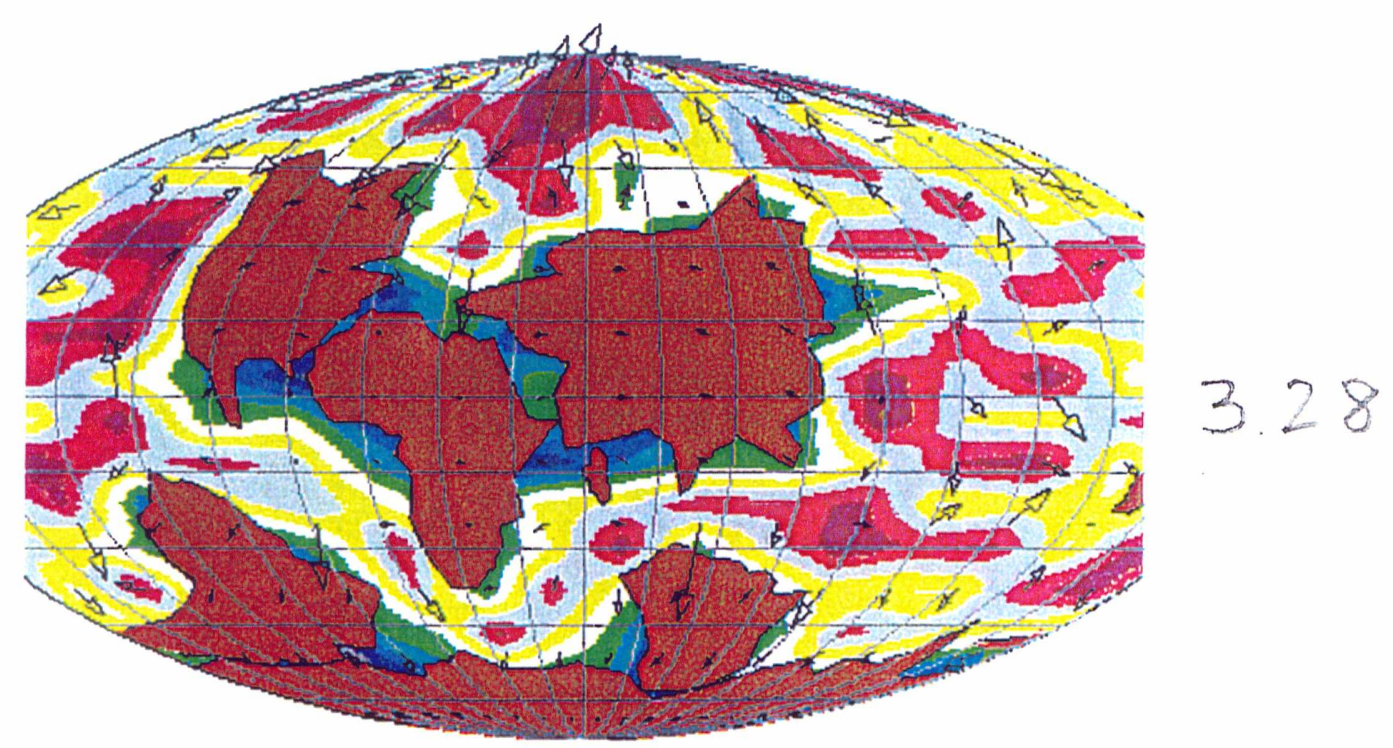


Time 1105.6750 Ma

Depth $\quad .000 \mathrm{~km}$ (90.000;0.000) Scale $\quad 800$

Velocity \{cm/y)

$\rightarrow: 2.553 \mathrm{E}+00$

Heat $\mathrm{F}$ low $\{\mathrm{mW} / \mathrm{m} 2\}$

—: $1.088 \mathrm{E}+01$

[: $1.900 \mathrm{E}+01$

: $2.713 \mathrm{E}+01$

: $3.525 \mathrm{E}+01$

ㄴ. $4.338 \mathrm{E}+01$

$5.150 E+01$

$5.963 \mathrm{E}+01$

6. $775 E+01$

7.587E+01

8. $400 E+01$

9. $212 \mathrm{E}+01$

Time 1212.3320 Ma

Depth $.000 \mathrm{~km}$

(90.000;0.000)

Scale $\quad 800$

Velocity $(\mathrm{cm} / \mathrm{y}\}$

$\rightarrow: 3.119 \mathrm{E}+00$

Heat Flow (m/ $/ \mathrm{m} 2)$

: $1.340 \mathrm{E}+01$

: $2.142 \mathrm{E}+01$

: $2.944 \mathrm{E}+01$

: $3.746 \mathrm{E}+01$

: $: 4.549 \mathrm{E}+01$

$\square: 5.351 \mathrm{E}+01$

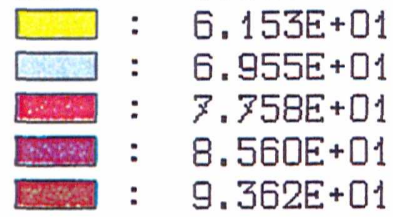
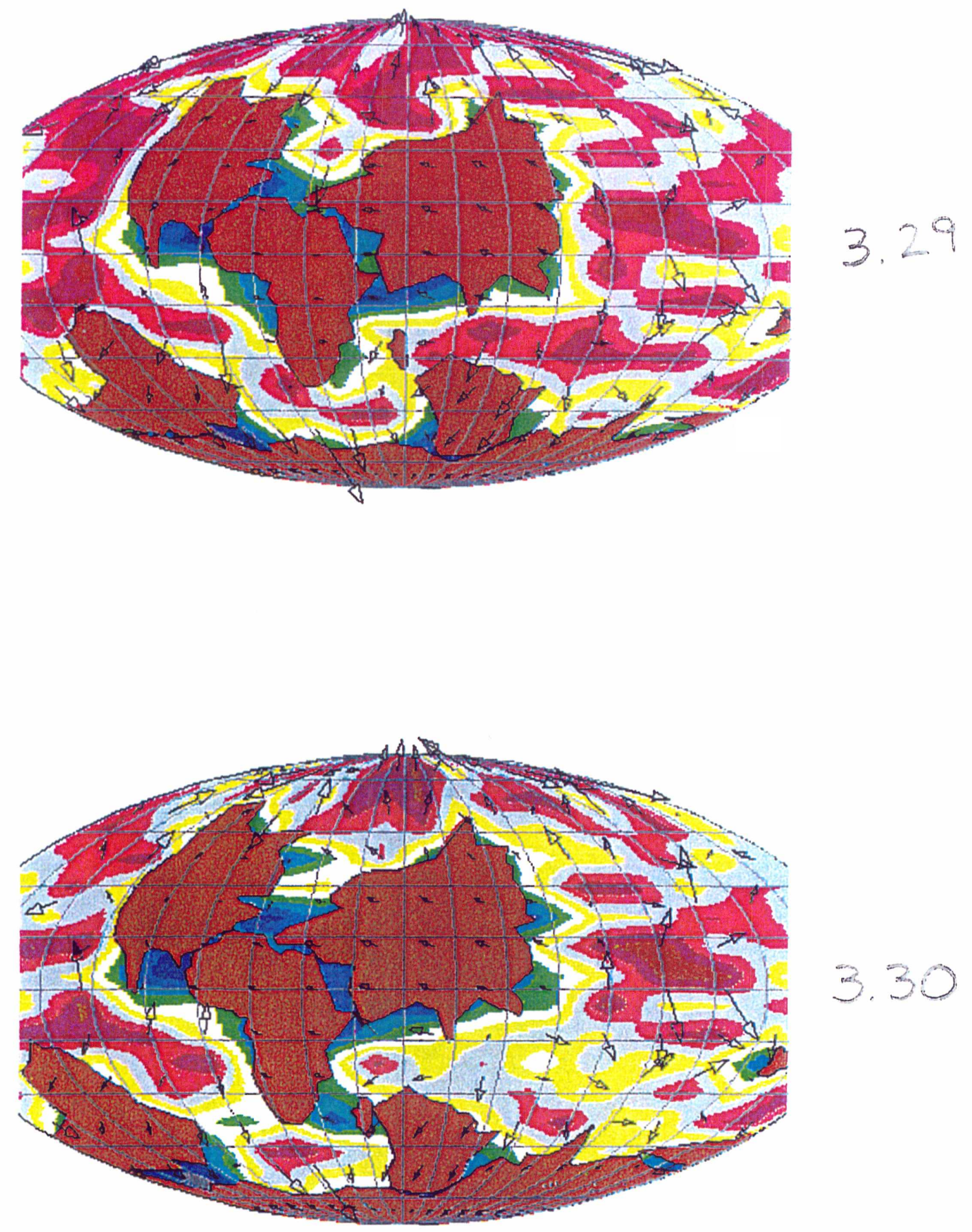
Time $0.0000000 \mathrm{My}$

$Q\left\{m[n\}=0.000^{\circ}\right.$

$Q\{$ max $)=180.000^{\circ}$

$F(m i n)=0.000^{\circ}$

$F(\max )=360.000^{\circ}$

- Tempezatuze (C) .0; 2500.0

so Tad (C)

. 0; 1075.0

se T+Tad (C)

.0; 3575.0

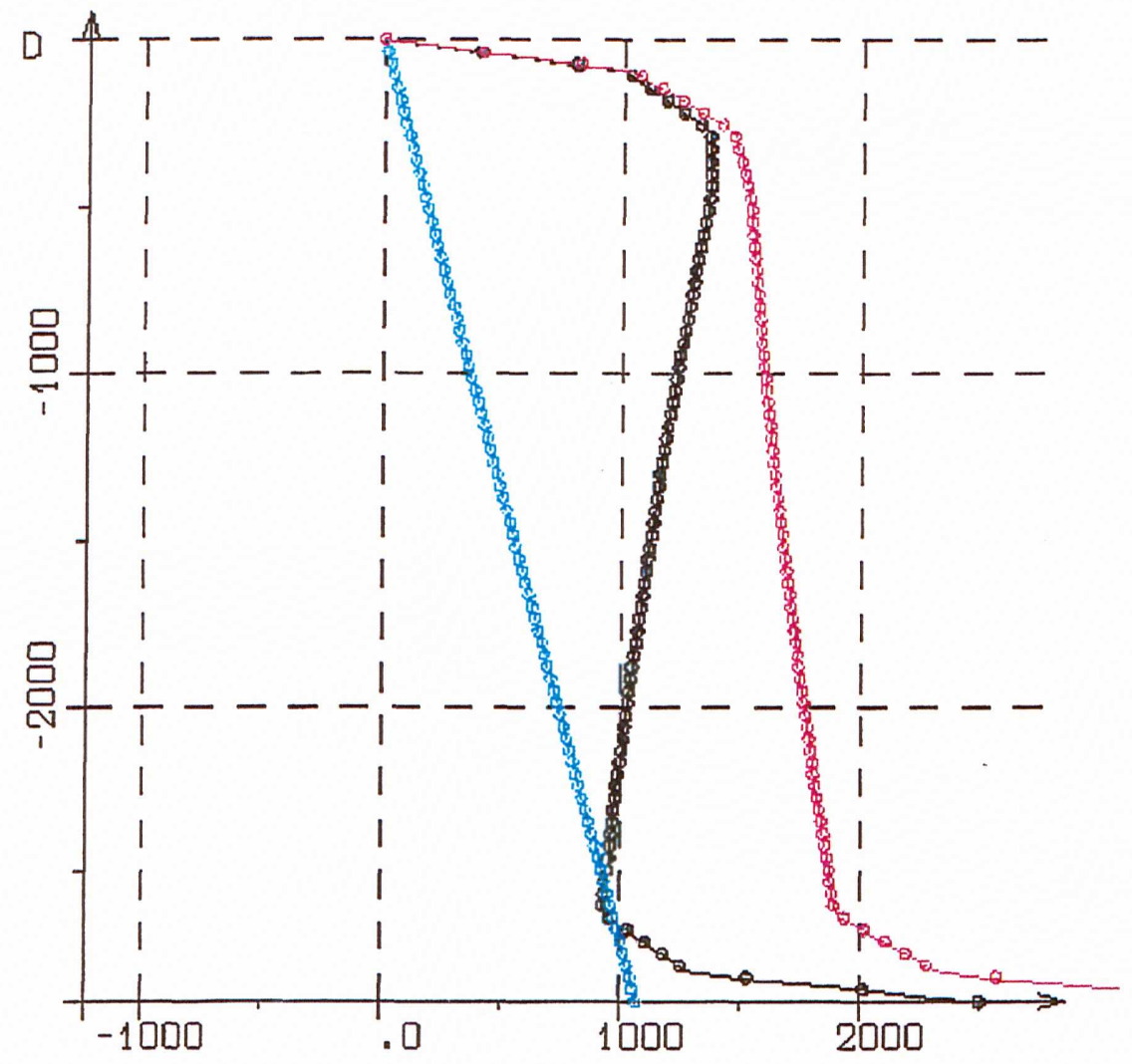

4.1

Time 0.0000000 Ma

$Q(m i n)=0.000^{\circ}$

$Q\{$ max $\}=180.000^{\circ}$

$F(m i n)=0.000^{\circ}$

$F(\max )=360.000^{\circ}$

- (Log Viscos.) -22

-1.0002; .8953

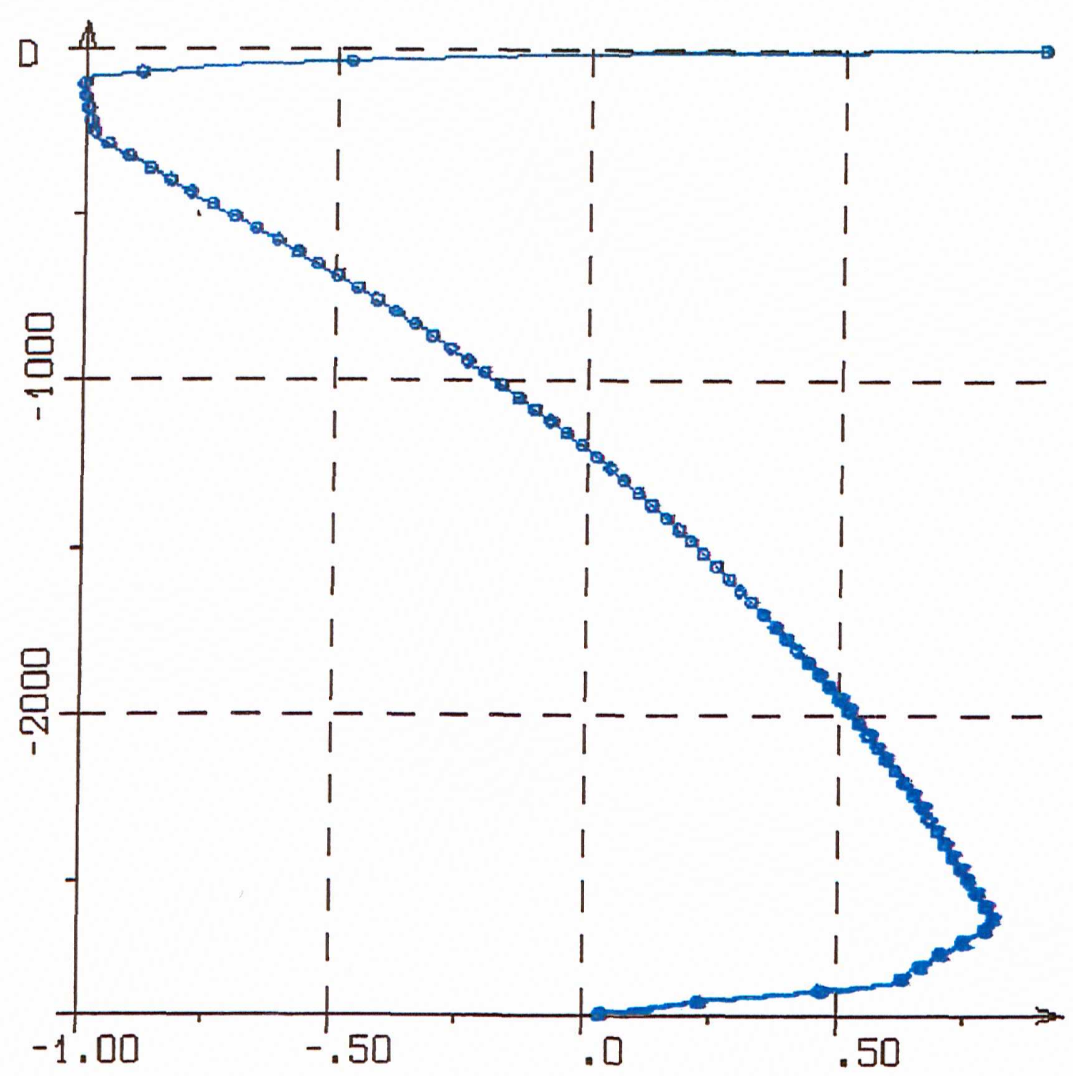

4.2 
Time 0.0000000 My Czoss $F=15.000^{\circ}$ ( 0.000; 0.000) Scale 1.300

Tempezatuze (C)

$: 1.389 E+02$

: $\quad 4.167 \mathrm{E}+02$

$\square: 6.944 \mathrm{E}+02$

: $: 9.722 \mathrm{E}+02$

$\square: 1.250 E+03$

- $1.528 \mathrm{E}+03$

: $: 2.083 \mathrm{E}+03$

: $2.361 \mathrm{E}+03$

- Heat $\{\mathrm{m} / \mathrm{m} / \mathrm{m} 2\}$ $51.439 ; \quad 71.297$ - Phase line

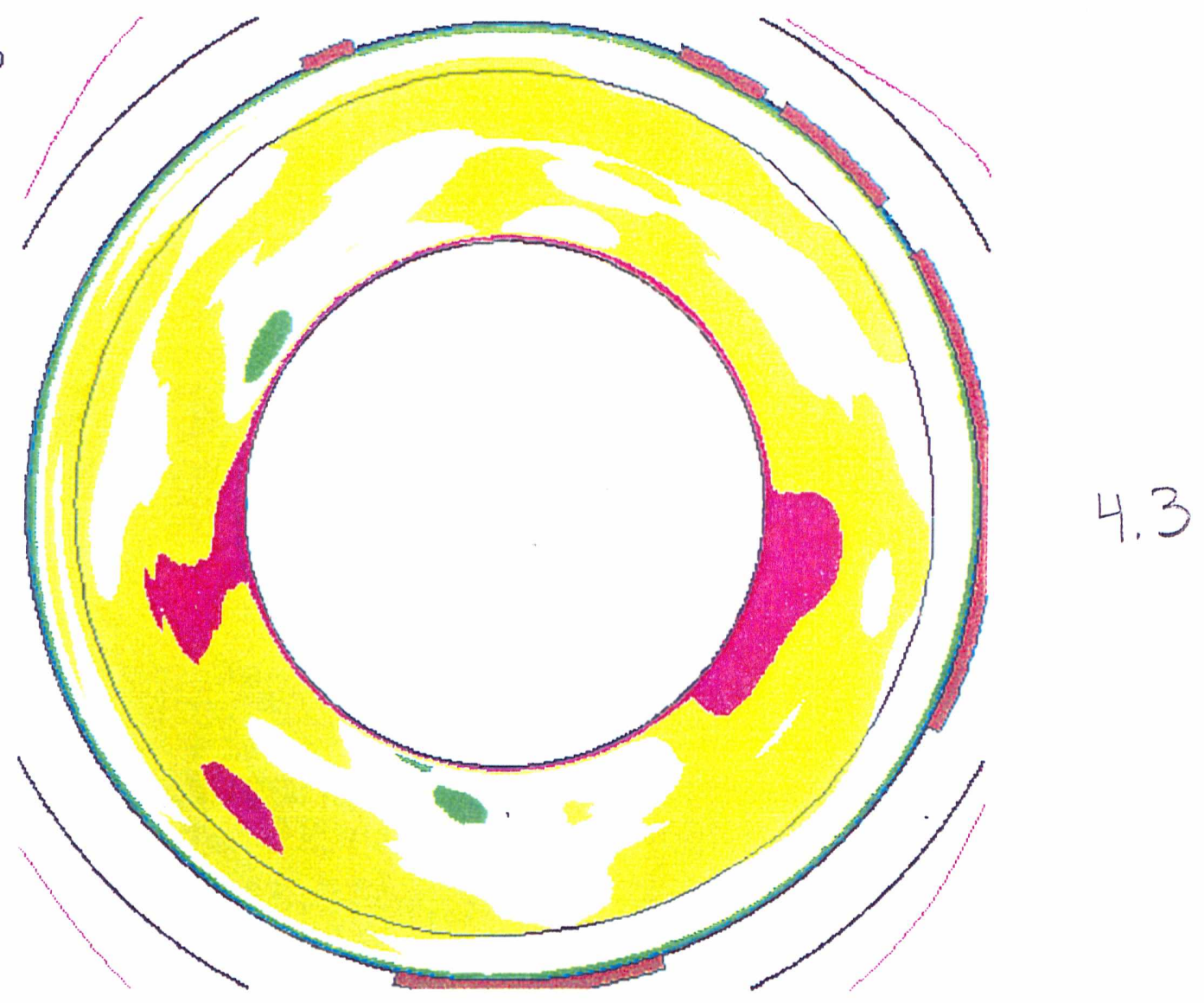
Time $0.0130000 \mathrm{My}$
Czoss $F=15.000^{\circ}$ ( 0.000; 0.000) Scale 1.300 Velocity $(\mathrm{cm} / \mathrm{y}$ ) $\rightarrow: 1.313 \mathrm{E}+00$ Tempezatuze (C)

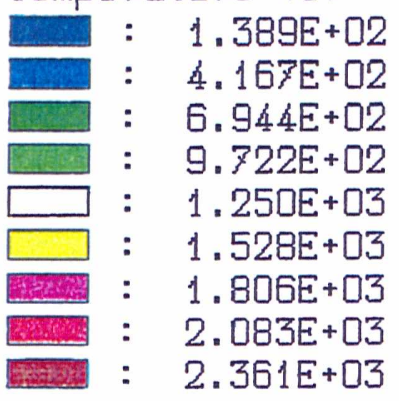

- Heat $(\mathrm{mW} / \mathrm{m} 2)$ $51.433 ; \quad 71.289$ - Phase line

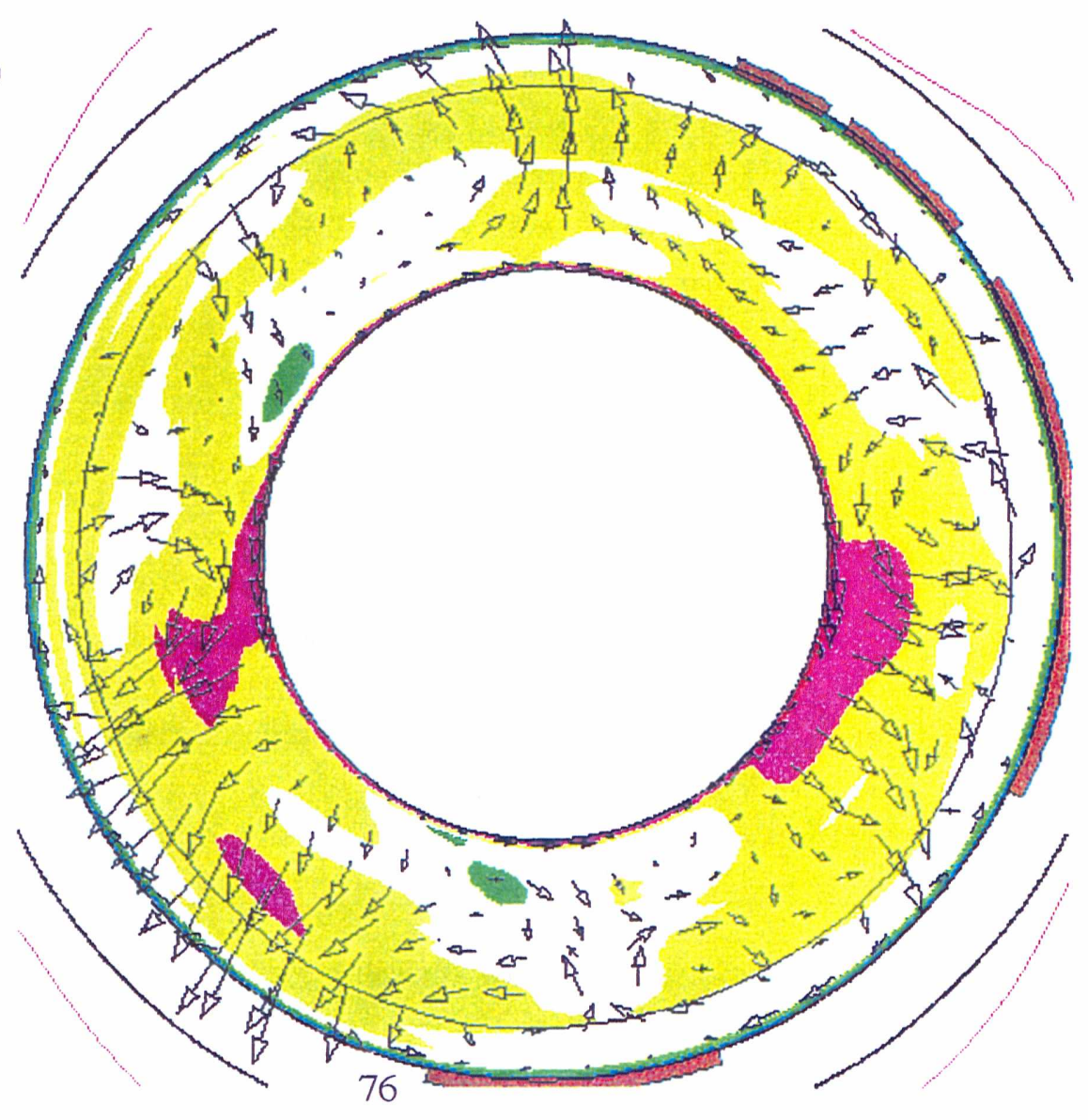


Time 50.301860 My Czoss F $=15.000^{\circ}$ ( 0.000; 0.000) Scale 1.300 Velocity (cm/y) $\rightarrow$ : $1.486 E-01$ Tempezatuze (C)
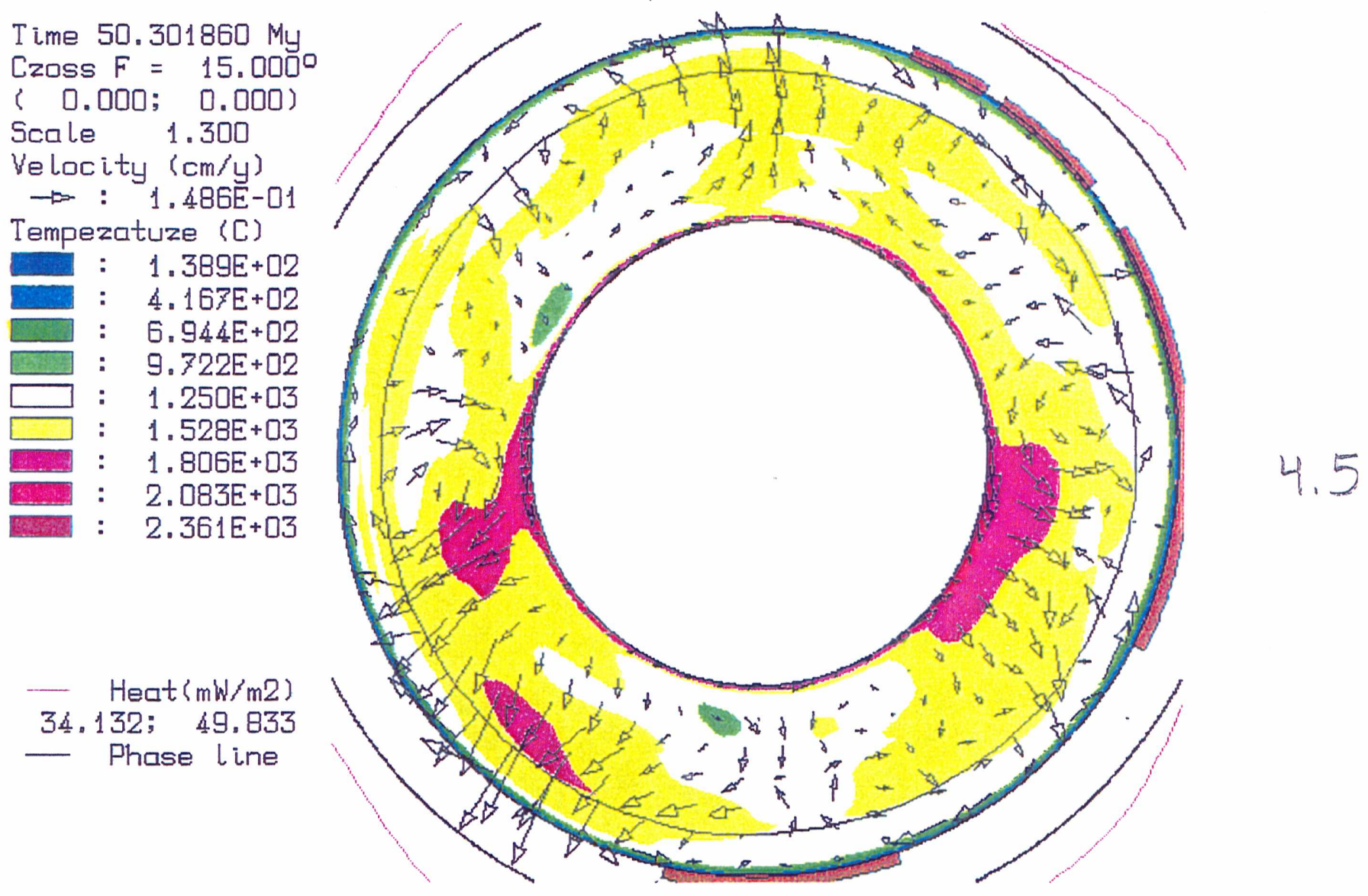

4.5

- Heat (mW/m2\}

$34.132 ; 49.833$

Phase line

Time 75.094780 My Czoss $F=15.000^{\circ}$ ( 0.000; 0.000) Scale 1.300 Velocity $(\mathrm{cm} / \mathrm{y})$ $\rightarrow$ : 5.303E-01 Tempezatuze (C)

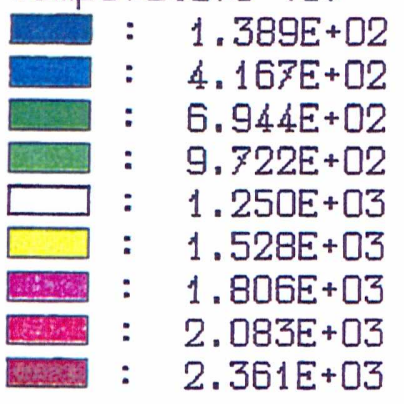

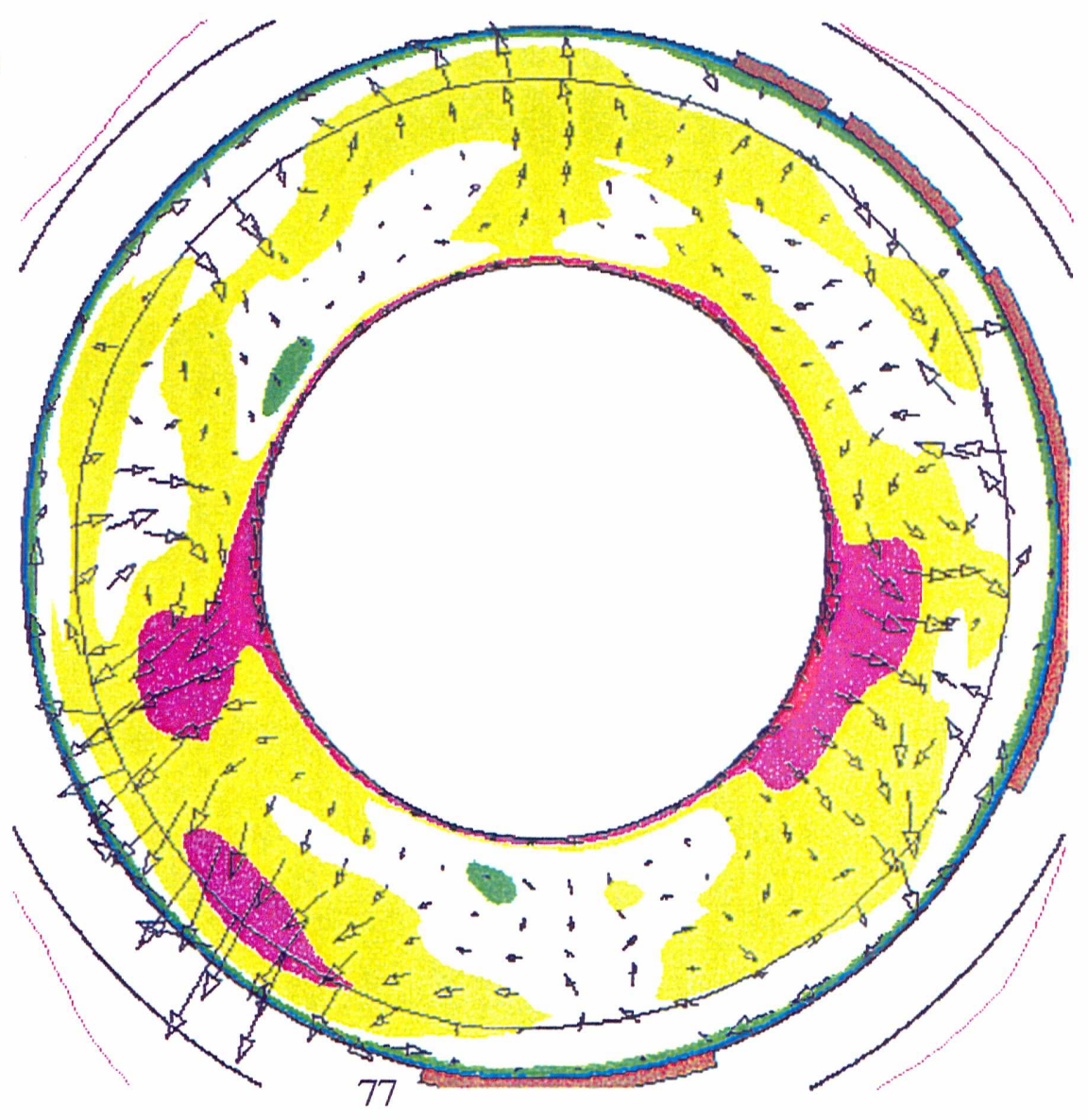
Phase line 
Time 80.091420 My

Czoss $F=15.000^{\circ}$ ( 0.000; 0.000)

Scale 1.300
Velocity $(\mathrm{cm} / \mathrm{y}\}$
$\rightarrow \rightarrow 0: 9.015 E-01$

Tempezatuze (C)

: $: 1.389 E+02$

ए $: 4.167 \mathrm{E}+02$

ए $6.944 \mathrm{E}+02$

: $\quad 9.722 \mathrm{E}+02$

$\square: 1.250 \mathrm{E}+03$

$\square: 1.528 \mathrm{E}+03$

: $: 1.806 \mathrm{E}+03$

: $: 2.083 E+03$

: $2.361 \mathrm{E}+03$

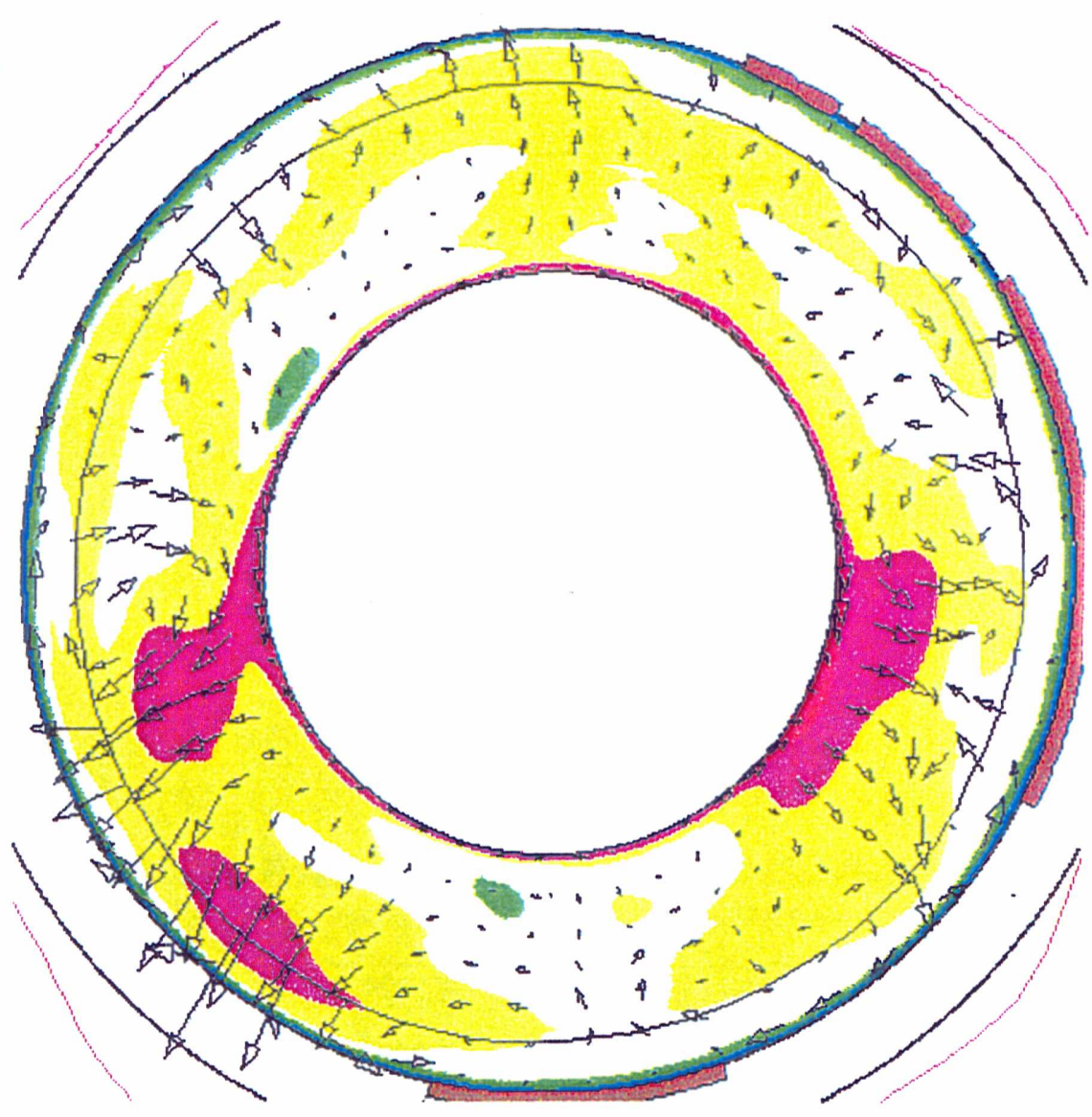

4.

- Heat $(\mathrm{m} / \mathrm{m} / \mathrm{m} 2)$

26.874; 50.682

Phase line

Time $91.342730 \mathrm{My}$

Czoss $F=15.000^{\circ}$

( 0.000; 0.000)

Scale 1.300

Velocity $(\mathrm{cm} / \mathrm{y}$ )

$\rightarrow: 2.242 \mathrm{E}+00$

Tempezatuze (C)

D: $1.389 E+02$

: $\quad 4.167 \mathrm{E}+02$

ए $\quad 6.944 E+02$

ए $\quad 9.722 \mathrm{E}+02$

$\square: 1.250 \mathrm{E}+03$

$\square: 1.528 E+03$

[1.806 : 1.806

파 $2.083 E+03$

파람 : $2.361 \mathrm{E}+03$

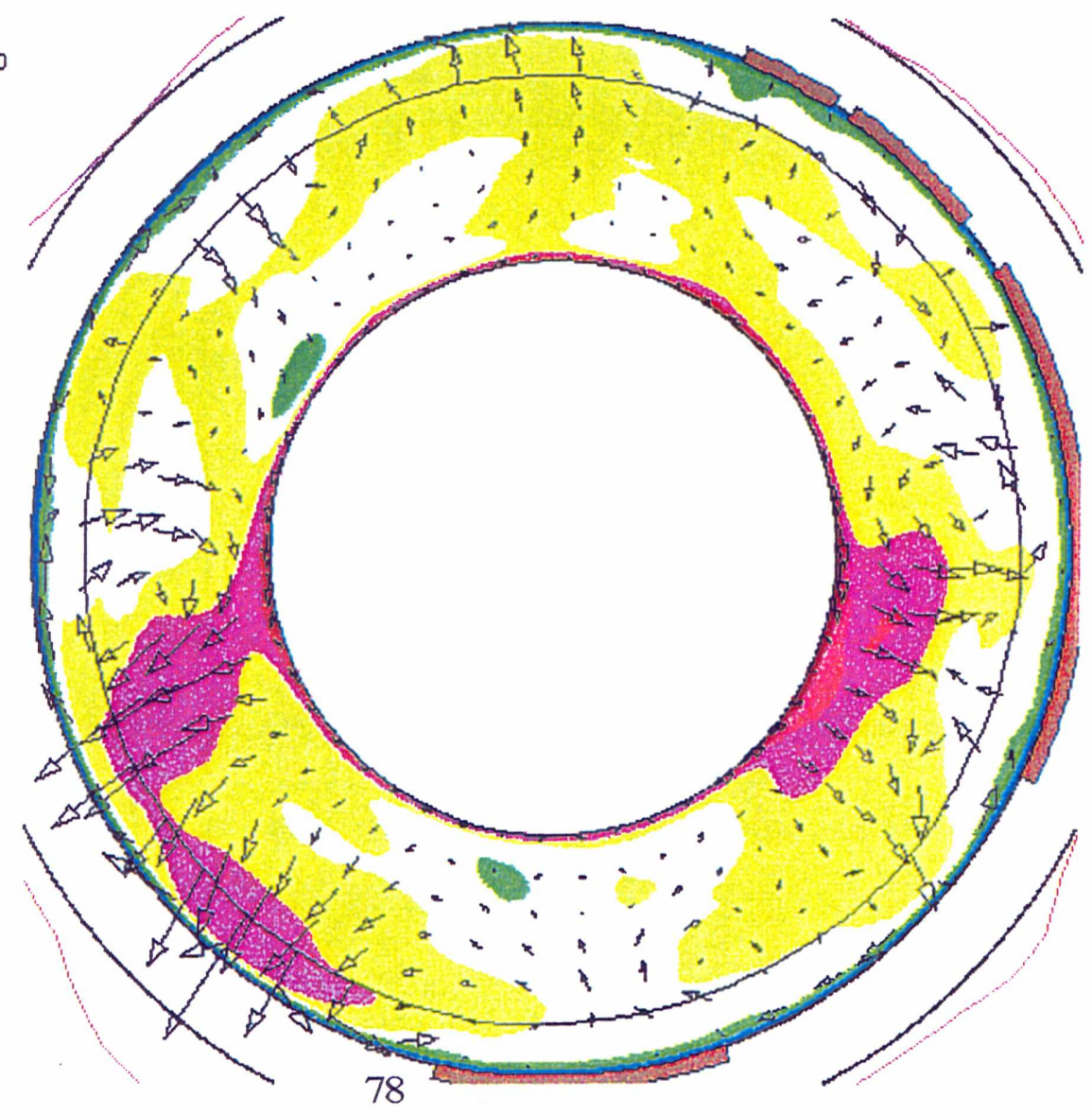

4.0

Heat $\{\mathrm{m}$ W/m2\}

24.322; 66.385

- Phase line 
Time 104.02520 My Czoss $F=15.000^{\circ}$ ( 0.000;0.000) Scale 1.300 Velocity $(\mathrm{cm} / \mathrm{l})$ $\rightarrow: 5.538 \mathrm{E}+00$ Tempezatuze (C)

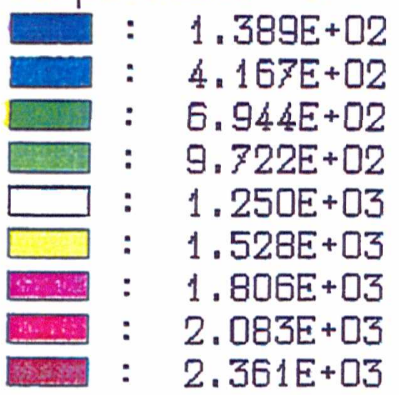

- Heat $\{\mathrm{mW} / \mathrm{m} 2\}$ 17.379; 110.023 - Phase line

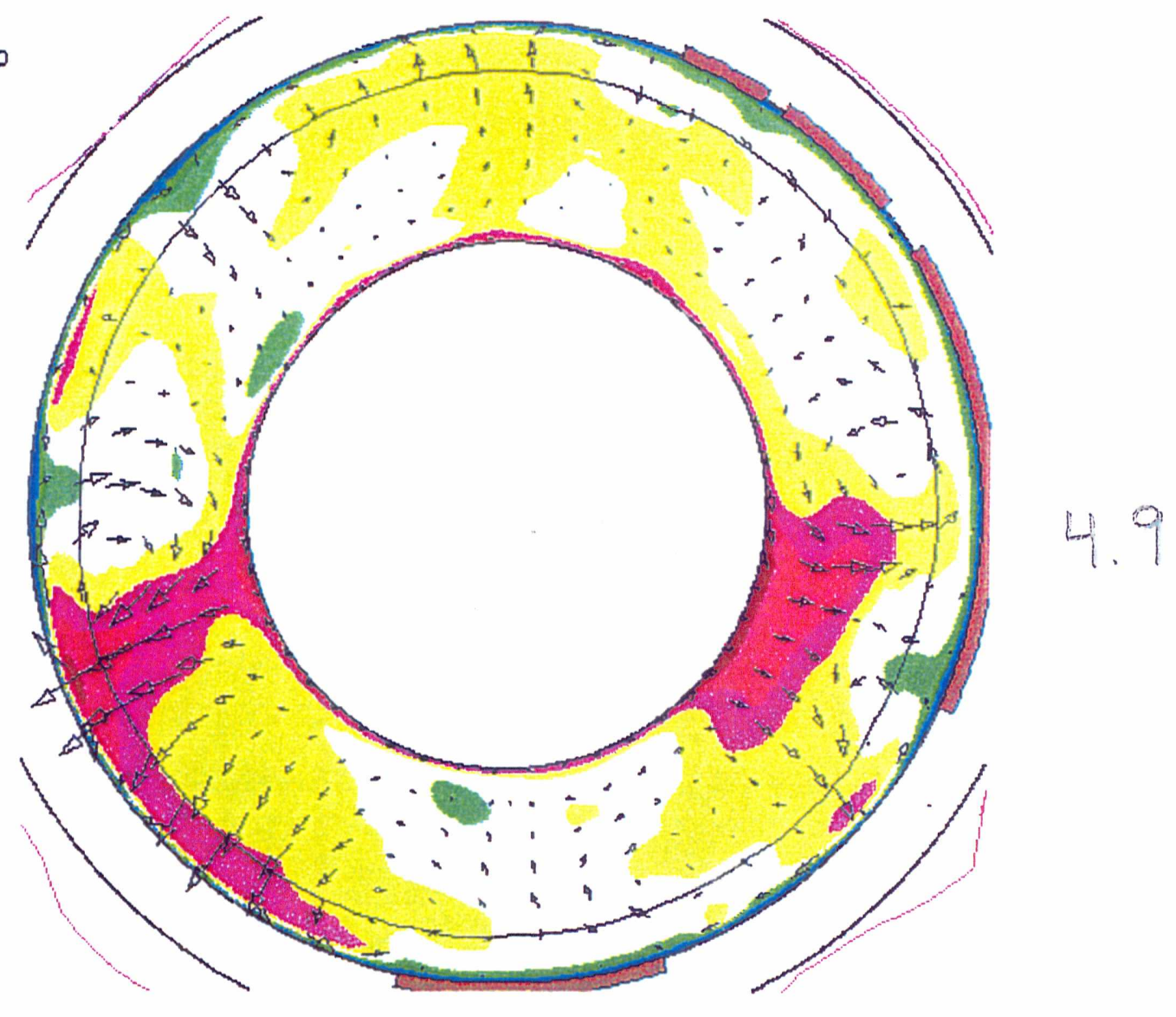
Time 106.66760 My
Czoss $F=15.000^{\circ}$ ( 0.000; 0.000) Scale 1.300 Velocity (cm/y) $\rightarrow$ : 5.524E+00 Tempezatuze (C)

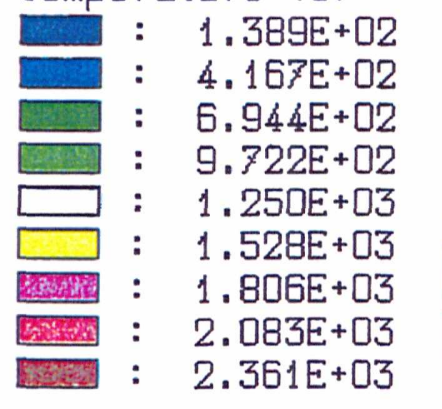

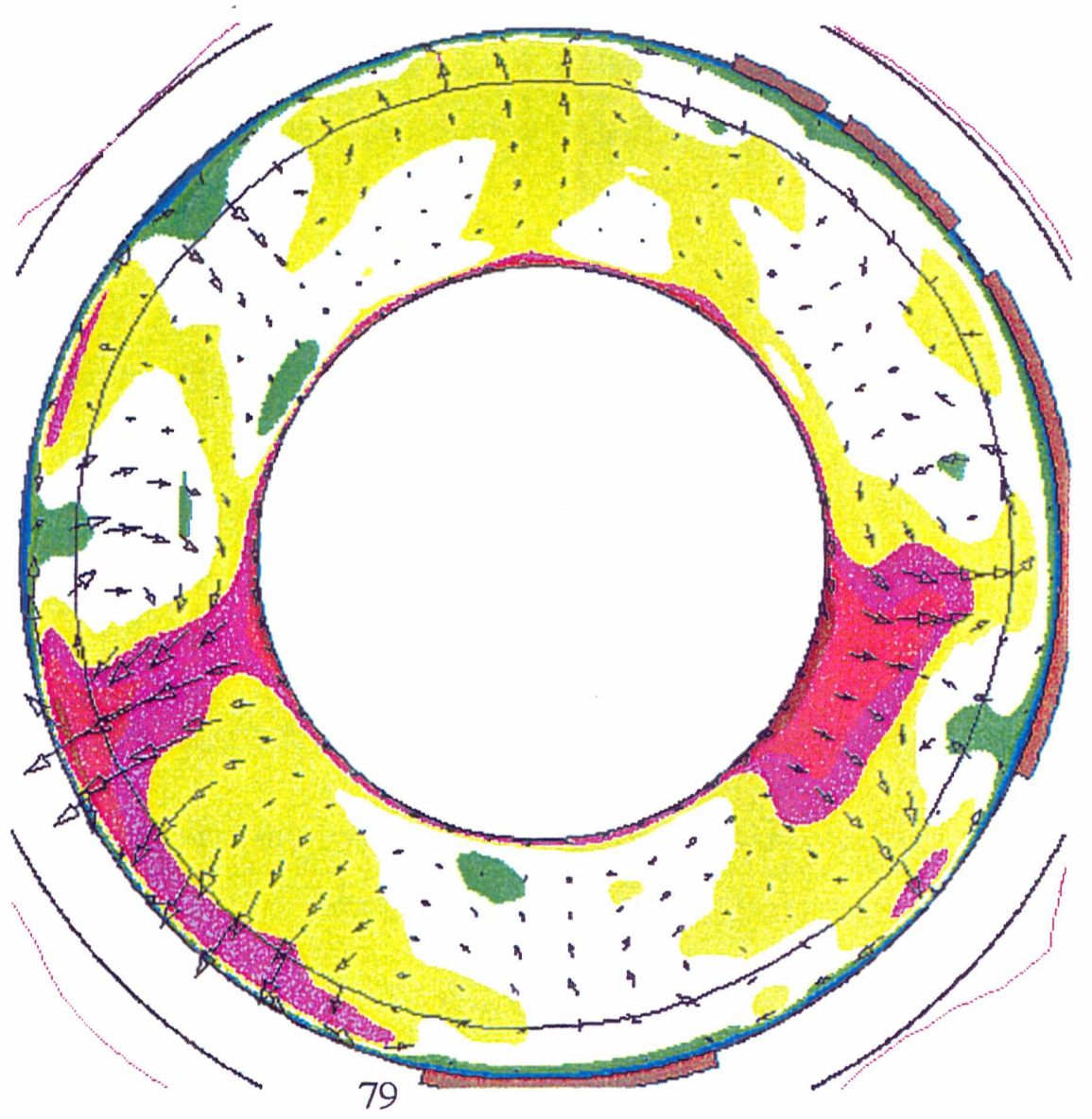

4.10

- Heat \{mw/m2\} 16.076; 127.930 - Phase line 
Time 109.30970 My Czoss $F=15.000^{\circ}$ ( 0.000; 0.000) Scale 1.300 Velocity $(\mathrm{cm} / \mathrm{y})$ $\rightarrow$ : $5.503 \mathrm{E}+00$ Tempezatuze (C)

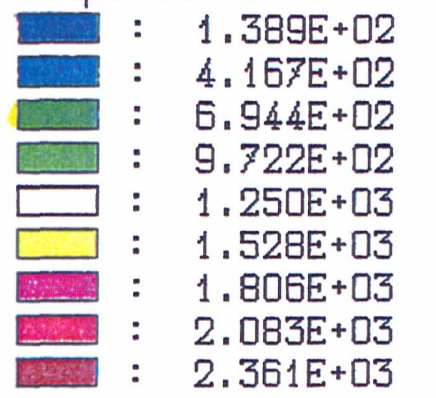

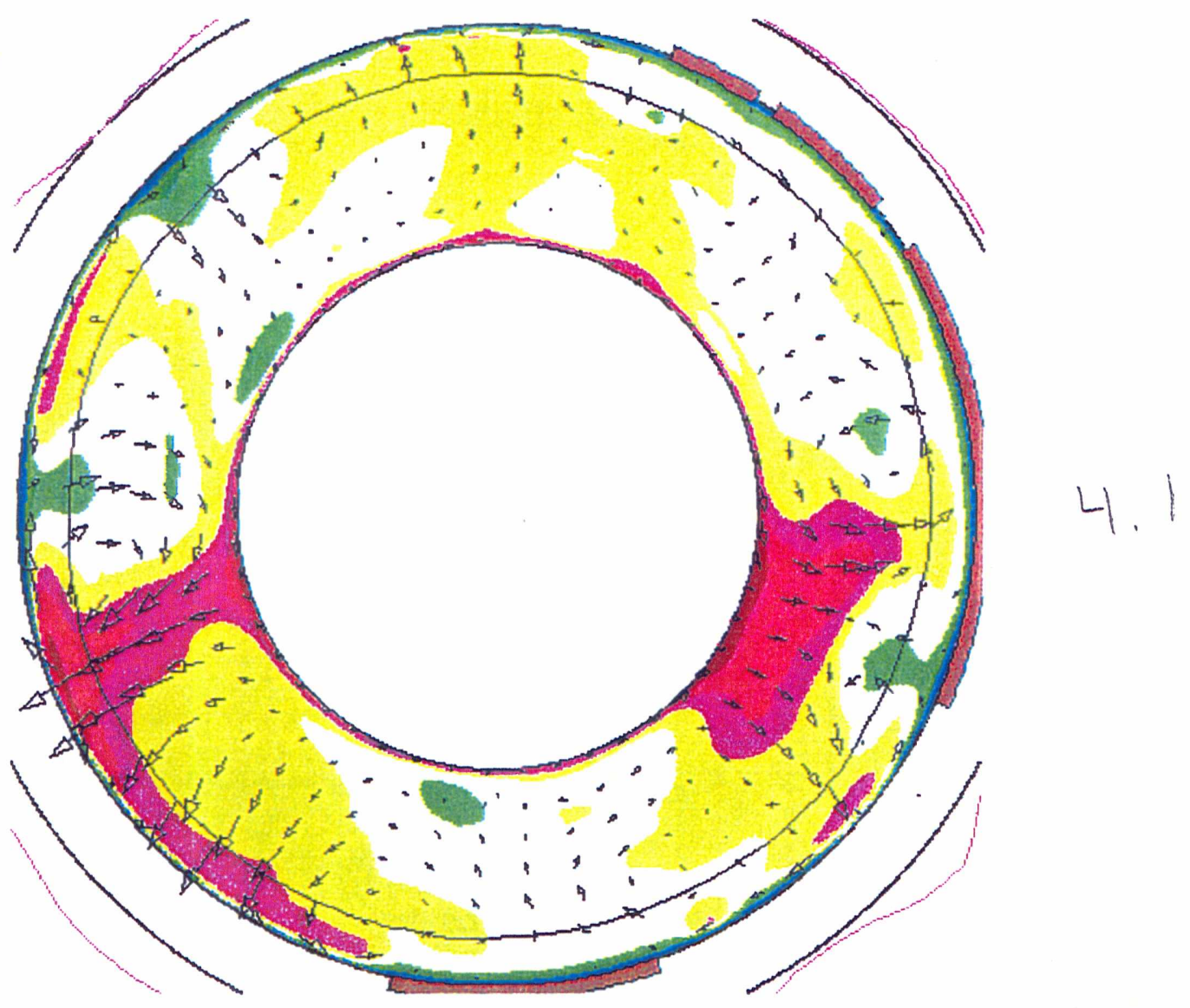

Time $111.89160 \mathrm{ML}$ Czoss $F=15.000^{\circ}$ ( 0.000;0.000) Scale 1.300 Velocity $(\mathrm{cm} / \mathrm{y})$ $\rightarrow$ : 6., 701E+00 Tempezatuze (C)
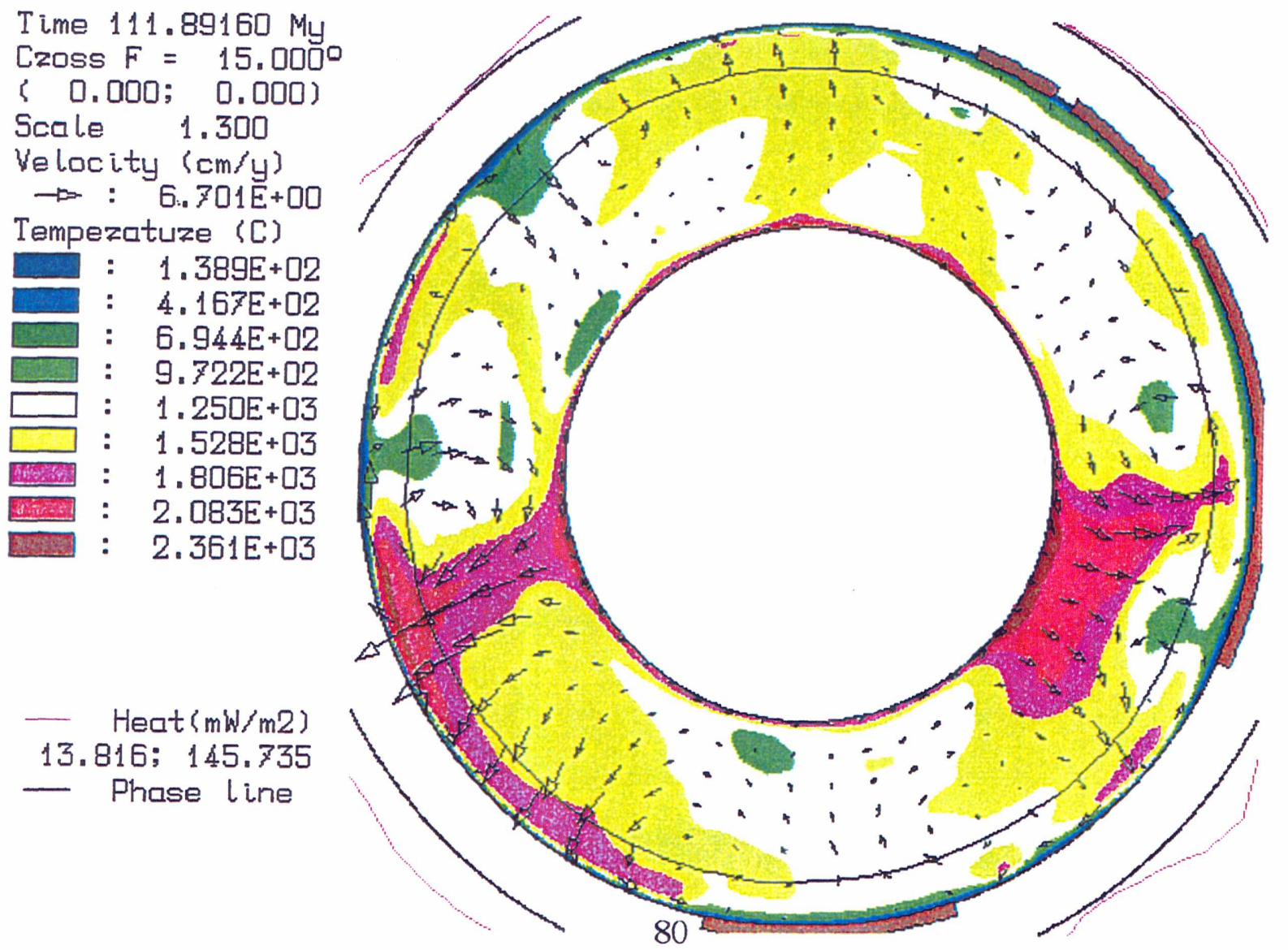

4.12

- Heat (mW/m2)

13.816; 145.735 - Phase line 
Time $117.05330 \mathrm{ML}$ Czoss $F=15.000^{\circ}$ ( 0.000; 0.000) Scale 1.300 Velocity $(\mathrm{cm} / \mathrm{y}$ ) $\rightarrow: \quad 9.082 \mathrm{E}+00$ Tempezatuze (C)

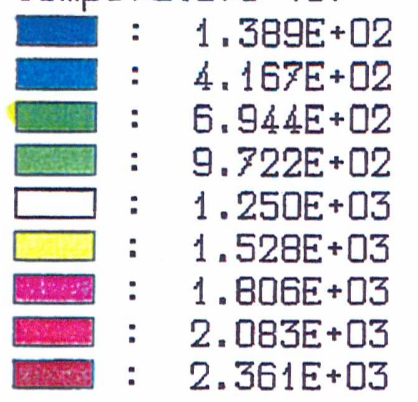

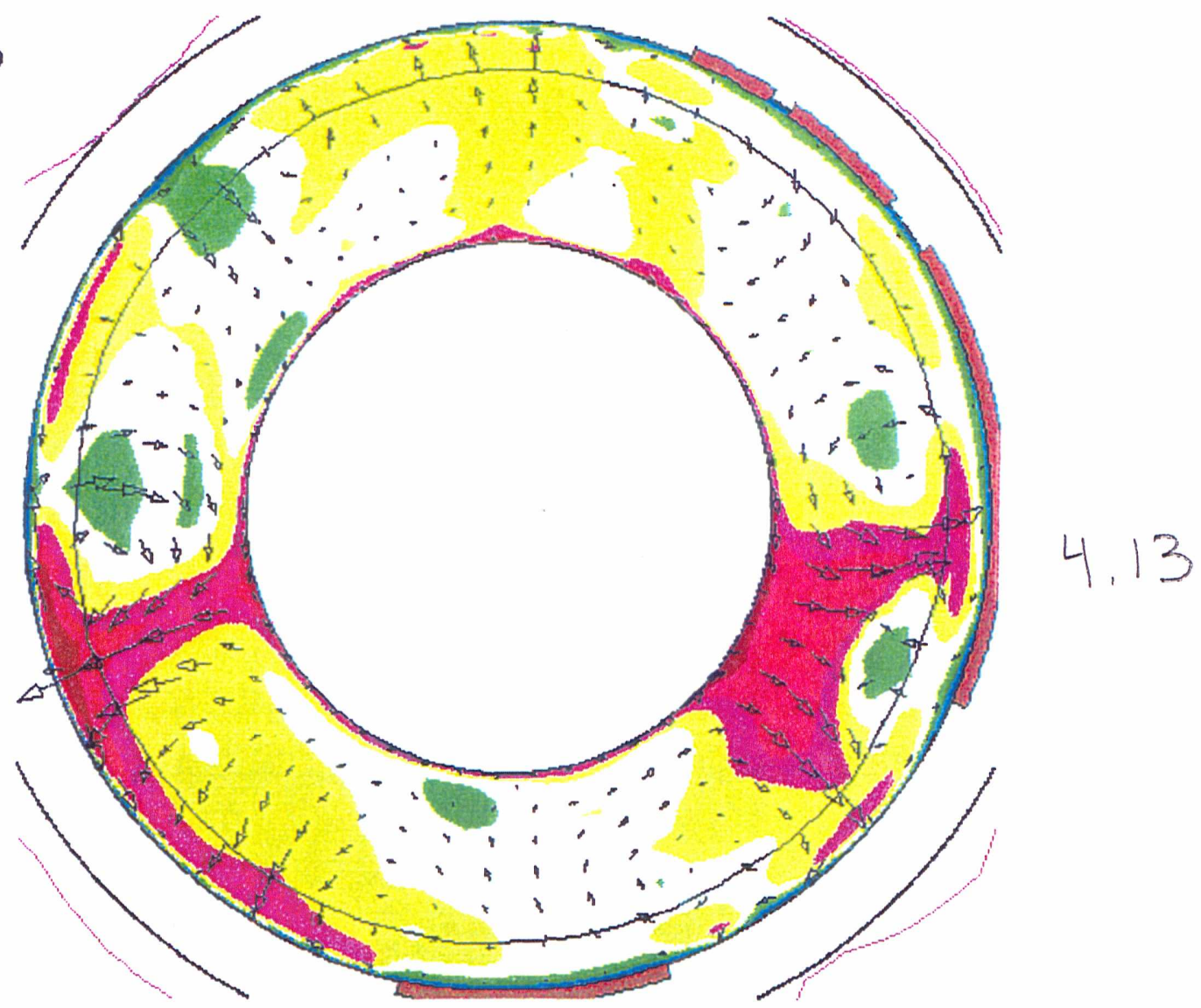

Time $122.24300 \mathrm{My}$ Czoss $F=15.000^{\circ}$ ( 0.000; 0.000) Scale 1.300 Velocity $(\mathrm{cm} / \mathrm{y})$ $\rightarrow$ : 9.939E+00 Tempezatuze (C)

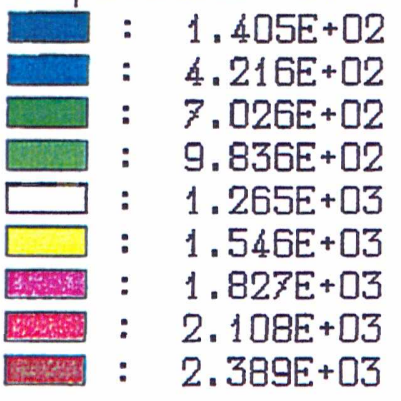

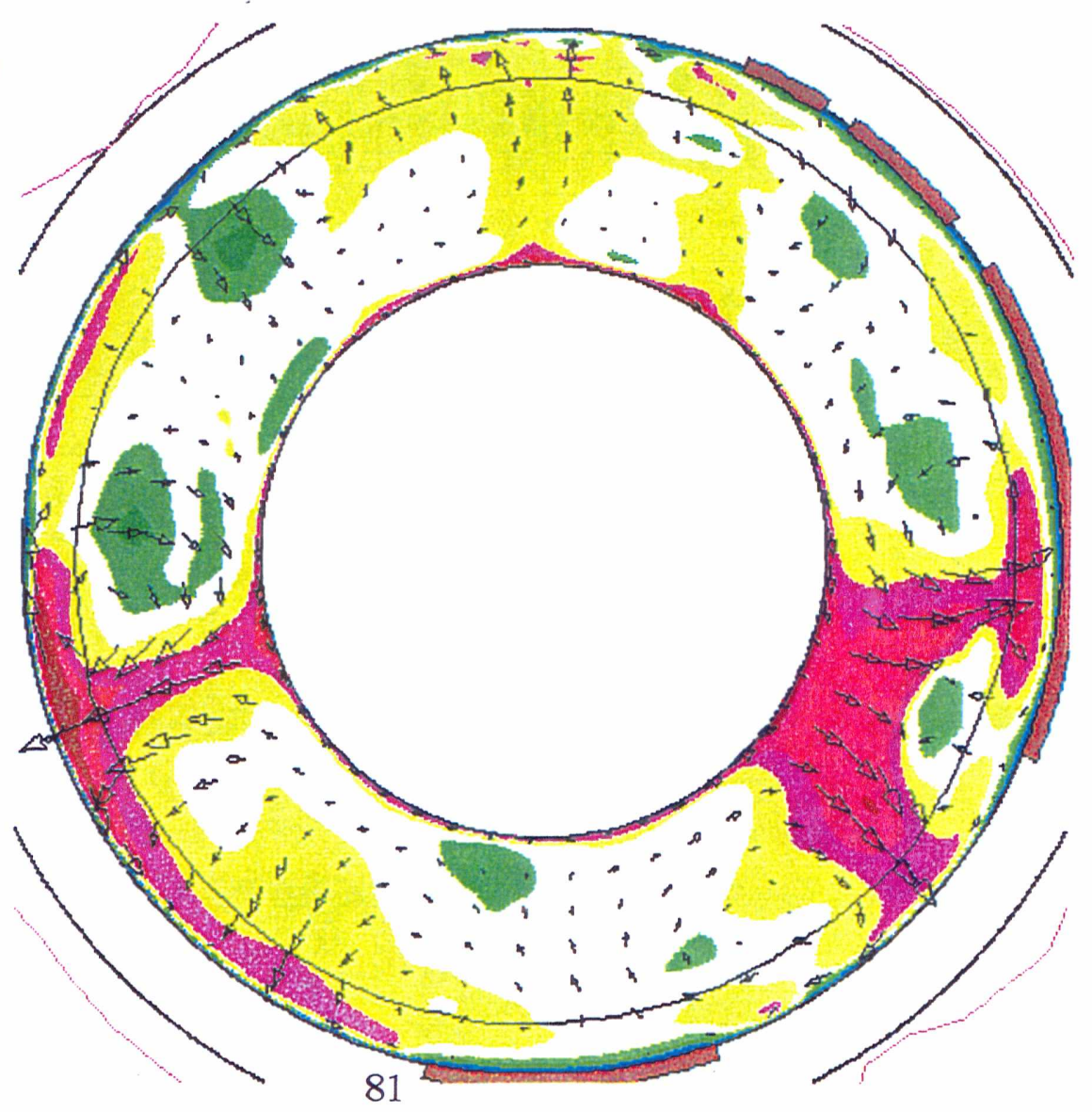

4.14

- Heat (mW/m2)

$12.091 ; 163.335$

- Phase line 
Time $127.43360 \mathrm{My}$ Czoss $F=15.000^{\circ}$ ( 0.000; 0.000) Scale 1.300 Velocity $(\mathrm{cm} / \mathrm{y})$ $\rightarrow: 1.096 \mathrm{E}+01$ Tempezatuze (C)

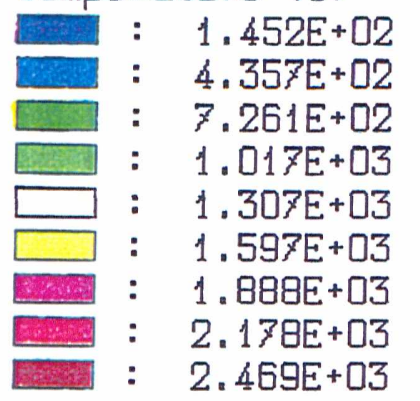

- Heat $(\mathrm{mW} / \mathrm{m} 2)$ $18.770 ; 174.693$ Phase Line

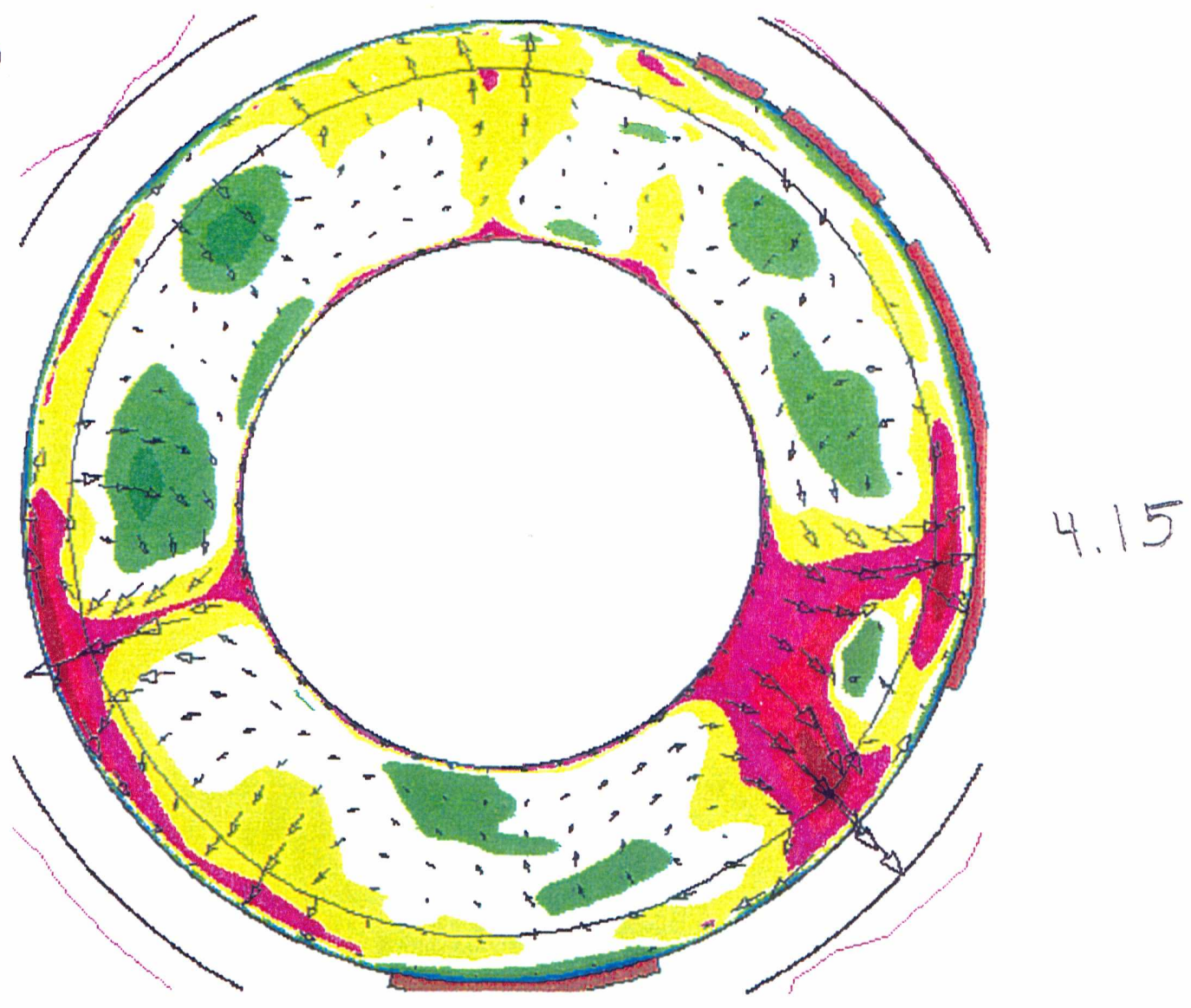

Time $132.68100 \mathrm{My}$ Czoss $F=15.000^{\circ}$ ( 0.000; 0.000) Scale 1.300 Velocity $(\mathrm{cm} / \mathrm{y})$ $\rightarrow \infty$ : 1:086E+01 Tempezatuze (C)
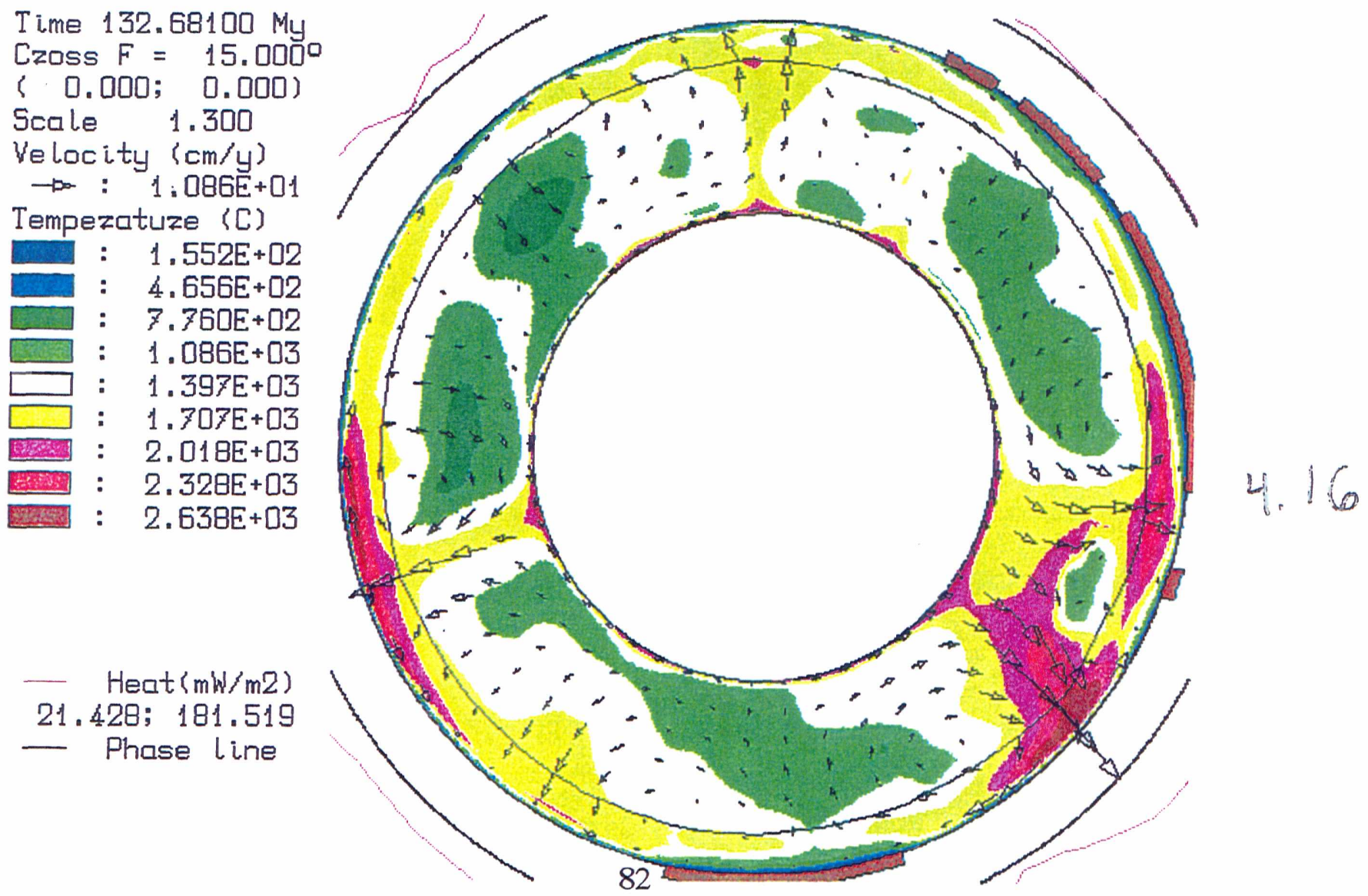

21. Heat (mW/m2) Phase line 
Time $137.81270 \mathrm{My}$ Czoss F $=15.000^{\circ}$ ( 0.000; 0.000) Scale 1.300 Velocity (cm/y) $\rightarrow$ : $1.369 E+01$ Tempezatuze (C)
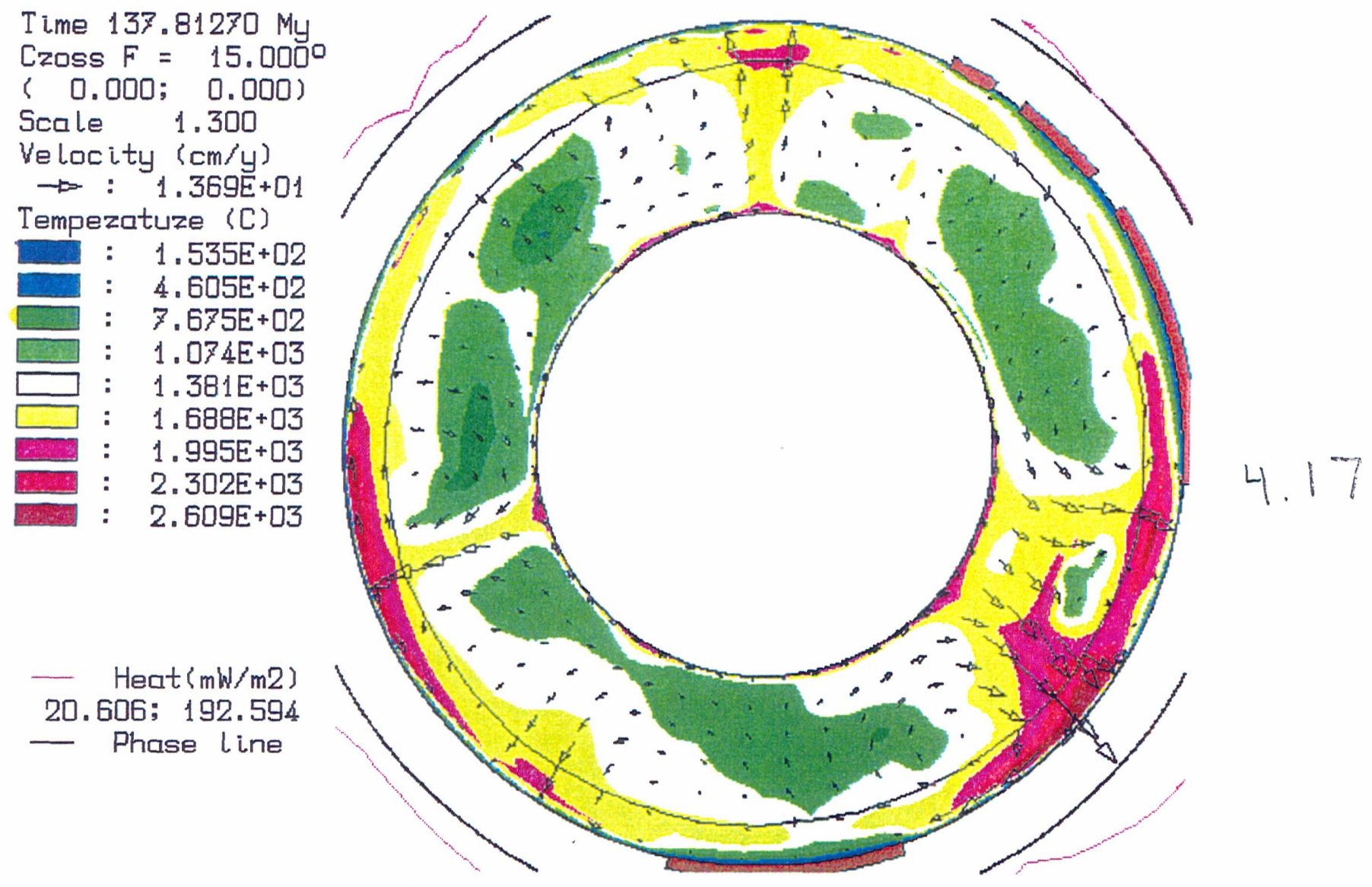

20. Heat ( $\mathrm{mW} / \mathrm{m} 2)$ Phase line

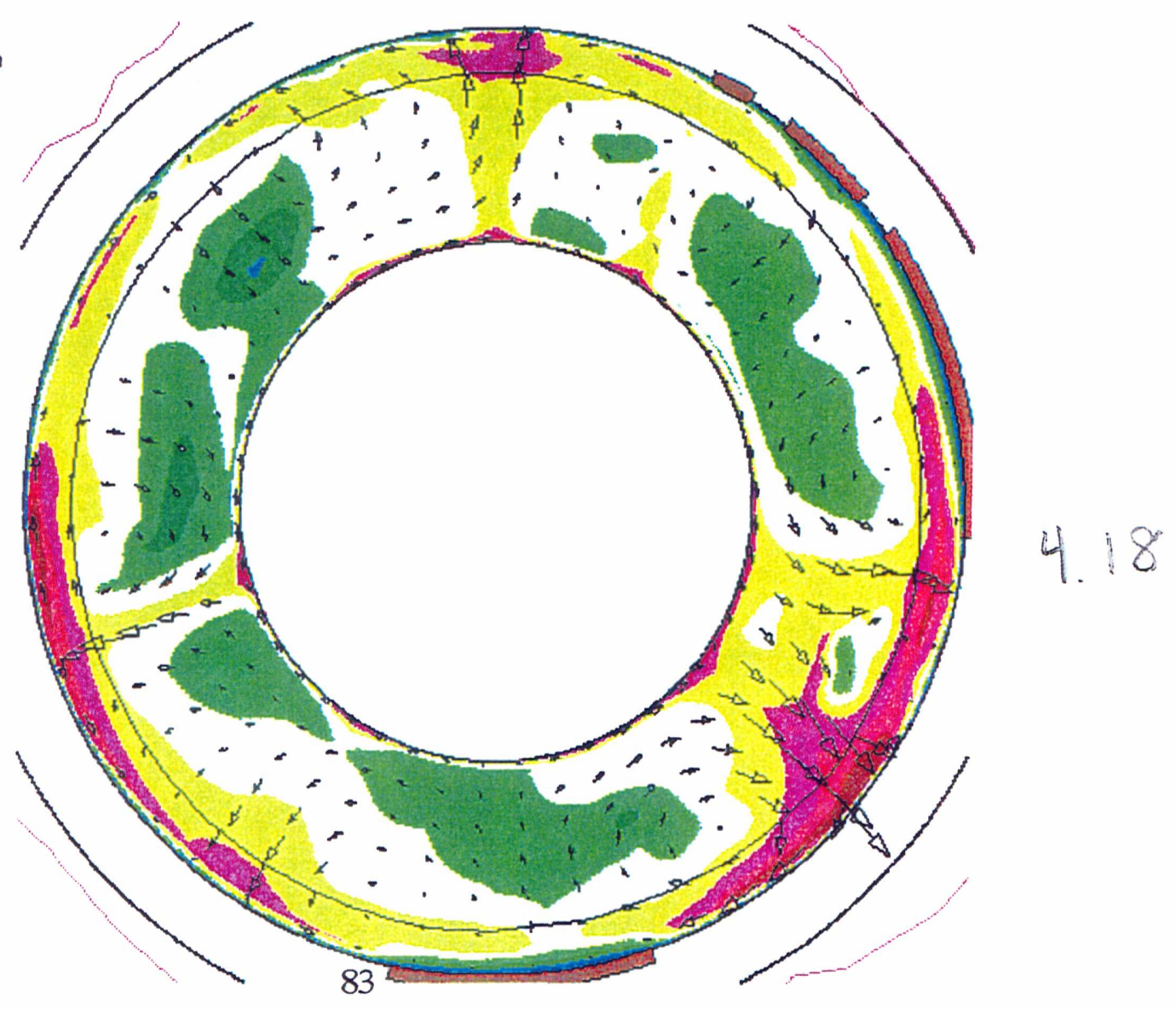
Time $140.46100 \mathrm{My}$
Czoss F $=15.0000$ ( 0.000; 0.000) Scale 1.300 Velocity $(\mathrm{cm} / \mathrm{y}$ ) $\rightarrow: \quad 1.209 E+01$ Tempezatuze (C)

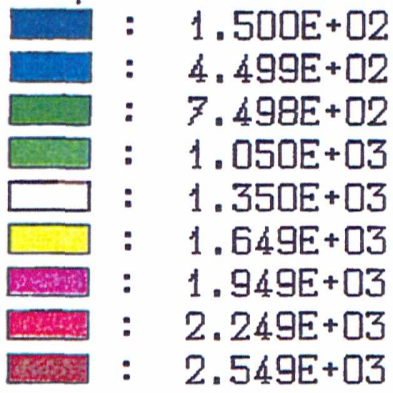

- Heat $\{\mathrm{m} / \mathrm{m} / \mathrm{m} 2\}$ 20.330; 194.708 - Phase line 
Time 145.63190 My

Czoss $F=15.000^{\circ}$ ( 0.000; 0.000) Scale 1.300 Velocity (cm/y) $\rightarrow: 1.148 \mathrm{E}+01$ Tempezatuze (C)

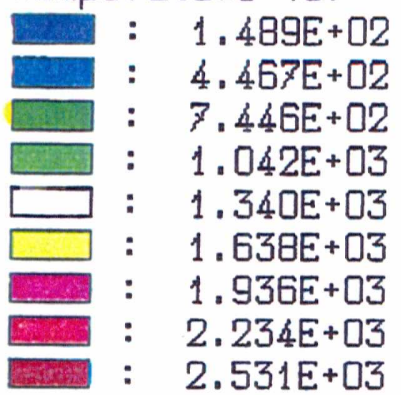

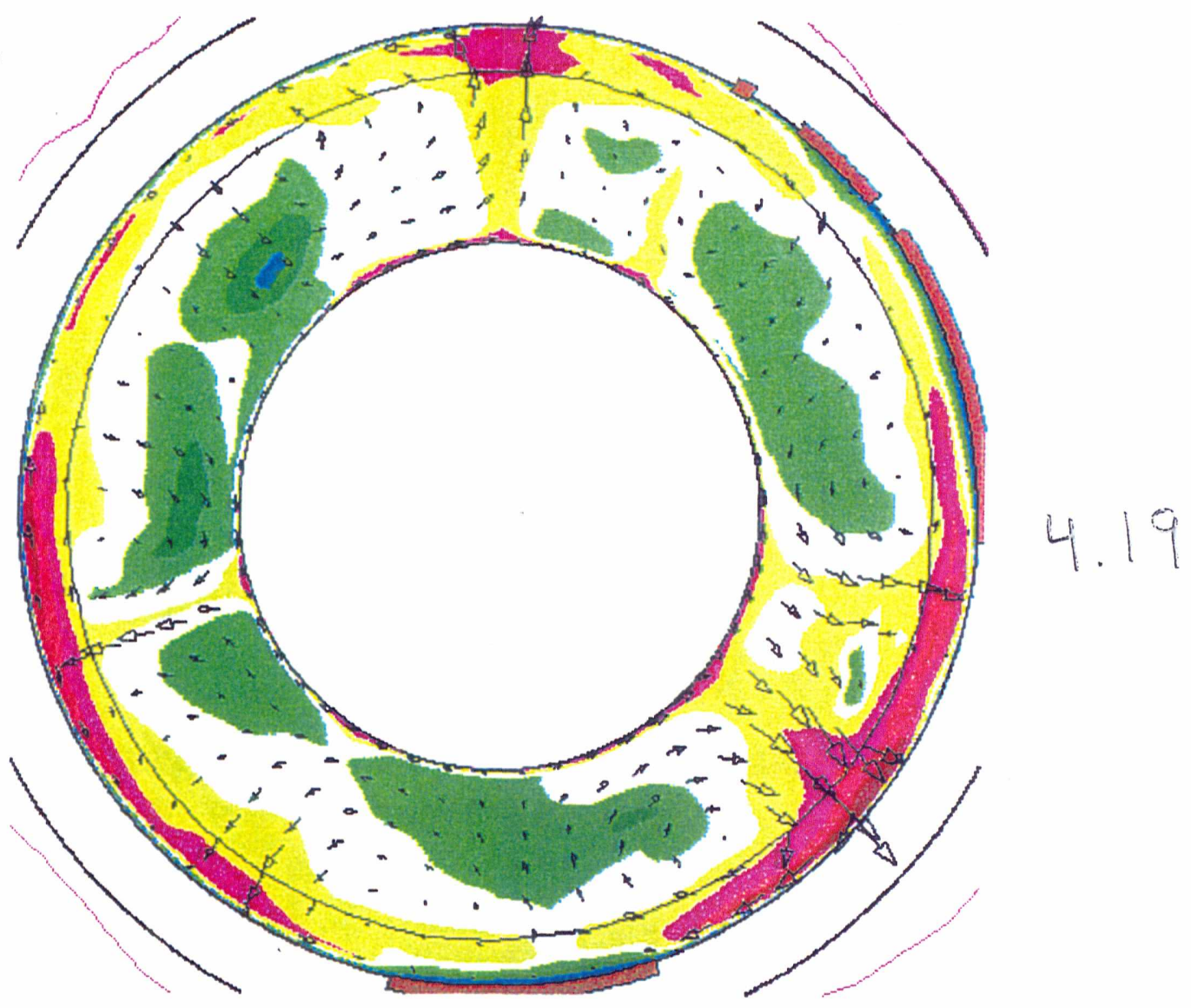

Time 150.82390 My Czoss $F=15.000^{\circ}$ ( 0.000; 0.000) Scale 1.300 Velocity (cm/y) $\rightarrow: 1: 018 \mathrm{E}+01$ Tempezatuze (C)
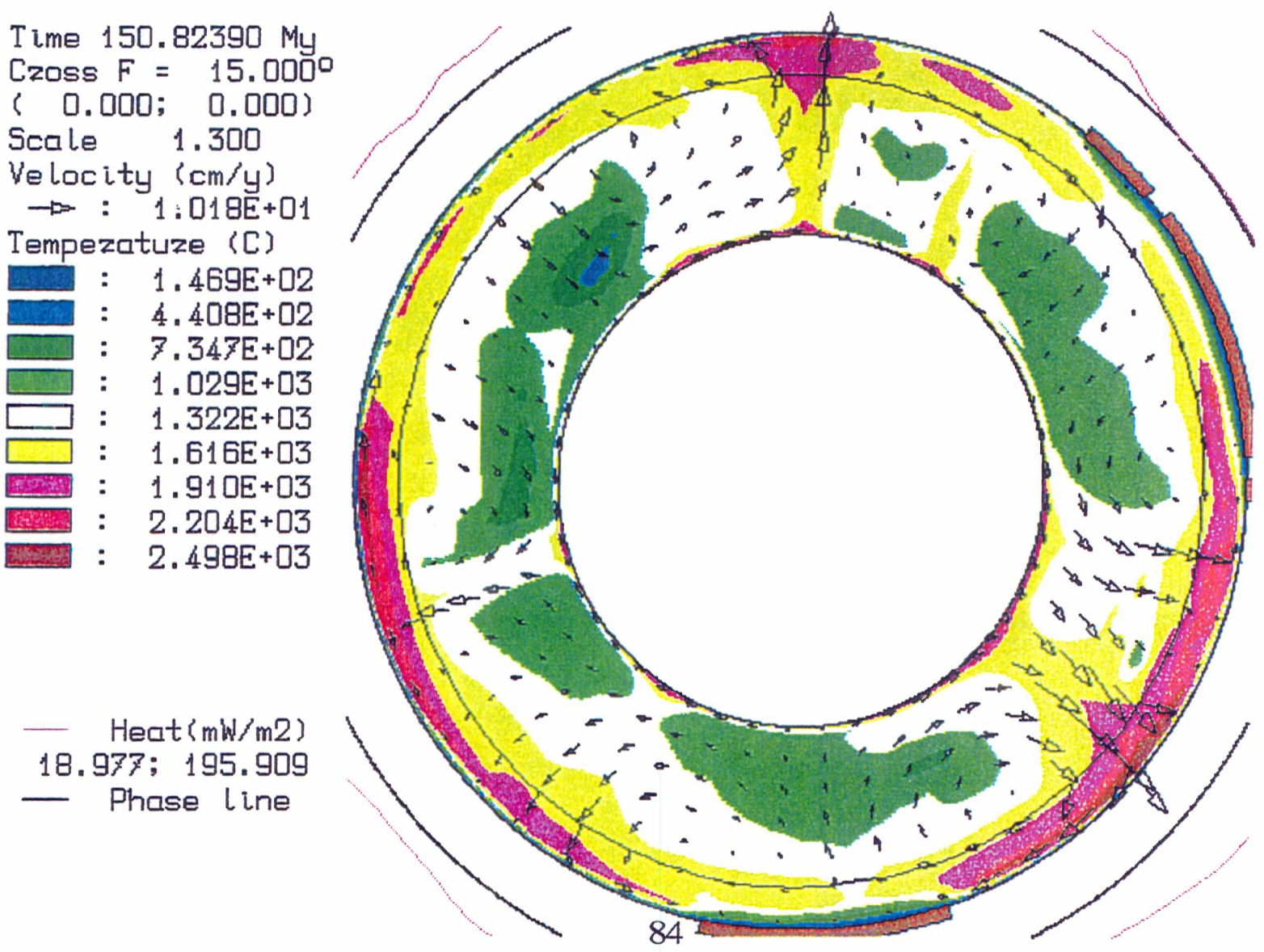

- Heat (mW/m2) 18.977; 195.909 - Phase line 
Time $156.06720 \mathrm{My}$ Czoss $F=15.000^{\circ}$ ( 0.000; 0.000) Scale 1.300 Velocity $(\mathrm{cm} / \mathrm{y})$ $\rightarrow: 8.822 \mathrm{E}+00$ Tempezatuze (C)

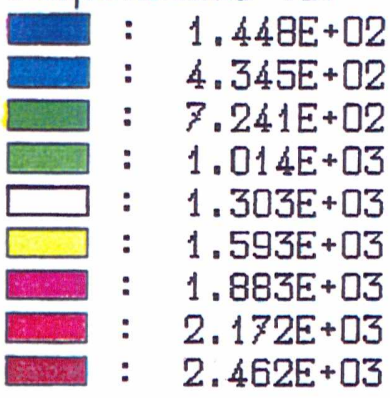

- Heat $(\mathrm{m} W / \mathrm{m} 2\}$ 17.105; 189. 305 Phase line

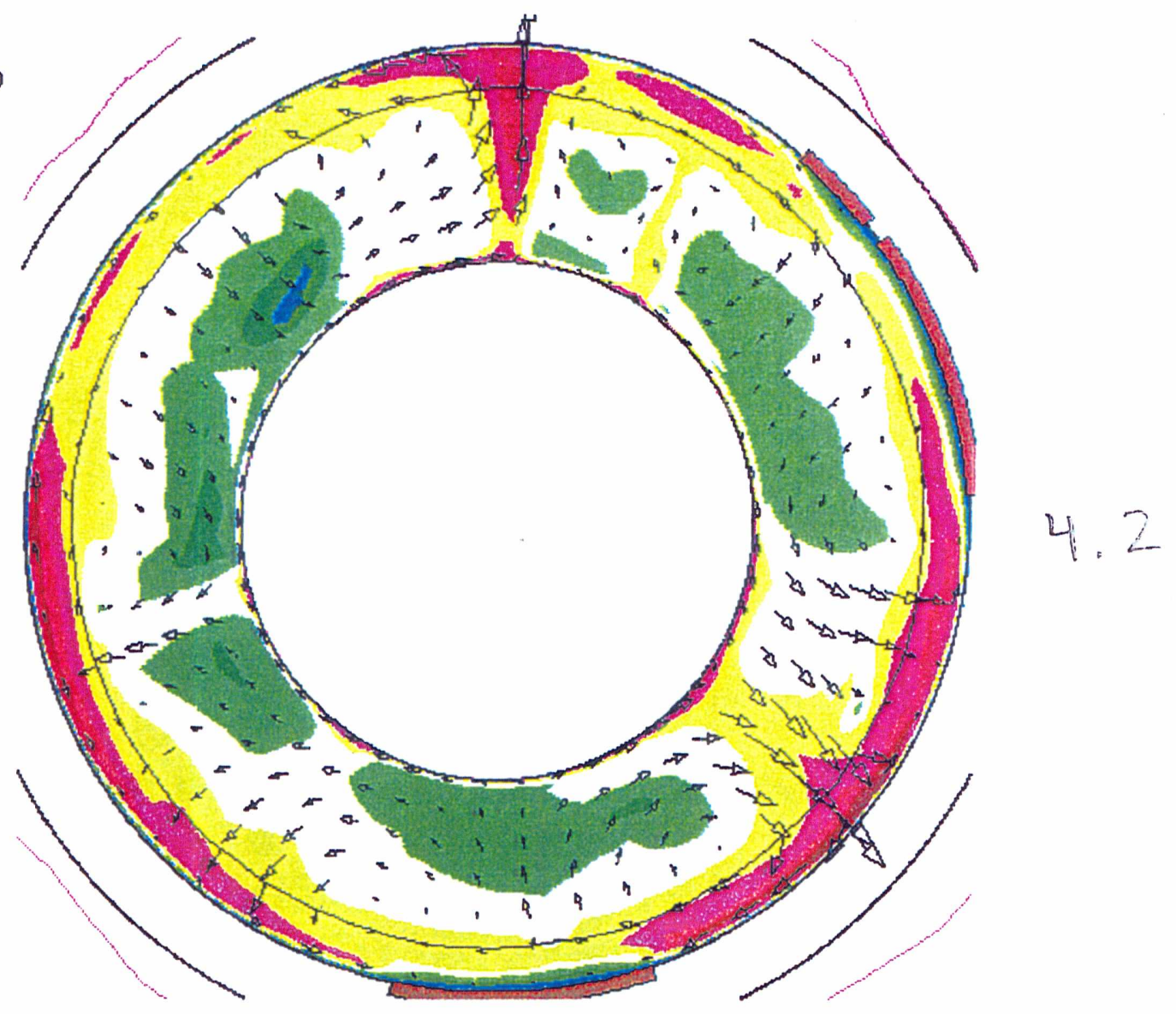

Time $161.28850 \mathrm{My}$ Czoss $F=15.000^{\circ}$ ( 0.000;0.000) Scale 1.300 Velocity $(\mathrm{cm} / \mathrm{y})$ $\rightarrow: 1: 046 \mathrm{E}+01$ Tempezatuze (C) $: 1.544 \mathrm{E}+02$
$: \quad 4.633 \mathrm{E}+02$
$: \quad 7.722 \mathrm{E}+02$
$: 1.081 \mathrm{E}+03$
$: 1.390 \mathrm{E}+03$
$: 1.699 \mathrm{E}+03$
$: 2.008 \mathrm{E}+03$
$: 2.317 \mathrm{E}+03$
$: 2.626 \mathrm{E}+03$

- Heat \{mi/m2\} 15.310; 181.975 - Phase line

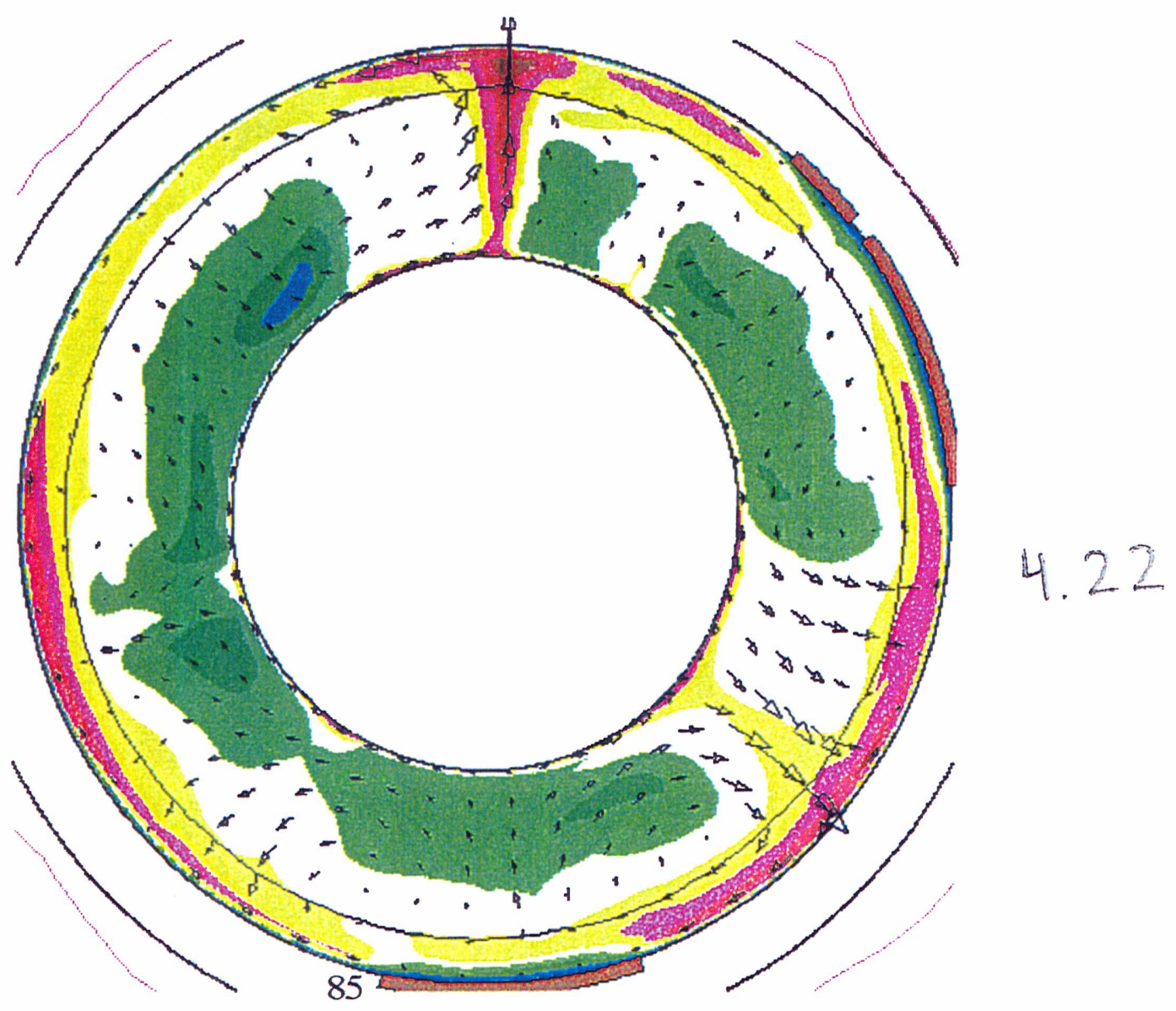


Time $166.44470 \mathrm{My}$ Czoss $F=15.000^{\circ}$ ( 0.000; 0.000) Scale 1.300 Velocity $(\mathrm{cm} / \mathrm{y}$ ) $\rightarrow: 9.372 \mathrm{E}+00$ Tempezatuze (C)

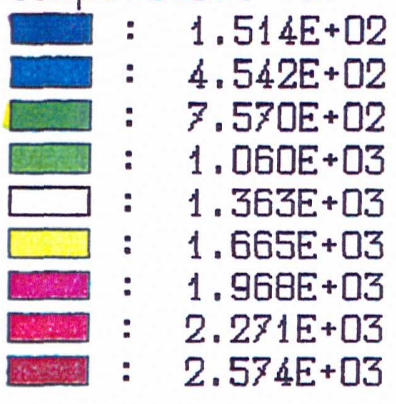

- Heat (mW/m2) 14.244; 199.821 Phase line
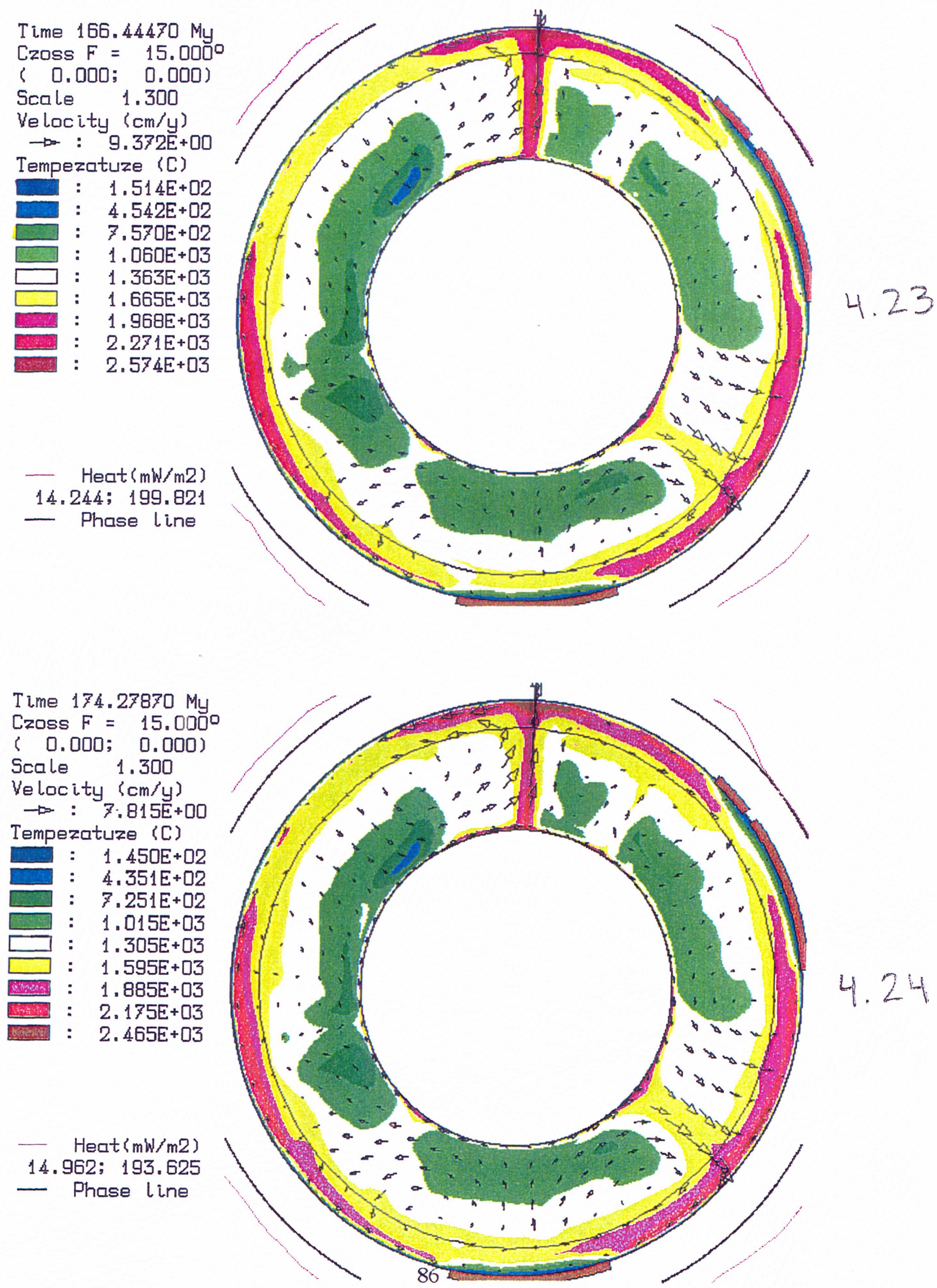

4.24

- Heat \{mil/m2\} 14.962; 193.625 - Phase line 
Time $179.52820 \mathrm{My}$ Czoss $F=15.000^{\circ}$ ( 0.000; 0.000) Scale 1.300 Velocity $(\mathrm{cm} / \mathrm{y})$ $\rightarrow$ : $6.516 \mathrm{E}+00$ Tempezatuze (C)

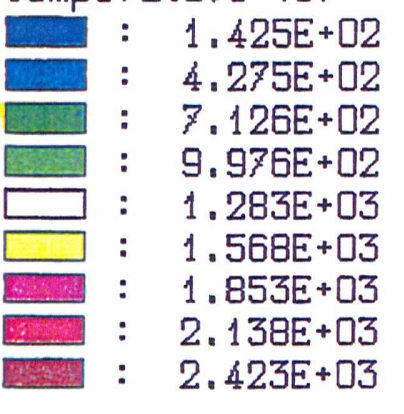

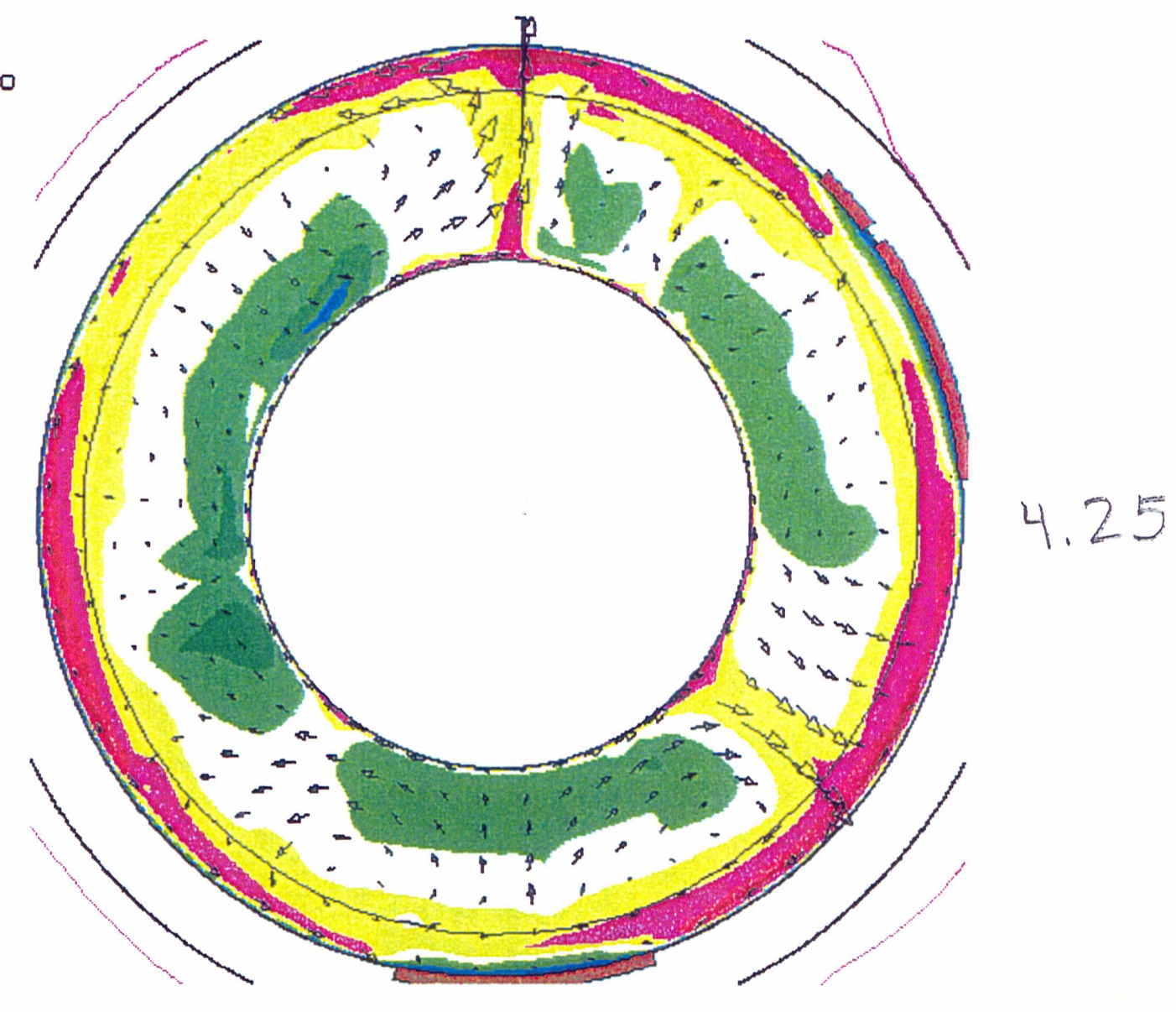

16.072; 186.677 - Phase Line Time $184.61600 \mathrm{My}$
Czoss $F=15.0000$ ( 0.000; 0.000) Scale 1.300 Velocity $\{\mathrm{cm} / \mathrm{y}\}$ $\rightarrow: 5.647 \mathrm{E}+00$ Tempezatuze (C)

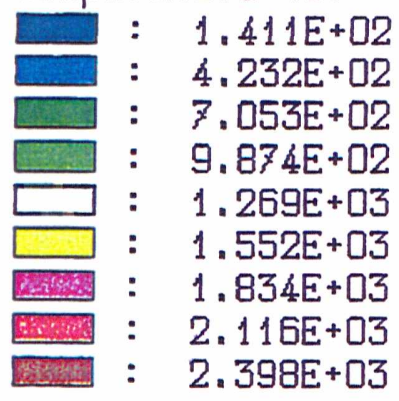

- Heat (mW/m2) 14.987; 185. 406 - Phase line

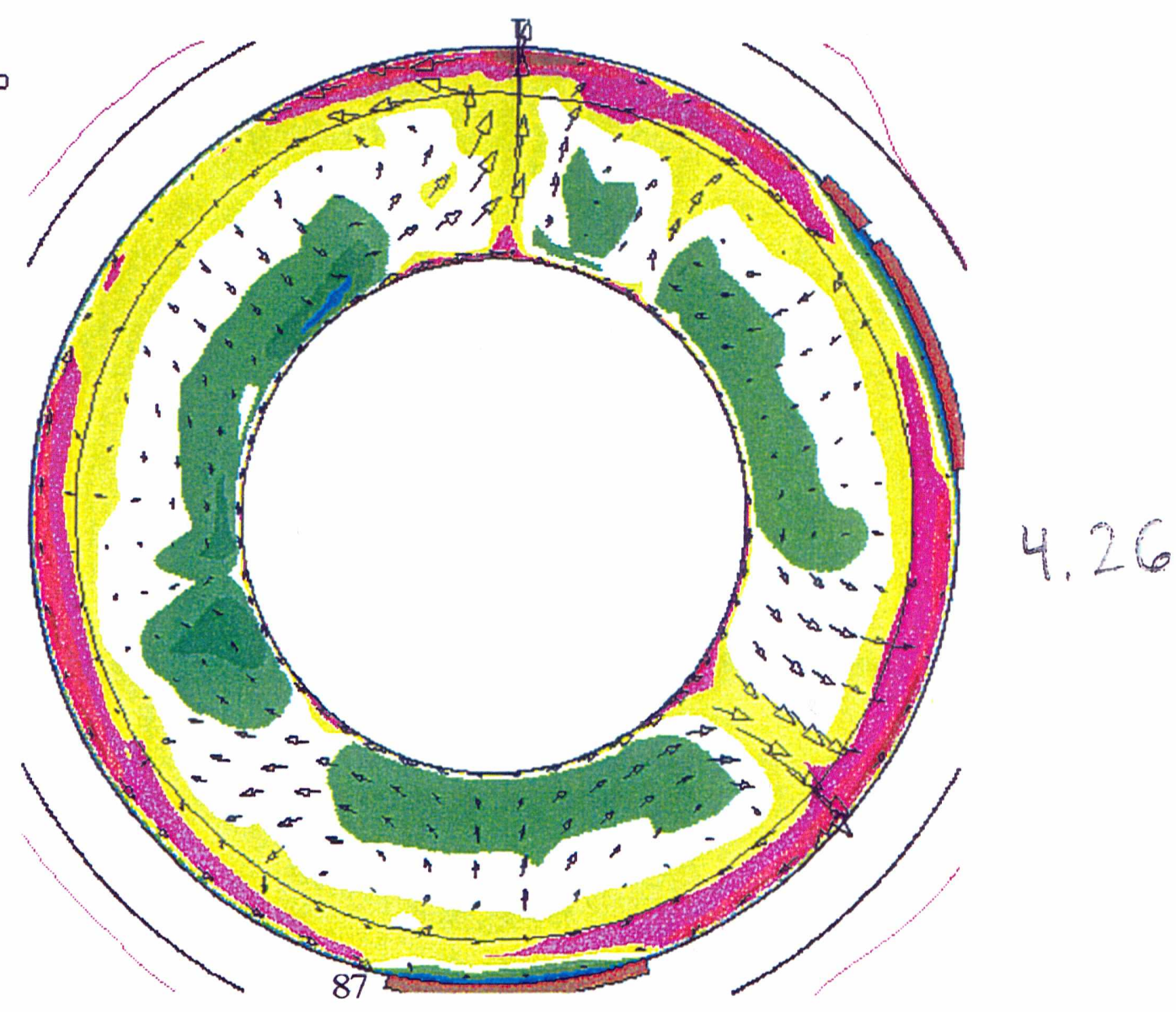


Time $189.90310 \mathrm{ML}$ Czoss $F=15.000^{\circ}$ ( 0.000; 0.000) Scale 1.300 Velocity $(\mathrm{cm} / \mathrm{y})$ $\rightarrow: 4.899 \mathrm{E}+00$ Tempezatuze (C)

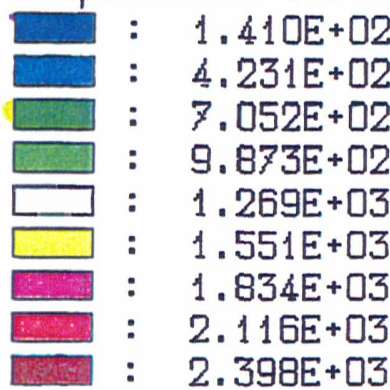

Heat $(\mathrm{m} / \mathrm{m} / \mathrm{m} 2)$ 13. $811 ; 185.404$ Phase line
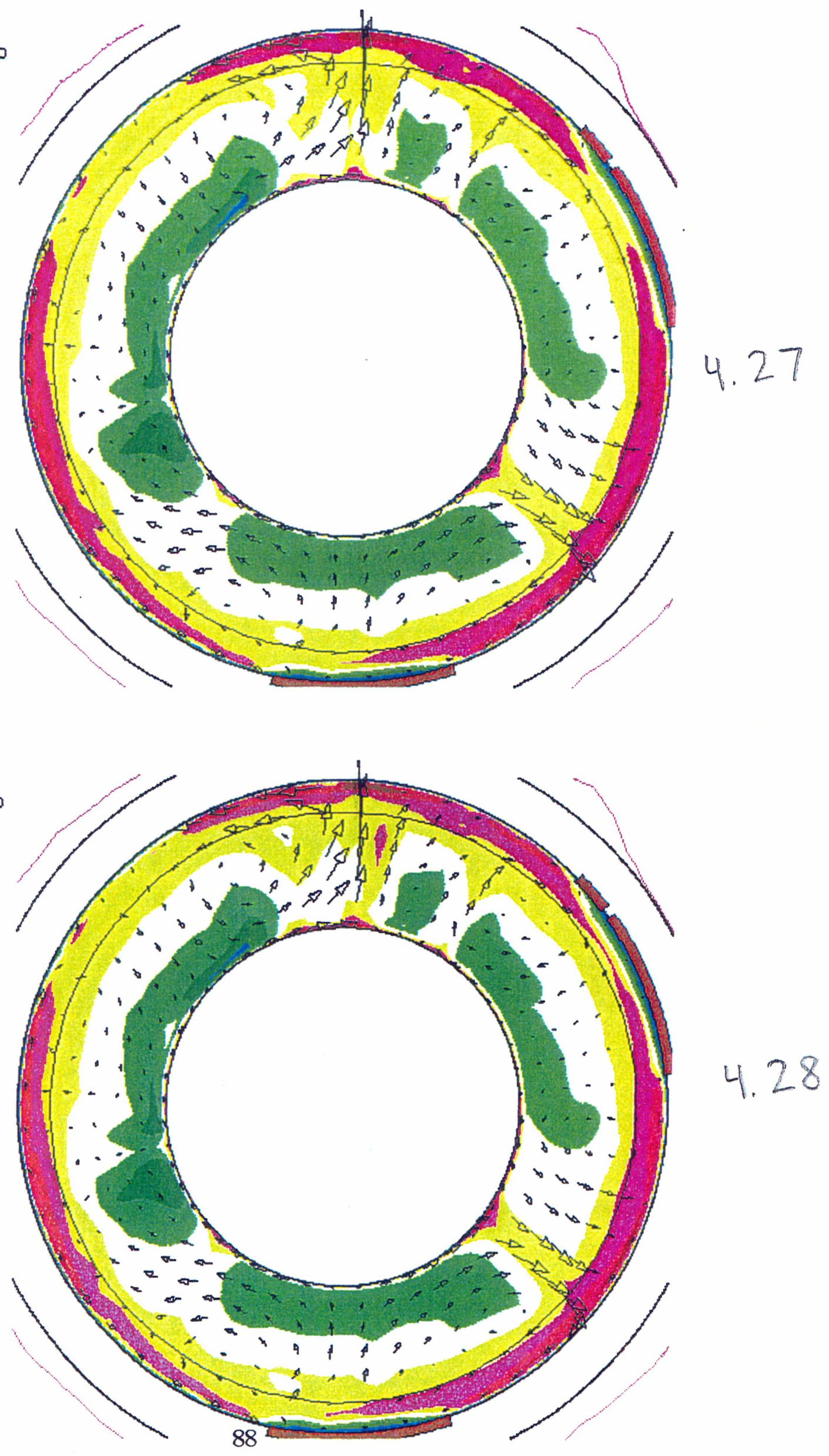
Time 195.12090 My
Czoss $F=15.000^{\circ}$ ( 0.000; 0.000) Scale 1.300 Velocity $(\mathrm{cm} / \mathrm{y})$ $\rightarrow$ : $4.535 \mathrm{E}+00$ Tempezatuze (C)

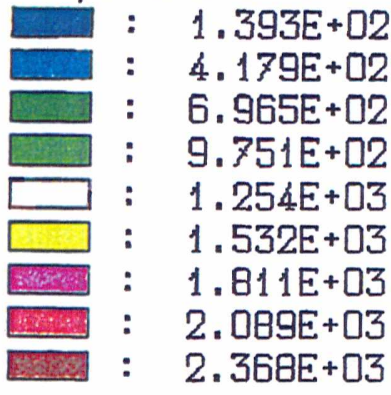

- Heat (mil/m2) 12.797; 188.857 - Phase line 